\title{
Über das Vorkommen, die Zusammensetzung und die Bildung von Eisenanhäufungen in und unter Mooren.
}

\author{
Von \\ J. M. VAN BEMMELTEN. \\ Unter Mitwirkung von C. Hortsema und E. A. KLobBre.
}

Mit 11 Figuren und einer Karte im Text.

Inhalt: I. Einleitung S, 313. - II. Zusammensetzung der Bildungen. A. Amorpher und krystallinischer Eisenspat S. 316. B. Eisenoxyd S. 321. C. Vivianit S. 323. D. Zusammensetzung der Eisenanhäufungen im allgemeinen in den Mooren S. 334. E. Das Quellwasser unter dem Moore za Ederveen S. 337. - III. Die bei der Bildung beteiligten chemisehen Reaktionen S. 339. - IV. Die Eisenanhäufung in den Niedermooren unter Hochmoor in Drenthe. A. Die Lage des Moores S. 345. B. Der Bau S. 348. C. Die Dargschicht S. 349. D. Lage, Verbreitung und Zusammensetzung der Nester von Eisenspat S. 352. E. Zur Erklärung der Bildung der Nester S. 355. - V. Die Eisenanhäufungen in den Wiesenmooren von Mecklenburg nach GaErtner S. 360. VI. Die Eisenanhänfungen unter Mooren oder moorigen Wiesen im niederländischen Diluvium S. 366. A. Der Raseneisenstein mit krystallinischem Eisenspat S. 367. B. Der Raseneisenstein ohne Eisenspat S. 374. - VII. Zusammenfassung S.376. - Anhang S. 378.

\section{Einleitung.}

Im Jahre 1895 publizierte ich eine Untersuchung über in einem Torfmoor gefundenes amorphes Ferrokarbonat, von Vivianit gesellt. ${ }^{1}$ Ich hatte im Jahre 1891 das Vorkommen und die Lagerung desselben beobachtet und untersucht, bei einer Exkursion im Hochmoor von Drenthe, speziell im Teil dieser grofsen Moorfläche, der den Namen Emmer Compascuum trägt, ${ }^{2}$ wie er mir von Prof. G. Molengraaff

1 Verhandelingen der kon. Akad. van Wetenschappen (1. Sektion) 3, 3. In französischer. Übersetzung in Archives Neerlandaises 30, 25-43.

${ }^{2}$ Siehe die Karte auf S. 344.

Z. anorg. Chem. XXII. 
angewiesen war. Nach meinem Wissen war dieses Mineral früher vielleicht wohl beobachtet, jedoch nie näher beschrieben worden. ${ }^{1}$

Es lag hier ein Fall einer Anbäufung von Eisen (Karbonat und Phosphat) vor, die in einem Moor unter bestimmten Umständen stattgefunden hatte. In einer vorigen Ablandlung ${ }^{2}$ machte ich schon darauf aufmerksam, wie wichtig es ist, die Erscheinungen der Anhäufung in der Natur bis in den kleinsten Einzelheiten nach zu spüren. Es schien mir darum erwünscht, die Untersuchung tortzusetzen, und auch zu den Anhäufungen unter einer Moorschicht auszubreiten, worin seitdem G. REINDERS ein krystallinisches Ferrokarbonat entdeckt hatte. Obgleich ich mir wohl bewufst bin, dafs die Erklärung der Erscheinungen noch sehr dürftig bleibt, so scheint es mir um so mehr geboten, Untersuchungsmaterial zu sammeln.

Dr. Hortsema hat auf meine Bitte das Emmer Compascuummoor aufs neue und wiederholt besucht, viele neue Beobachtungen und Ansichten zur Erklärung der Bildung gesammelt und einige neue Muster analysiert. Dr. KLOBBIE hat die sämtlichen Proben mikroskopisch beobachtet, zum Teil analysiert, und alle mikroskopische Untersuchungen gemacht. Unter Zurückweisung auf meine erste Abhandlung teile ich jetzt mit, was die fortgesetzte Untersuchung uns gelehrt hat. Ich benutze dabei:

1. Die im Jahre 1897 erschienene Schrift von A. GaErtner über eine analoge Bildung in den Mecklenburger Niederungsmooren. ${ }^{3}$

2. Die im Jahre 1896 publizierte Untersuchung von G. REINDERS über die Zusammensetzung und Bildungsweise von Raseneisenerz unter einer Moorschicht zu Ederveen." Herr G. Reinders hat mir

1 Gaertarer bestätigt solches, indem er im Jahre 1897 schreibt: „Für das Vorhandensein des Karbonats von Eisenoxydul in Torfmooren habe auch ich nur sehr unbestimmte Andeutungen bei Wregmann, Senfft u. s. w. finden können." STrapF, der im Jahre 1876 schrieb: „Über die Entstehung der Seeerze“, hat es auch nicht gekannt. Nur Ramans, wie ich später bemerkt habe, erwähnt das Vorkommen in norddeutschen Mooren.

${ }^{2}$ Die Absorptionsanhäufungen von $\mathrm{CaFl}_{2}, \mathrm{CaO}$, und Phosphat in fossilen Knochen (Z. anorg. Chem. 15, 30, 31).

3 A. GaERTner, Inauguroldissertation: Über Vivianit und Eisenspat in mecklenburgischen Mooren. Güstrow 1897.

${ }^{4} G$. REInders: Het voorkomen van gekristalliseerd ferrokarbonat in Moeras-yzererts, en eene bydrage tot de kennis en het ontstaan van dit urts in den Nederlardschen bodem. - Verhandelingen der kon. Akad. van Wetenschappen (2. Sektie) [V.] $[1896]$ 5, S. 1-40. 
frisch ausgegrabene Proben dieses Erzes zur fortgesetzten Untersuchung geschickt.

Man darf annehmen, dals das Eisenoxyd, welches im diluvialen Boden als "Eisenoer" (Eisenocker) vorkommt, aus den Gesteinen herstammt, woraus durch physische und chemische Verwitterung die Lehm-, Sand- und Geschiebe-Schichten des Niederländischen und Norddeutschen Diluvialgebietes entstanden sind. Dieses "Oer" ist an vielfache Versetzung, Anhäufung und Zerstreuung ausgesetzt gewesen, und dieser Prozels dauert noch immer fort.

Zerstreut wird es, wo es, unter dem Einflufs der Humusbildung, zu Ferrobikarbonat und sogenanntem Ferrohumat reduziert, im Bodenwasser gelöst und abgeführt wird. Angehänft wird es: 1. wo dieses Bodenwasser sich ansammelt, und die Ferroverbindung durch den Sauerstoff der Luft oder auf andere Weise oxydiert und unlöslich wird, 2. wo zufolge verschiedener physischer und chemischer Wirkungen Ferrokarbonat-, Phosphat-, Silikat sich aus diesem Bodenwasser absetzt.

Die Umstände, worunter die Eisenabsetzungen stattfinden, und ihre Zusammensetzung sind also sehr verschieden. Man hat sie jedoch früher nicht gehörig unterschieden, so dals auf diesem Gebiete wenig Klarheit herrscht, wie Rkinusess schon angezeigt hat. ${ }^{1}$

Ich hebe hier die folgenden Fälle hervor:

Wo eisenhaltiges Bodenwasser in eine See ausströmt, da bildet sich das sogenannte Seeerz. Wo sich in eisenhaltigen Bächen oder in den von Bächen überschwemmten Niederungen Thon, Lehm, Sand absetzen, da setzt sich in diesem Schlick auch viel Eisenoxyd ab, und dieses Eisenoxyd kann allmählich unter dem Einflufs der Humifikation der Pflanzenreste in eine tiefere Schicht versetzt werden. Indem ich diese Fälle hier aufser weiterer Betrachtung lasse, so beschränke ich mich auf die Fälle, wo die Eisenabsetzung in, und wo sie unter einer Moorschicht stattgefunden hat.

Bevor diese Formationen im ganzen (Vorkommen, Lage, Bildungsweise u.s.w.) zu betrachten, teile ich erst die Zusammensetzung der verschiedenen Eisenkonkretionen (Eisenspat, Vivianit, EisenockerYzeroer) und des Bodenwassers mit; und zweitens eine Übersicht

1 Die Mitteilungen und Ansichten der verschiedenen Beobachter über diese Bildungen (Bischoff, Stapfi, Wallerius, Hausmane, Daubré, Suögren u. s. w.) sind ziemlich verwirrt und verwirrend, wenn man versucht, sie miteinander in Zusammenhang zu bringen. Siehe die kritische Übersicht von RkrNDERs, gegeben in geiner Abh. S. 15-32. 
unserer Kenntnisse über die chemischen Reaktionen, welche bei diesen Bildungen in Betracht kommen.

\section{Die Zusammensetzung der Bildungen von Eisenspat, Eisenoxyd, Vivianit in und unter Moorschichten.}

\section{A. Eisenspat.}

a) Amorphes Ferrokarbonat. Im Rasenmoor unter Hochmoor, im obengenannten Emmer Compascuum, ${ }^{1}$ kommen Nester einer Substanz von weifser Farbe vor, die durch die Moorarbeiter „,witte klien" (= weifse Torfsubstanz) genannt wird. Das Eisen ist ganz als Ferrokarbonat darin enthalten. Sobald sie an die Luft kommt, färbt sie sich in sehr kurzer Zeit hellrot. Das amorphe kolloydale Ferrokarbonat geht in amorphes kollordales Eisenoxyd über. Nach meiner vorigen Untersuchung ${ }^{2}$ besteht sie aus:

$$
\begin{array}{ll}
86-90 \% & \mathrm{FeCO}_{3}, \\
3-6, & \mathrm{CaCO}_{3}, \\
7-8 \%, & \text { Pflanzenfaser, }
\end{array}
$$

mit einer geringen Menge Phosphorsäure $(0 \cdot 2 \%)$, Schwefelsäure. Magnesia und Alkalien $(<1.0 \%)$.

Die neue Untersuchung hat gelehrt, dals nach der Oxydation sich zwei Farben hervorthun, eine gelbbraune und eine rotbraune, und dafs die Substanz dann noch etwas Kohlensäure enthält, an $\mathrm{FeO}$ gebunden. Da nun von RFinders gefunden und von mir bestätigt ist, dals das krystallinische Ferrokarbonat sich nicht an der Luft oxydiert, so ist damit der Beweis geliefert, dafs auch in diesen Nestern neben dem amorphen Eisenspat eine kleine Menge krystallinisches vorkommt. Ijie Analysen ergaben für die Zusammensetzung

\begin{tabular}{|c|c|c|}
\hline & $\begin{array}{c}(\text { Horrsema. }) \\
\text { A. Nach der Oxydation } \\
\text { gelbbraun }\end{array}$ & $\begin{array}{l}\text { (Horrsema.) } \\
\text { B. Nach der Oxydation } \\
\text { rotbraun }\end{array}$ \\
\hline $\mathrm{FeCO}_{3}$ krystallinisch & $5.9^{5}$ & 3.7 \\
\hline $\mathrm{FeCO}_{3}$ amorph . . & $84.3^{5}$ & 90.5 \\
\hline $\mathrm{CaCO}_{3} \cdot . \cdot . .$. & 1.1 & $1.6^{5}$ \\
\hline \multirow[t]{2}{*}{ P'flanzenfaser . . . } & 8.6 & $4.1^{5}$ \\
\hline & $100.0^{\circ}$ & $100.0^{\circ}$ \\
\hline
\end{tabular}
der ursprünglichen, noch nicht oxydierten Substanz:

Tabelle I.

' In dem folgenden bezeichne ich zur Abkürzung das Emmer Compascuum mit E. C.

${ }^{2}$ Siehe die Analysen der frischen Substanz (Archives Neerl. 30. S. 28). 
Wieviel Wasser die Substanz vor und nach der Oxydation enthält, ist nicht angegeben, da es ohne Wert ${ }^{1}$ ist.

Aus den obigen Analysen läfst sich noch keine Erklärung der verschiedenen Farbe ableiten. Allerdings war das rotbraune etwas reicher an Eisenoxyd als das gelbbraune. Die nach Oxydierung rotbraun werdende Substanz kommt in grölserer Menge vor als die nach Oxydierung gelbbraun werdende Substanz. Doch waren bei zahlreichen Nestern beide Farben zu sehen, und immer die gelbbraune im obersten Teil. Die Trennungslinie war horizontal in der Richtung, nach welcher die Nester sich ausdehnten (siehe unten S. 352). Merkwürdigerweise zeigten die kleinen Flecken und Aderchen zwischen den krystallinischen Bildungen von Vivianit und Eisenspat immer die gelbbraune Farbe. ${ }^{2}$

'In ihrer ursprünglichen Lage ist die „weifse Klien“ in den Nestern sehr nafs. Auch wenn dieses Ferrokarbonat ohne Zutritt der Luft getrocknet wird, ist sein Wassergehalt, da es amorph ist, eine unbestimmte, von Temperatur und Feuchtigkeitsgehalt der Gasphase abhängige Gröfse. Nach der Oxydation gilt ein Gleiches für das amorphe Eisenoxyd; der gefundene Wassergehalt entspricht 4-3 Mol. $\mathrm{H}_{2} \mathrm{O}$ auf $1 \mathrm{Mol}$. $\mathrm{Fe}_{2} \mathrm{O}_{3}$, also eine Menge, derjenigen âhnlieh, welche der aus einer Ferrilösung mit Ammoniak präzipitierte Hydrogel zurückhält, wenn er lufttrocken geworden ist.

${ }^{2}$ Man ist weit davon entfernt, dafs die Ursachen der verschiedenen Farben von chemischen Verbindungen, die übrigens identisch scheinen, so wie von HgO (OsTwald, Zeilschr. phys. Chem. 18, 159), HgJ u. s. w., erklärt wären. Die Ursachen sind verschiedener Art. Sie hängen sowohl von Verschiedenheiten im molaren Bau (z. B. der Dichte) ab, wie von Beimischungen. So ändert das kolloïdale Eisenoxyd seine Farbe, je nachdem es durch die Zeit, durch Verbleiben unter Wasser, durch Erhitzen u. s. w. dichter wird, und dabei an Absorptionsvermögen für Wasser einbülst (siehe meine Abh. in $Z$. anorg. Chem. 20. 204). Wenn es stark und lang geglüht ist und in Säuren ganz unlöslich geworden, hat es eine fast schwarze Farbe erhalten und absorbiert gar kein Wasser mehr.

Wenn es nicht aus einer Ferrilösung durch Ammoniak präzipitiert ist, sondern nach der Methode von PhinIPps (auch Muck, Tommasi) bereitet ist, hat es eine gelbe Farbe. Ich habe nachgewiesen, dafs diese Modifikation ihr absorbiertes Wasser stärker zurückhält, zwischen der gewöhnlichen Temperatur und ungefähr $200^{\circ}$, als das rotbraune Kolloïd.

Wenn das Fisenoxyd mit anderen Substanzen absorptiv oder chemisch verbunden ist, ändert sich die Farbe.

SPRING hat neulich nachgewiesen, dafs die verschiedenen Farben der Sandsteine und Schiefer (Grès et Schistes) zuzuschreiben waren:

Die rote am losen, unverbundenen Eisenoxyd.

Die gelbe an mit $\mathrm{SiO}_{2}, \mathrm{Al}_{2} \mathrm{O}_{3}, \mathrm{CaO}, \mathrm{MgO}$ gemischtem oder verbundenem Eisenoxyd. 
b) Krystallinisches Ferrokarbonat (Eisenspat). Diese Substanz ist nicht allein bei dem amorphen Ferrokarbonat in kleiner Menge gefunden, sondern auch absonderlich an einzelnen Stellen der Dargschicht des Emmer Compascuummoores, in kleinen Adern und Stellen. Sie ist fast nie frei gefunden von Vivianit, und ist auch noch mit etwas amorphem Ferrokarbonat vermischt, das nach der Oxydation gelbbraun wird. Sie ist von schmutzigweifser Farbe, wobei man im Auge behalten mufs, dafs sie $1 / 4$ Überbleibsel von Pflanzenfasern enthält. Das krystallinische Eisenkarbonat ist daran zu erkennen: 1. dafs es sich nicht an der Luft oxydiert, sondern sich Jahre lang erhält; 2. dafs es mit kalten verdünnten Säuren nicht aufbraust, sondern erst nach Erwärmung, oder mit konzentrierteren Säuren. ${ }^{1}$

Unter dem Mikroskop ist es nur daran erkennbar, dals es Polarisationserscheinungen giebt. Die Krystalle sind zu klein, um die Krystallform und Flächen zu unterscheiden. Bei gekreuzten Nikols zeigen sich eine Menge leuchtender Pünktchen, die bei Drehung der Nikols auslöschen. ${ }^{2}$

Die Analyse ergab (wasserfrei berechnet):

(Hortsema)

61.8 krystallinisches Ferrokarbonat,

12.3 amorphes

$0.6 \mathrm{CaCO}_{3}$,

24.7 Pflanzenfaser,

0.6 Unlösliches.

100.0 .

Die grüne an ein Ferroferrisilikat.

Wenn das Eisenoxyd zusammen mit $\mathrm{AI}_{2} \mathrm{O}_{3}, \mathrm{MgO}, \mathrm{ZnO}$ aus einer wässerigen Lösung niedergeschlagen wird, erhält es eine gelbe Farbe. Diese Gels halten das Wasser stärker fest als der Gel von $\mathrm{Fe}_{2} \mathrm{O}_{3}$ allein, wie es Sprova's Versuche (Erhitzung mit Lösungen eines Alkalichlorürs bei $180^{\circ}$ ) nachweisen.

Über die gelbe Modifikation des Kolloïds schweigt Sprise.

I Dies bezieht sich natürlich auf die trocken gewordene Substanz, worin also der kleine Teil amorphen Karbonats durch Oxydation schon in Eisenoxyd übergegangen ist.

2 Unter dem Mikroskop sieht man weifse, gelblich und grünlich gefärbte Teile. Die weifsen sind Pflanzenfasern. Anorganische und organische Teile sind schwer zu trennen. Es gelang Herrn KLoввiE durch Alkohol eine Menge der im polarisierten Lichte leuchtenden Pünktchen (also der Eisenspat) nach den Rändern des Tropfes auf dem Objektgläschen zu treiben, so dafs dann sehr viele dieser Teilchen nebeneinander sichtbar wurden, und dadurch bewiesen wurde, dafs die Erscheinung nicht dem kleinen Gehalt $(0.5-1 \%)$ an $\mathrm{CaCO}_{3}$ zuzuschreiben war. 
Die Substanz besteht also gröfstenteils aus krystallinischem Eisenspat zwischen Pflanzeufasern gebildet, doch fehlt dabei das amorphe Karbonat nicht.

In den Raseneisensteinbildungen zu Ederveen ${ }^{1}$ ist der krystallinische Eisenspat von REINDERS zuerst entdeckt und beschrieben. Die Substanz hat sich im Diluvialsande unter einem humösen Rasenboden gebildet. Sie kommt also bier nicht mit Pflanzenfasern, sondern mit Sandkörnern gemischt vor.

Die folgenden Analysen erläutern die Zusammensetzung dieses Raseneisensteins:

Tabelle II.

\begin{tabular}{|c|c|c|c|c|c|c|c|}
\hline & & & & III & I & $\mathrm{II}^{2}$ & IV ${ }^{2}$ \\
\hline \multicolumn{4}{|c|}{ Analysiert von } & REINDERS & Klobbie & $J_{\mathrm{AGER}}$ & KetTNeR \\
\hline \multirow{3}{*}{$\begin{array}{l}\text { Krystallin } \\
\text { Amorphes } \\
\text { Krystallin }\end{array}$} & $\mathrm{FeCO}_{\mathrm{g}}$ & . . & $\cdot$. & $20.7^{7}$ & $37.7^{\circ}$ & 30.6 & $6.1^{2}$ \\
\hline & $\mathrm{Fe}_{2} \mathrm{O}_{3}$ & . . & $\cdot \cdot$ & $10.5^{8}$ & $2.4^{9}$ & 8.0 & $36.4^{9}$ \\
\hline & $\mathrm{MnCO}_{3}$ & - . & . & $4.0^{4}$ & $0.6^{7}$ & - & $2.9^{1}$ \\
\hline$"$ & $\mathrm{CaCO}_{3}$ & . . &. & $2.2^{7}$ & $4.4^{6}$ & 4.0 & $4.1^{0}$ \\
\hline & $\mathrm{MgCO}_{3}$ & . . & .. & - $\quad 0.1^{7}$ & $0.1^{0}$ & - & $0.2^{1}$ \\
\hline$"$ & $\mathrm{Fe}_{8}\left(\mathrm{PO}_{4}\right)^{2}$ & . . & .. & $4.3^{0}$ & - & 2.9 & $5.4^{7}$ \\
\hline & $\mathrm{Fe}_{2}\left(\mathrm{PO}_{4}\right)^{2}$ & . . & . & - & $1.7^{5}$ & - & $1.7^{6}$ \\
\hline$"$ & $\mathrm{CaSO}_{4}$ & . . & $\cdot$ & $0.0^{7}$ & - & - & - \\
\hline$"$ & $\mathrm{Al}_{2} \mathrm{O}_{3}$ & . . & $\cdot$ & $0.9^{\mathrm{a}}$ & $0.2^{1}$ & - & 0.6 \\
\hline, & $\mathrm{KCl} \cdot$. & . . & $\cdots$ & $0.0^{8}$ & Spur & - & Spur \\
\hline, & $\mathrm{NaCl} \cdot$ & . . & $\cdot$ & $0.2^{8}$ & $"$ & - & Spur \\
\hline$"$ & $\mathrm{SiO}_{2}$ (löslich & 1) . & . & 49.3 & $0.8^{2}$ & 49.1 & 6.3 \\
\hline Sand . . & $\cdot \cdot \cdot \cdot \cdot$ & . . & . & & $50.0^{2}$ & & 19.3 \\
\hline Organische & e Substanz & . . & .. & $1.5^{7}$ & 0.3 & 1.8 & 1.2 \\
\hline Wasser be & ei $100^{\circ}$ ausge & trieb & ben & $3.6^{8}$ & $0.9^{5}$ & 3.3 & 12.1 \\
\hline Wasser bei & i Glühhitze & $"$ & & $2.0^{\hat{6}}$ & $1.1^{2}$ & 0.0 & 4.0 \\
\hline & & & & 100 & $100^{6}$ & & $100^{5}$ \\
\hline
\end{tabular}

Die Analyse I bezieht sich auf eine sandreichste Partie, die am meisten Ferrokarbonat enthält, am wenigsten Eisenoxyd; sie ist härter, und von einer lichteren Farbe als die übrigen Partien. Analyse IV bezieht sich auf den dunkelst gefärbten und sanftesten Teil des Raseneisensteines, der sand- und ferrokarbonatärmer, eisenoxydreicher ist. Dazwischen stehen III (früher von ReINDERs

1. Im folgenden wird Ederveen zur Abkürzung mit E. V. bezeichnet.

2 Die Analysen II und IV warden unter meiner Aufsicht von den Herren Chem. Kand. F. M. JäaEs und C. H. KeTtNer gemacht. 
analysiert ${ }^{1}$ ) und II, was Härte, Farbe und Zusammensetzung anbetrifft. Die sandreichsten Partien enthalten am meisten krystallinisches Ferrokarbonat, die sandärmeren mehr amorphes, das zu Eisenoxyd oxydiert ist. Mangan-, Calcium- und eine Spur Magnesiumkarbonat begleiten es, wie auch Eisenphosphat. Einzelne Partien in den Konkretionen bestehen fast allein aus Eisenspat mit etwas Vivianit. Den Bau dieser Bildungen werde ich unten ausführlich besprechen (S. 368).

Das krystallinischeEisenkarbonat ist auch hier mikrokrystallinisch, so dals nur die leuchtenden Pünktchen beim polarisierten Lichte zu erkennen sind (siehe oben S. 318). ${ }^{2}$ Es hat dieselben chemischen Eigenschaften als das in der Dargschicht vom Emmer Compascuum vorkommende Eisenkarbonat.

$\mathrm{Ob}$ das Eisenphosphat teilweise als Oxyd anwesend ist, ist nicht sicher. ${ }^{3}$ Das im trockenen Stein anwesende Eisenoxyd ist in den obigen Analysen nicht als amorphes $\mathrm{FeCO}_{3}$ in Rechnung gebracht; doch ist es wahrscheinlich so gewesen, solange die Schicht mit Wasser getränkt und von der Luft abgeschlossen war. Als die (analysierten) Stücken im Sommer ausgegraben wurden, war das Wasserniveau niedrig, und unter der Raseneisensteinschicht gelegen. Merkwürdig ist es, dafs IV $6 \%$ lösliches $\mathrm{SiO}_{2}$ enthielt ${ }^{4}$ und nur 1.6 lösliches $\mathrm{Al}_{2} \mathrm{O}_{3}$. Man mufs also annehmen, dafs diese Kieselsäure im amorphen Komplex mit Eisenoxyd absorptiv verbunden ist. Der Wassergehalt in den vier Analysen 2.07, 3.3, 5.74, 16.1 stimmt ungefähr mit dem Gehalt an amorphem Eisenoxyd und an Vivianit überein, ${ }^{5}$

1 Diese Analyse bezieht sich auf eine Mittelprobe; denn Reinders erwähnt, dafs er dieselbe aus den lichter- und dunklergefärbten Partieen, die in dem härteren Teil des Steines vorkommen, zusammengestellt hat.

${ }^{2} \mathrm{Es}$ ist Herrn K $\mathrm{LOBBIE}$ nicht gelungen, die gelblichen, doppeltbrechenden Krystallfragmente zu beobachten, die Reinders (S. 11 seiner Abhandlung) erwähnt.

- Ich habe in Analyse I und II eine Menge Ferriphosphat angegeben, auf Grund der Äquivalentberechnungen; jedoch sind die Eisenoxydulbestimmungen dafür nicht genau genug, um dies sicher zu stellen.

4 Über die Art und Weise der Bestimmung der löslichen Kieselsäure siehe den Anhang.

${ }^{5}$ Das ergiebt sich aus der folgenden Berechnung, wobei für Vivianit 8 Mol. Hydratwasser und für das amorphe Eisenoxyd 3 oder 4 Mol. Absorptionswasser in Rechnung gebracht sind.

(Die Fortsetzung dieser Note befindet sich auf S. 321.) 
wenn für das Eisenoxyd $\pm 31 / 2$ Mol. Absorptionswasser angenommen werden.

B. Eisenocker ohne krystallinischen Eisenspat.

Enthält der Raseneisenstein von E.V. in dessen verschiedenen Teilen mehr oder weniger krystallinischen Eisenspat neben Eisenoxyd, viel öfter kommt im Niederländischen Diluvium unter moorigen Rasen ein Eisenocker (Yzeroer) vor, welcher nur Eisenoxyd enthält. Einzelne, wohl nicht genaue, Analysen davon sind früher gemacht. ${ }^{1}$

\begin{tabular}{|c|c|c|c|c|c|c|}
\hline \multirow{3}{*}{ Analyse } & \multicolumn{3}{|c|}{ Moleküle $\mathrm{H}_{2} \mathrm{O}$} & \multicolumn{3}{|c|}{ Prozente $\mathrm{H}_{2} \mathrm{O}$} \\
\hline & \multirow[t]{2}{*}{ Gefunden } & \multicolumn{2}{|c|}{$\begin{array}{l}\text { Berechnet } \\
\text { für }\end{array}$} & \multirow[t]{2}{*}{ Gefunden } & \multicolumn{2}{|c|}{$\begin{array}{l}\text { Berechnet } \\
\text { für }\end{array}$} \\
\hline & & $3 \mathrm{H}_{2} \mathrm{O}$ & $4 \mathrm{H}_{2} \mathrm{O}$ & & $3 \mathrm{H}_{2} \mathrm{O}$ & $4 \mathrm{H}_{2} \mathrm{O}$ \\
\hline I & $11^{5}$ & $8^{6}$ & $10^{2}$ & 2 & $1.5^{6}$ & $1.8^{4}$ \\
\hline II & $18^{3}$ & $21^{4}$ & $26^{4}$ & 3.3 & 3.8 & 4.7 \\
\hline III & 32 & $29^{4}$ & 36 & 5.7 & 5.3 & 6.5 \\
\hline IV & 89 & 84 & 107 & 16.1 & 15.2 & 19.3 \\
\hline
\end{tabular}

Man bedenke, dafs die Wasserbestimmung nur als eine Annäherung zu betrachten ist (siehe den Anhang) und dafs der Wassergehalt des lufttrockenen amorphen Eisenoxyds zwischen $\pm 4^{\mathrm{b}}$ und \pm 2 Mol. schwankt, nachdem die Luft feuchtigkeit fällt, oder nachdem das Oxyd durch Alter und durch Verbleiben unter Wasser an Absorptionsvermögen einbülst. (Siehe z. B. die Isotherme des kolloïdalen Eisenoxyds bei $15^{\circ}$. Z. anorg. Chem. (1899) 20, 201-203.)

${ }^{1}$ Im Jahre 1860 zusammengestellt von G. J. MULDER in seiner ,Scheikunde der bouwbare aarde" (deutsche Übersetzung: „Die Chemie der Ackerkrume") Bd. 2, S. 263. Ein „Oer" aus einem Bruchland bei Loo (Gemeinde Apeldoorn) und bei Barneveld (Provinz Gelderland), von MuLDER's Assistenten analysiert, ergab:

\begin{tabular}{llll|c|c}
\hline \hline & & \\
\hline
\end{tabular}

Die übrigen noch älteren Analysen von "Yzeroer" aus verschiedenen Ortschaften: Vorden, Hees, Apeldoorn, Ommen, Ockenbroek haben geringen Wert. Nor ergiebt es sich, dafs der Eisenoxydgehalt zwischen 60 und $80 \%$ beträgt. 
Herr ReInders besorgte mir zur Analyse eine frisch ausgegrabene Probe dieses "Yzeroer" aus Tubbergen (Provinz Overyssel). Er hat selbst im Jahre 1896 eine Probe aus der Stroewiese bei Apeldoorn (Provinz Gelderland) analysiert. ${ }^{1}$

Tabelle III.

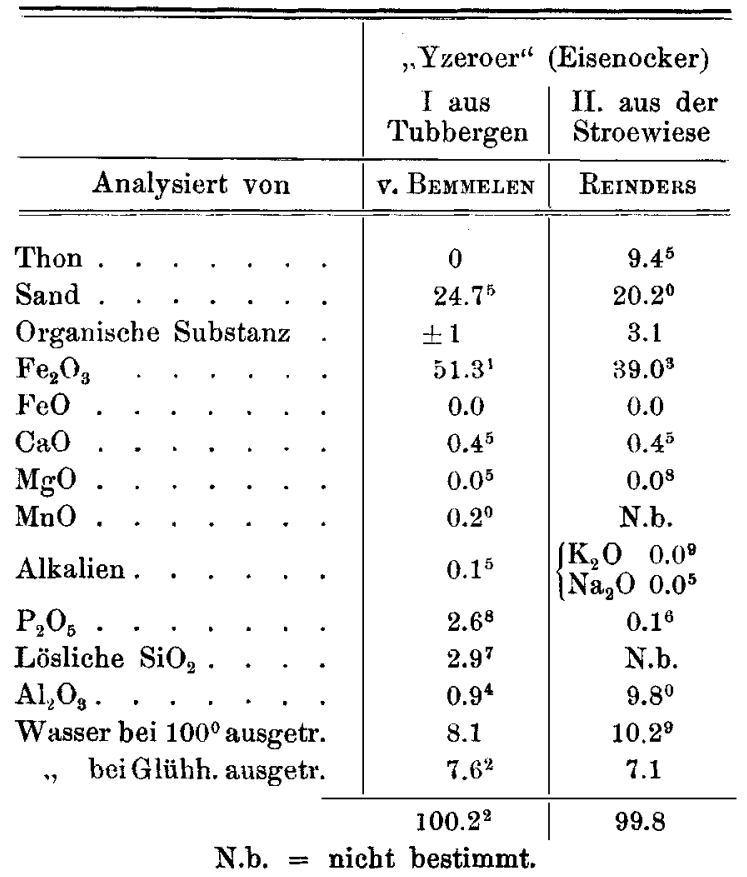

Das Eisenoxyd ist bei I zwischen feinen Sandkörnern, bei II zwischen lehmigem Sand abgesetzt.

Das Wasser mufs bei I fast ganz am Eisenoxyd absorbiert sein. Denn das Molekülverhältnis ist:

$$
1 \mathrm{Fe}_{2} \mathrm{O}_{3}: 2.9 \mathrm{H}_{2} \mathrm{O}
$$

und nach Trocknung an der Luft bei $100^{\circ}$

$$
1 \mathrm{Fe}_{2} \mathrm{O}_{3}: 1.3 \mathrm{H}_{2} \mathrm{O} \text {. }
$$

Das letzte Verhältnis habe ich auch beim präzipitierten, amorphen

${ }^{1}$ G. Rernders: De samenstelling en het ontstaan der zoogenaamde Oerbanken in de Nederlandsche heidegronden. (Verh. der kon. Akad. 2 . Wetensch. Amsterdam [1889] S. 41.) 
Eisenoxyd gefunden. ${ }^{1}$ Dagegen ist das Verhältnis von $1: 2.7 \mathrm{Mol}$. niedrig und kommt mit einem präzipitierten kollordalen Eisenoxyd überein, das sein Absorptionsvermögen für Wasser schon bedeutend eingebülst hat. ${ }^{2}$

Dasselbe gilt wahrscheinlich auch für II; denn, obgleich das Verhältnis ist $1 \mathrm{Fe}_{2} \mathrm{O}_{3}: 4 \mathrm{H}_{2} \mathrm{O}$, so kommt ein Teil dieses Wassers den $\pm 20 \%$ Thon zu. Dieser Thon ist für einen bedeutenden Teil durch Salzsäure zersetzbar, denn es lösten sich etwa $10 \%$ Alaunerde.

\section{Vivianit.}

Im E. C. kommen Stellen vor, wo der an der Luft blau werdende Vivianit angehäuft ist, zwischen Pflanzenfasern, namentlich an den Enden der Nester (siehe unten S. 354). Auch zwischen dem ,Witte klien": kommen grauweifse, blaue, gelbbraune Fleckchen und Äderchen vor, die hauptsächlich aus Vivianit bestehen. Aufserdem sind weifse Adern beobachtet, die beim Fintrocknen gelb oder braun werden, und Ferriphosphat enthalten.

In E. V. enthält der Raseneisenstein Stellen, wo der Vivianit auftritt: als blaues Pulver ohne sichtbare Krystallform, als deutliche Krystalle, als Gebilde von der Form eines Wärzchens oder Ästchens. ${ }^{3}$

Wir können unterscheiden:

a) Die im Moore ursprünglich weifse, an der Luft bald hellblau werdende Substanz (im E. C. und im E. V.).

b) Die nicht blau werdende Substanz, die getrocknet eine graugelbe bis graubraune Farbe annimmt (im E. C.).

$\left.c^{1}\right)$ Die Krystallanbäufungen mit blauem Schein (im E. V.).

$\left.\mathrm{c}^{2}\right)$ Die Krystalle, in kleinen Höhlen abgesetzt, welche keinen blaven, sondern einen metallischen Schein zeigen (im E. V.).

d) Die Wärzchen und Ästchen in den kleinen Höhlen (im E. V.).

a) Die weifse, an der Luft blau werdende Vivianitsubstanz im E. C. und ebenso im E. V. Sie ist nur scheinbar

1 Z. pr. Chem. (1892) 46, 500. Nach Erhitzung bis $100^{\circ}$ an der Luft während einer Stunde.

3an vergleiche die Bemerkung auf S. 321. Präzipitiertes, kolloïdales Eisenoxyd, das frisch bereitet, $5 \mathrm{Mol} . \mathrm{H}_{2} \mathrm{O}$ enthielt, nachdem es an der Luft trocken geworden war, enthielt nach längerem Verbleiben unter Wasser nur \pm 1.5 Mol. (v. Bemmelen, Z. anorg. Chem. [1899] 20, 201-203).

${ }^{3}$ Die nähere Beschreibung folgt im VI. Abschnitt S. 371. 
amorph. ${ }^{1}$ Unter dem Mikroskop zeigt sie sich teilweise als ein höchst feines Pulver, teilweise als kleine, zusammenhängende Klümpchen, frei von Fasern (denn sie lösen sich ganz in verdünnten Süuren). Eine kleine Menge organischer Reste ist damit vermischt Das feine Pulver zeigt mit Wasser die Brows'schen Bewegungen; es ist bei auffallendem Lichte blau; die Klümpchen dunkelblau (oder schwarz). Beim durchfallenden Licht ist die Farbe des Pulvers schmutzig weifs. Im parallel polarisierten Lichte ist die blaue Farbe der gröfseren Partikel intensiver, und zeigt sich die Substanz also dichrortisch. Je nachdem sie bei stärkerer Vergrölserung betrachtet wird, zeigen mehr Teilchen ${ }^{2}$ Dichroismus. Zwischen gekreuzten Nikols treten viele leuchtende Punkte hervor, die bei Drehung des Mikroskop-Tisches auslöschen.

Man darf also das blaue Pulver, auch das feinste, für krystallinisch halten, wenn auch nur ausnahmsweise im E. C. eine Krystallkante oder Fläche zu erkennen war; im E. V. war dies mehr der Fall und konnten bei einzelnen Partien Aggregate erkannt werden; der Dichroismus und die rechte Auslöschung waren deutlich zu beobachten.

b) Die nicht blau werdende Substanz. Diese polarisiert das Licht nicht und ist also amorph. Nach der chemischen Analyse Tab. IV II (S. 331) besteht sie hauptsächlich aus Ferriphosphat mit Pflanzenfasern. Die kleinen Einmischungen blauer Substanz, die in derselben vorkommen, zeigen dagegen die oben beschriebenen Polarisationserscheinungen. Es ist also hier ein amorphes Ferriphosphat konstatiert.

c) Die Krystalle. Die erwähnten Krystallanhäufungen mit blauem Schein $\left(c^{1}\right)$ im E. V. bestehen aus Vivianit und sind also der Substanz a) ähnlich. Nur besitzen die Krystalle grölsere Abmessungen.

Werden die Krystalle im polarisierten Lichte durch die Orthopinakơdfläche betrachtet, so dafs die lamelläre Struktur hervortritt,

1 Auch Gaertner beschreibt noch den Vivianit in den Mecklenburger Mooren als ,erdige Varietät" (S. 56 seiner Abh.), und meint, denselben nur in Drüsen von Eisenspat krystallinisch gefunden zu haben.

2 Bei den feinsten Partikelchen ist der Dichroismus nicht zu beobachten, auch wenn man die Brows'schen Bewegungen durch eine Spur Alkohol oder Salzsäure aufhebt. Sie sind dazu zu klein. 
dann zeigen sie mehr oder weniger eine blaue Farbe und löschen rechts aus. Die blaue Farbe ist nicht allein an den Seiten, wo die Lamellen aneinander liegen, sichtbar, sondern auch stellenweise und streifartig verwachsen in den Lamellen. Werden die Krystalle durch die Klinopinakordfläche beobachtet (wie bekannt, sind sie nakch $\infty$ Ro spaltbar), dann sind sie farblos und löschen schief aus. \$ie sind also dichrortisch, wie es rom Vivianit bekannt ist.

Die Krystalle $\mathrm{c}^{2}$, die vereinzelt oder wie kleine, fächerförmige Bündel (Fig. 1) in den Höhlen des Raseneisensteins von E. V. vor-

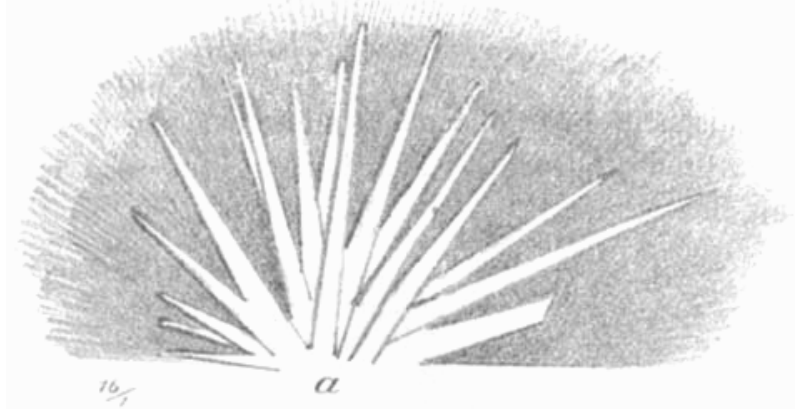

Fig. 1.

kommen, haben durch die Lichtreflexion der Krystallfäche einen metallartigen Glanz. Sie sind glashell, scheinbar nicht dichroitisch, löschen schief aus $\left(28-30^{\circ}\right)$ und geben erst bei stärkerer Vergrölserung ein gutes Axenbild. Jedoch sind sie nicht verschieden von den Krystallen $\mathrm{c}^{1}$, wie Reindens meinte. ${ }^{1}$ Dafs sie farblos und gar nicht dichrortisch scheinen, liegt nur daran, dals sie bei dieser Beobachtung auf ihrer Klinopinakoidfläche ruhen; um ihre Nadelaxe gedreht, werden sie rechts auslöschend. Sie zeigen jedoch nur stellenweise die blaue Farbe. Einzelne zeigen fast keine blauen Stellen. Nach einer genauen mikrochemischen Untersuchung enthalten die letzteren nur $\mathrm{P}_{2} \mathrm{O}_{5}$ und $\mathrm{FeO}$.

d) Die Ästchen und Wärzchen in den kleinen Höhlen im Raseneisenstein von E. V. Diese Bildung ist merkwürdig. Die nähere Beschreibung, wie sie in diesen Höhlen vorkommen,

1 Siehe seine Abh. S. 13. Er fand Magnesium und Kalium (oder $\mathrm{NH}_{4}$ ) in denselben; doch muls dies auf einem Irrtum beruhen. 
folgt auf S. 371. Ein Ästchen ist in Fig. 2, ein Wärzchen in Fig. 3 abgebildet. Sie bestehen aus krystallinischem Ferrokarbonat

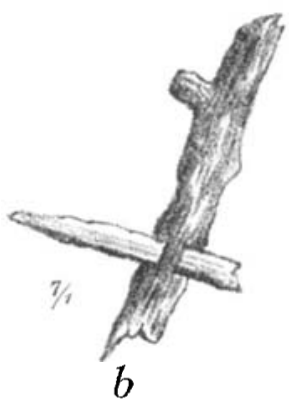

Fig 2.

und krystallinischem Ferrophosphat, mit einer geringen Menge Calciunkarbonat (und Phosphat). Aus beiden ragt eine Krystallnadel von Vivianit hervor.

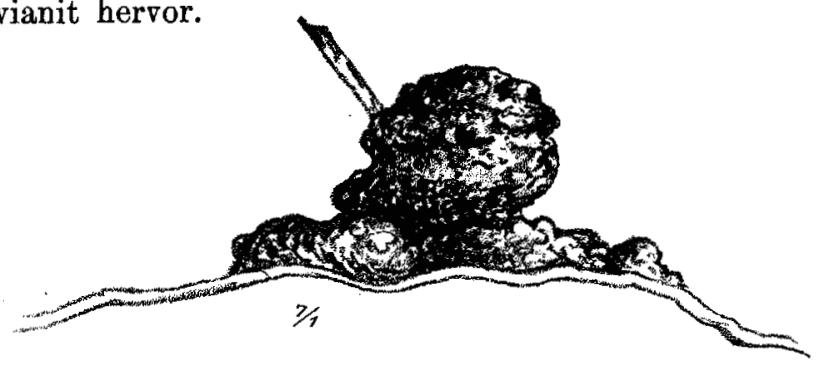

Fig. 3.

Die mikroskopische Beobachtung lehrte das Folgende: Durch verdünnte Salzsäure wird das Karbonat mit einer Spur Phos-

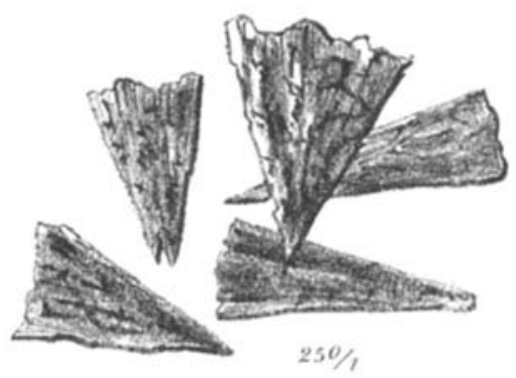

Fig. 4.

phat langsam gelöst und dann fällt der Körper auseinander in durehsichtige Teile von der Form einer Pfeilspitze (Fig. 4). 
Diese müssen in einem Kreis gelegen haben, mit den Spitzen dem Mittelpunkt zugekehrt (wie Zirkelsektoren) und frei geworden sein, nachdem die dazwischen liegenden Schichten oder Teile Ferrokarbonat gelöst sind. Mit Wasser abgewaschen, damit das gelöste Ferrosalz entfernt wird, lösen sie sich in einer stärkeren Salzsäure langsam auf. Diese Lösung findet auf eine eigentümliche Weise statt. Die Körperchen, Fig. 5a, werden bei $a^{\prime}$ am stärksten ange-
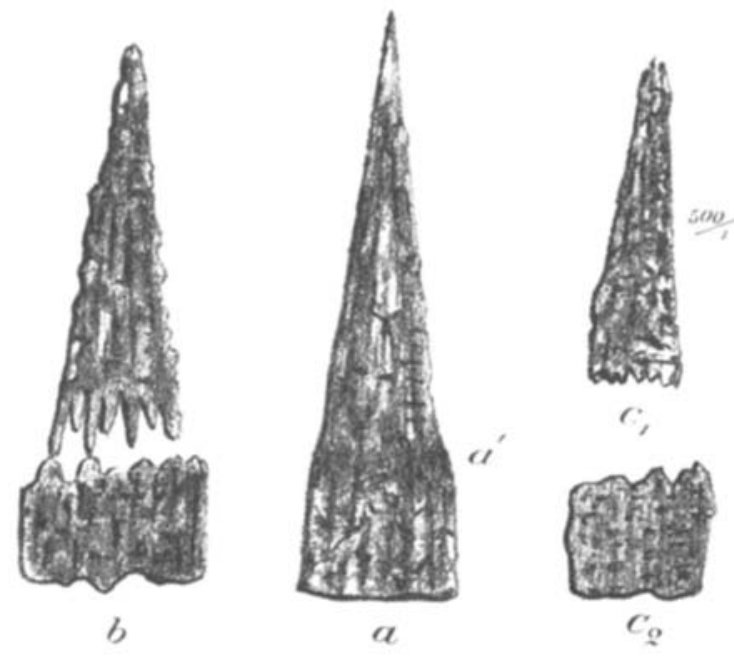

Fig. 5.

fressen, so dafs die Gestalt $b$ entsteht und diese sich spaltet in die Stücke $c_{1}$ und $c_{2}$, welche dann weiter sich ganz lösen. Wenn ein Ästchen gelöst ist, bleibt eine Pflanzenfaser übrig, um welche sich also das Ästchen gebildet hat.

Die Pfeilspitzen bestehen nach der mikrochemischen Untersuchung (mit Ammoniummolybdat, Ferricyankalium, Natron und $\mathrm{H}_{2} \mathrm{O}_{2}$ ) aus Ferrophosphat mit einer Spur Calciumphosphat. Es ergab sich, dafs dieses Ferrophosphat in seinen Eigenschaften einigermalsen von den anderen Vivianitkrystallen abweicht, denn: 1. Es löst sich viel schwerer in Säuren. In einer verdünnten Salzsäure, welche Vivianitkrystalle in einigen Sekunden löst, bleiben diese Sektoren 15 Minuten ungelöst. Auch von Salpetersäure werden sie viel langsamer angegriffen.

2. Es ist nicht dichrortisch und wird es nicht durch $\mathrm{H}_{2} \mathrm{O}_{2}$ aq. Wohl zeigen sie beim einfach polarisierten Lichte einen Stand, wo 
sie am hellsten, und einen Stand, wo sie am dunkelsten sind unabhängig vom Stande des Spiegels. In der Vibrationsrichtung des Polarisators sind sie durchsichtig; senkrecht darauf weniger undurchsichtig, und zwar grau.

Die Ursache des verschiedenen Verhaltens gegenüber Säuren und $\mathrm{H}_{2} \mathrm{O}_{2}$ liegt vielleicht in einem kleinen Unterschied im Bau des Krystalls, wodurch sie schwerer angreifbar sind für Säuren, und ebenso für Sauerstoff. Die Erscheinung bleibt noch unerklärt.

Die blaue Farbe der Vivianitkrystalle. Die obigen Beobachtungen von Dr. KLoBbie haben gelehrt, dafs 1. das höchst feine krystallinische Pulver ursprünglich - so, wie es von der Luft abgeschlossen in der Moorschicht liegt - weils ist, ${ }^{1}$ nachher, an der Luft trocken geworden, intensiv blau wird, und unter dem Mikroskop sich dichroitisch zeigt; 2. dals die sichtbaren Krystalle nur stellenweise einen stärkeren oder schwächeren Dichrorsmus zeigen; 3 . dafs die krystallinische Bildungen in den Ästchen und Wärzchen keinen Dichroísmus zeigen. Auch Fiscere erwähnt farblose Krystalle. ${ }^{2}$ Obgleich nun den monoklinen Vivianitkrystallen Polychrösmus zukommt, so scheint dieser zu schwach, um beobachtet zu werden. Man hat dann auch immer angenommen, dals die blaue Farbe einer Oxydation des Ferrophosphats zu verdanken ist.

Wir haben zum Überflufs diese Annahme noch mikrochemisch geprüft. Ein Krystall, der stark dichroitisch war, wurde unter dem Polarisationsmikroskop in Rhodankaliumlösung gebettet und dann mit einem Tropfen Säure versetzt; die Eisenoxydreaktion zeigte sich. Sobald die blauen Partien gelöst waren und ein farbloses Stück Vivianit übergeblieben war, das sich nicht mehr dichroïtisch erwies, wurde dasselbe abgewaschen und von neuem mit Rhodankalium und Säure versetzt; die Eisenoxydreaktion blieb aus bis zur vollständigen Lösung des Vivianitfragmentes. Die blaue Farbe und der Dichroismus werden also durch das Eisenoxyd zweifellos hervorgebracht.

1 Auch Gamptner hat den Vivianit in den mecklenburgischenMooren weifs befunden, überall wo die Luft nicht zugetreten war.

${ }^{2}$ Er hat dieselbe im Sande der Delaware beobachtet, und hält sie für eisenoxydfrei. Sie wurden an der Luft grünlich (NAUMANN-Zirkel, Elemente der Mineralogie 1898, S. 586). 
Die Menge Eisenoxyd braucht nicht grofs zu sein, um eine blaue Farbe hervorzubringen. ${ }^{1}$ GAERTNER hat frisch ausgegrabenen, noch weifsen Vivianit aus dem Teschendorfer Moor mit destilliertem Wasser dekantiert und darin nach 10 Tagen, als es sich schon deutlich blau gefärbt hatte, nur $1.3 \mathrm{Mol} . \mathrm{Fe}_{2} \mathrm{O}_{3}$ auf $100 \mathrm{Mol}$. FeO gefunden; ${ }^{2}$ er konnte dieses $\mathrm{Fe}_{2} \mathrm{O}_{3}$ aufserdem noch als eingemischtes Eisenoxyd betrachten, ${ }^{3}$ denn drei übereinstimmende Analysen der noch weifsen Substanz ergaben noch mehr Überschul's an Eisenoxyd.4

Um die Einwirkung von Sauerstoff näher zu untersuchen, wurde ein Krystall, der, durch die Orthopinakoldfläche betrachtet, schwach blau war (mit einem dunkelblauen Streifen), mit einigen Tropfen einer neutralen $3 \%$ igen Lösung von $\mathrm{H}_{2} \mathrm{O}_{2}$ versetzt. Nach Verdampfung der Lösung war die blaue Farbe stark erhöht. Doch blieb es, durch die Klinopinakoidfläche betrachtet, durchsichtig und fast farblos. ${ }^{5}$ Dieser Versuch wurde, mit gleichem Erfolg, mit verschiedenen Krystallen wiederholt.

Bei vielmaliger Wiederholung der Behandlung mit $\mathrm{H}_{2} \mathrm{O}_{2}$ wurden sie immer blauer und schliefslich undurchsichtig; in dem zweiten Stand wurde die Farbe fahlbraun, jedoch die Durchsichtigkeit blieb. Die Spaltungsrichtung hatte jedoch einen anderen Verlauf als beim ursprünglichen Vivianit bekommen. Nachdem die Behandlung mit $\mathrm{H}_{2} \mathrm{O}_{2} 20 \mathrm{mal}$ wiederholt war in einem Zeitverlauf von 14 Tagen, enthielten die Krystalle noch immer Eisenoxydul. Entweder war das $\mathrm{H}_{2} \mathrm{O}_{2}$ noch nicht überall durchgedrungen oder das Phosphat widerstand der weiteren Oxydation um so mehr, je nachdem sein

- Es ist bekannt, dafs kleine Mengen von $\mathrm{FeO}, \mathrm{Fe}_{2} \mathrm{O}_{3}, \mathrm{MnO}, \mathrm{CrO}_{3}, \mathrm{CoO}$, C u. s. w. genügen, um in Krystallen oder Gläsern Farben hervorzubringen.

2 Gaentner wirft darum noch die Frage auf: „Oder sollte die Blaufärbung nicht allein von dem Gehalt an Eisenoxydphosphat, sondern auch von einem gleichzeitigen Krystallwassergehalt abhängen."

${ }^{3}$ Seine Analyse ergab:

$\begin{array}{ccc}\mathrm{mg} & \text { Molek. } & \text { Verhältnis } \\ 820.8 \mathrm{FeO} & 11.4 & 3.1^{6} \\ 25.6 \mathrm{Fe}_{2} \mathrm{O}_{3} & 0.1^{6} & 0.0^{4} \\ 512.5 \mathrm{P}_{2} \mathrm{O}_{5} & 3.6^{1} & 1 .-\end{array}$

4 Die Substanz war im Kohlensäurestrom getrocknet und weifs geblieben. Sie enthielt auf $100 \mathrm{Mol}$. $\mathrm{FeO} 3.5 \mathrm{Mol}$. $\mathrm{Fe}_{2} \mathrm{O}_{3}$.

${ }^{5}$ Dies zeigte sich am deutlichsten beim Zerdrücken eines dunkelgefärbten Krystalls, wobei es auseinander fiel, in Platten (parallel der Klinopinakoïdfäche), welche umfielen und sich jetzt durchsichtig mit fahlbrauner Farbe zeigten.

Z. anorg. Chem. XXII. 
Gehalt an Eisenoxyd zunahm. In der Natur kommen Vivianite vor, die weniger oder mehr, bisweilen fast ganz, in Beraunit verwandelt und krystallinisch geblieben sind. ${ }^{1}$

Wie mufs man sich diese Umwandlung vorstellen? Der Beraunit hat eine andere Krystallform als der Vivianit; er ist zwar monoklin, jedoch das Axenverhältnis ist ein anderes." Man kann also schwerlich annehmen, dafs die oxydierten Teile isomorph mit den nicht oxydierten Teilen zusammenkrystallisiert sind. Man ist geneigt, Mischkrystalle (in fester Lösung) anzunehmen, derart, dafs bei fortschreitender Oxydation die Beraunitteile zunehmen und schliefslich die Überhand bekommen. ${ }^{3}$ Gewils ist die Umwandlung, die hier stattfindet, ohne dals die krystallinische Struktur gestört wird, ein merkwürdiges Beispiel dieses Vorganges. Das Studium desselben verkehrt noch in der ersten Anfangsperiode, und so kann ich nur darauf hinweisen.

Übrigens ist im E. C. ein amorphes Ferriphosphat gefunden (S. 333). Doch ist es ungewifs, ob dieses durch vollständige (0xydation des Vivianits entstanden ist oder ursprünglich im Moore gebildet.

Chemische Zusammensetzung. Nach den obigen mikrochemischen Beobachtungen und Untersuchungen lälst sich jetzt die chemische Zusammensetzung näher betrachten.

Die Krystalle bestehen nur aus $(\mathrm{FeO})^{3} \mathrm{P}_{2} \mathrm{O}_{5} \cdot 8 \mathrm{H}_{2} \mathrm{O}$, insoweit sie farblos sind; ein ganz geringer Gehalt an $\mathrm{Fe}_{2} \mathrm{O}_{3}$ durch Oxydation bringt, schon die blaue Farbe hervor.

Die folgende Tabelle enthält die Analyse der pulverförmigen Substanzen I und II. Substanz I stammte rom Ende eines Nestes. Ursprünglich weifs, war sie, an der Luft getrocknet, hochblau geworden. Substanz II, die sich an der Luft nicht blau gefärbt hatte, stammte aus einer Ader; soviel möglich waren die grauweifsen Teile ausgesucht und die blawen und braunen Teile zur Seite ge-

1 Naumann-Zirket sagt, dals das Eisenoxyd bei den verschiedenen, in der Natur vorkommenden Vivianiten wechselt zwischen 1.1 auf $38 \% \%$.

${ }^{2}$ Naumann-Zirker giebt die Zahlen:

Vivianit $0.75: 1: 0.70$,

Beraunit 2.75: $1: 4.01$.

${ }^{3}$ Daraus lielse sich erklären, dafs eine andere Spaltungsrichtung hervortritt (S. 329 Z. 6 v. u.). 
stellt. In der Annahme, dafs das Phosphat ursprünglich Ferrophosphat und an der Luft teilweise oxydiert ist, babe ich die Menge Eisenoxyd, welche nötig ist, um mit dem Ferriphosphat Beraunit zu bilden, ${ }^{1}$ besonders angegeben.

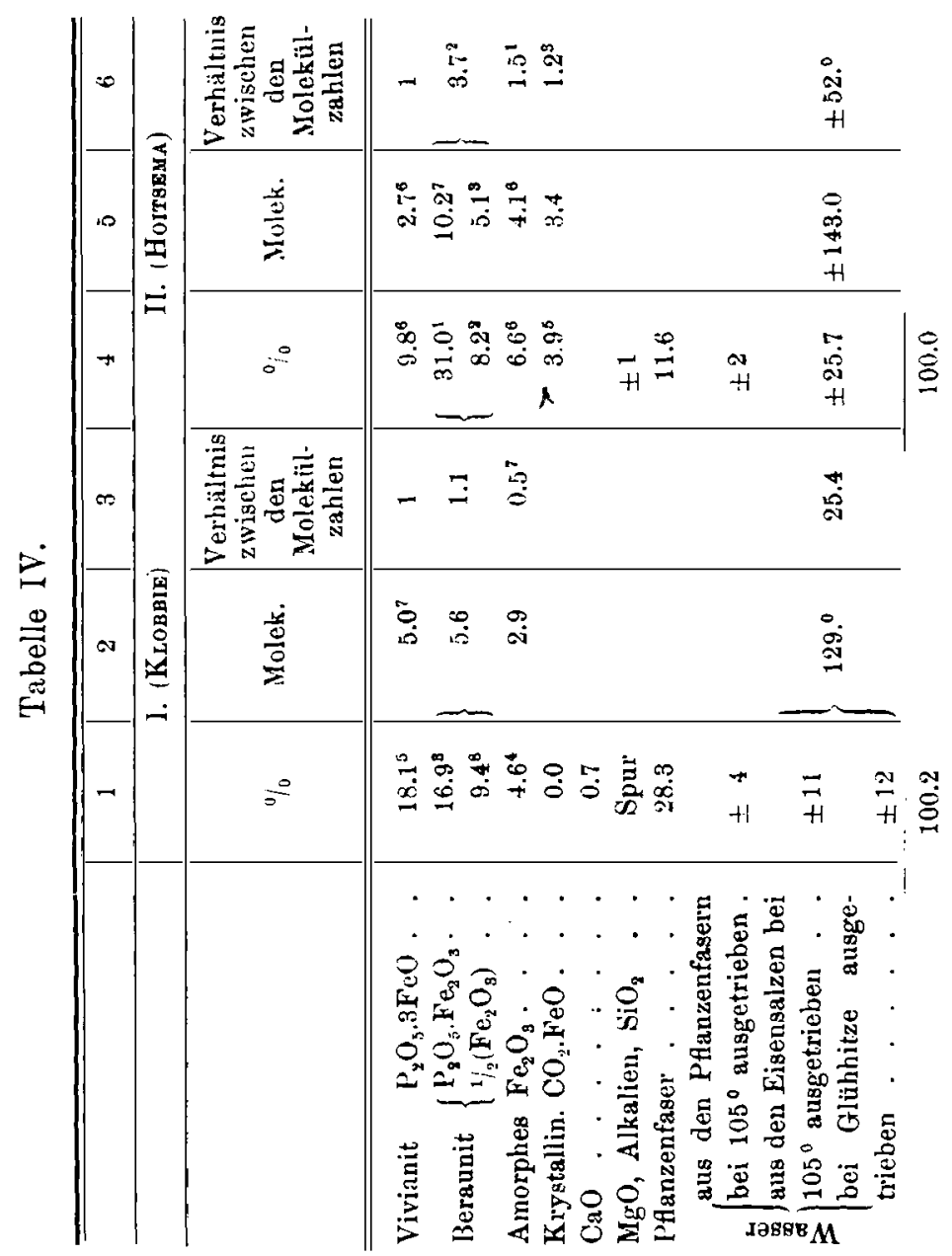

1 Aus 2 Mol. Ferrophosphat eutsteht 1 Mol. Beraunit

$2\left(\mathrm{P}_{2} \mathrm{O}_{5} .3 \mathrm{FeO}\right)+3 \mathrm{O}=\left(\mathrm{P}_{2} \mathrm{O}_{5}\right)^{2} \cdot\left(\mathrm{Fe}_{2} \mathrm{O}_{\mathbf{g}}\right)^{\mathrm{y}}$. 
Die früher von mir gemachte Analyse (Ia) eines blauen Vivianits, aus dem Ende eines Nestes gesammelt, gab mit I übereinstimmende Zahlen. Die Menge Pflanzenfaser war kleiner. ${ }^{1}$

Nimmt man an, dafs alles Eisen Oxydul gewesen ist, so ist die ursprüngliche Zusammensetzung von I gewesen.

Tabelle VI.

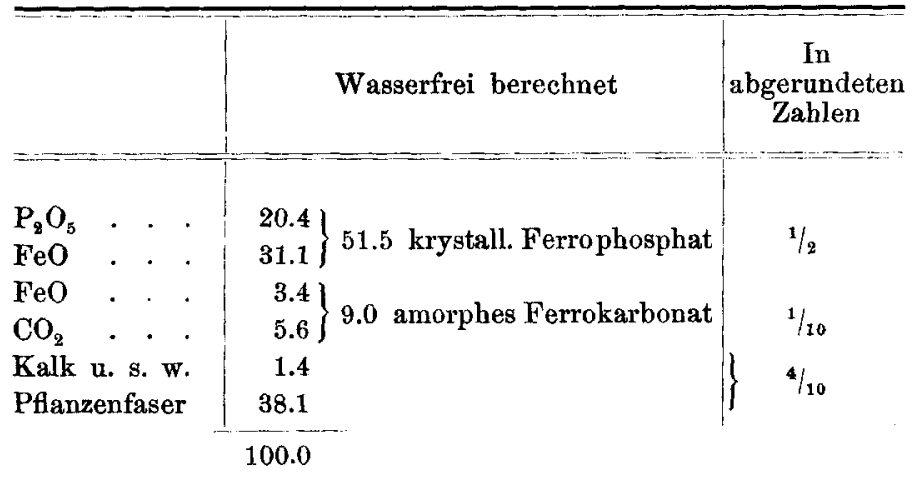

An der Luft ist ungefähr die Hälfte des Ferrophosphats und alles Karbonat oxydiert, wie Spalte 3 der Tabelle IV ersichtlich

1 Das Eisenoxydul wurde nicht absonderlich bestimmt, sondern alles Eisen als $\mathrm{Fe}_{2} \mathrm{O}_{3}$ gewogen. Zur Vergleichung schreibe ich die resp. Prozentzahlen von I und II daneben.

Tabelle V.

\begin{tabular}{|c|c|c|c|}
\hline & I a (v. B.) & I (Kl.) & II (H.) \\
\hline . . . . & & $10.9^{5}$ & 8.4 \\
\hline $\mathrm{Fe}_{2} \mathrm{O}_{8}$. . . . . . . . & $36.1^{0}$ & $18.0^{8}$ & 31.3 \\
\hline $\mathrm{P}_{2} \mathbf{O}_{3} \ldots \ldots$ & $17.5^{7}$ & $15.1^{6}$ & 18.5 \\
\hline $\mathrm{CO}_{2} \cdot \cdot \cdot \cdot \cdot \cdot \cdot \cdot \cdot \cdot$ & 0.0 & 0.0 & 1.5 \\
\hline Übrige lösliche Teile . . & \pm 1 & \pm 1 & \pm 1 \\
\hline $\mathrm{SiO}_{2} \cdot \ldots . . .$. & 0.3 & & \\
\hline Pflanzenfaser . . . . . & $14.7^{5}$ & 28.3 & 11.6 \\
\hline Wasser bei $100^{\circ}$ ausgetr. & 16.5 & 15 & 28.7 \\
\hline \multirow[t]{2}{*}{ Wasser bei Glühh. ausgetr. } & 15.3 & 12 & 20.0 \\
\hline & 101.5 & $100 .^{8}$ & 100 \\
\hline \multirow[t]{2}{*}{ Ab Sauerstoff } & \pm 1.5 & & \\
\hline & 100 & & \\
\hline
\end{tabular}


macht. ${ }^{1}$ Der Wassergehalt $(23 \%)$ ist etwas höher ${ }^{2}$ als sich aus der Annahme berechnen lä/st, dafs der Vivianit, insofern er oxydiert ist, in (krystallinischen) Beraunit übergegangen ist. Doch ist die Wasserbestimmung nicht sehr genau, und die Menge amorphe Substanz vielleicht etwas grölser und wasserhaltiger als angenommen ist. Da das Pulver hellblau und krystallinisch befunden ist, so hat sich also die Hälfte der Vivianitteile in den Krystallen zu Beraunitteilen oxydiert, ohne dafs die Krystallstruktur und der Dichroismus aufgehoben sind.

Die Substanz II, die sich an der Luft nicht blaut, besteht gröfstenteils aus a morph e m Ferriphosphat (oder amorphem Beraunit) (siehe Spalte 6) und enthält dabei etwas krystallin. Vivianit, krystall. Eisenspat und Eisenoxyd, das von amorphem Eisenspat herstammt. ${ }^{3}$ Die ursprüngliche Zusammensetzung ist beschwerlich

1 Ähnliches hat auch GaErTNER durch seine Analysen von Vivianit ans den Mecklenburger Mooren bewiesen. Siehe seine Analysenzahlen von Vivianit: noch ganz weifs, 1 Monat und 1/4 Jahr alt. (S. 25-28 seiner Abhandl.)

${ }^{2}$ Der Wassergehalt von Vivianit ist $8 \mathrm{H}_{2} \mathrm{O}$; von krystallinischem Beraunit ebenso $8 \mathrm{H}_{2} \mathrm{O}$ nach RAMMELSBera and NAOMAN-Zirkri; von amorphem $\mathrm{Fe}_{2} \mathrm{O}_{3}$ (lufttrocken) nach meinen Bestimmungen (Z. anorg. Chem. 20, 185) $4-5 \mathrm{H}_{9} \mathrm{O}$. Es lälst sich darans nach Spalte 3 der Tabelle IV berechnen:

Tabelle VII.

\begin{tabular}{|c|c|c|}
\hline & & Auf die ganze Menge \\
\hline $\begin{array}{c}\text { Eür } 1 \mathrm{Mol} \text {. Vivianit } \\
\text { " } 1.1 \mathrm{Mol} \text {. Beraunit . } \\
" \quad 0.57 \mathrm{Mol} . \mathrm{Fe}_{2} \mathrm{O}_{3}\end{array}$ & $\begin{array}{lrr}8 & \mathrm{Mol} . & \mathrm{H}_{2} \mathrm{O} \\
8^{8} & " & , " \\
2^{9} & ", & ,\end{array}$ & $\begin{array}{lcc}\mathbf{4} 0^{6} & \mathrm{Mol} . & \mathrm{H}_{2} \mathrm{O} \\
\mathbf{4} 4^{6} & " \quad " \\
14^{7} & " \quad "\end{array}$ \\
\hline $\begin{array}{l}\text { Berechnet } \\
\text { Gefunden }\end{array}$ & $\begin{array}{l}19^{7} \text { Mol. } \mathrm{H}_{2} \mathrm{O} \\
25^{4}, ", \quad,\end{array}$ & $\begin{aligned} 99.9 \text { Mol. } \mathrm{H}_{2} \mathrm{O} & =18 \text { Gewichtsprozente } \\
129.0 ", \quad " & =23\end{aligned}$ \\
\hline
\end{tabular}

${ }^{s}$ Der gefundene Wassergehalt ist nicht viel von dem berechneten verschieden. Nach Spaite 6 der Tabelle IV wird berechnet:

Tabelle VIII.

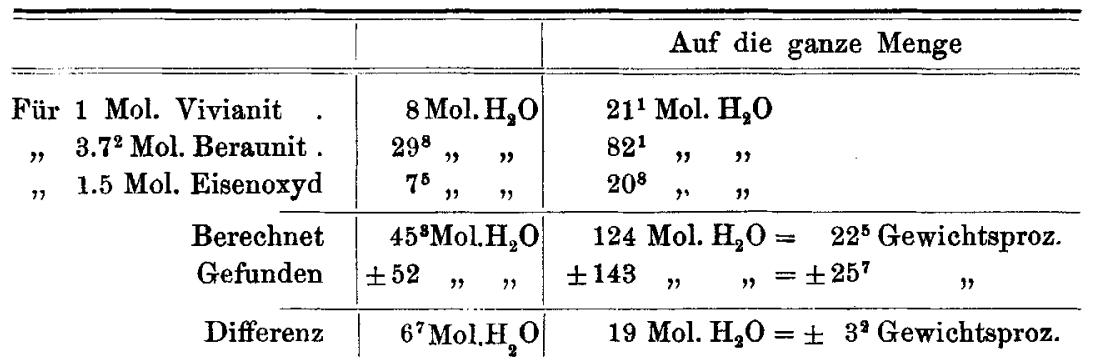


festzustellen. Mufs man annehmen, dafs ursprünglich Ferriphosphat im Moor abgesetzt und nicht reduziert ist? Das ist für eine Moorschicht wie die des E. C. fraglich. Oder mul's man annehmen, dafs hier ein Vivianit vorliegt, der durch vollständige Oxydation in ein amorphes, basisches Ferriphosphat übergegangen ist? Dagegen spricht, dafs blau werdende Vivianitteilchen zwischen diesen weifsbleibenden beobachtet sind. Ich mufs die Erledigung der Frage weiteren. Untersuchungen überlassen.

\section{Zusammensetzung}

im allgemeinen der Eisenanhäufungen in den Mooren.

Konkretionen in allen Verhältnissen von Eisenkarbonat, Eisenphosphat, Calciumkarbonat (oft mit etwas Mangan- und Magnesiumkarbonat) kommen in den Bruchmooren vor, wie besonders aus den Beobachtungen von GaERTNER in den Mecklenburger Mooren sich ergeben hat.

Um dies deutlich ins Licht zu stellen, ist es nötig, das Verhältnis zwischen den an $\mathrm{CO}_{2}$ und an $\mathrm{P}_{2} \mathrm{O}_{5}$ gebundenen Basen $\mathrm{FeO}$ und $\mathrm{CaO}(\mathrm{MgO}, \mathrm{MnO})$ zu berechnen, oder umgekehrt zwischen den an den Basen gebundenen Säuren zu berechnen, und zwar in Molekülen (nicht in Gewichtsprozenten). Ich habe die erstgenannte Berechnung für die analysierte Substanzen gemacht und in Tabelle $\mathrm{X}$ zusammengestellt (S. 336).

Es erhellt daraus, dafs dabei alle Verhältnisse ${ }^{1}$ zwischen einem Eisenspat vorkommen, der (als Mischung) enthält:

Auf $100 \mathrm{Mol}$. der Basen ( $\mathrm{FeO}, \mathrm{CaO}, \mathrm{MnO}, \mathrm{MgO}$ ):

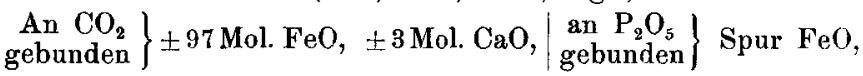

und einem Vivianit, der ebenso als Mischung enthält:

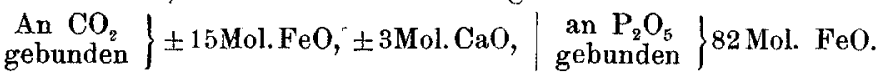

Das Karbonat ist teilweise amorph, teilweise krystallinisch, doch ist dies nur bei den Konkretionen aus E. C. und E. V. angegeben. Für

1 Bei den roten Knollen von TeschendorfF kann die Zusammensetzung auf zweierlei Weise berechnet werden. Diese kamen schon ganz oxydiert im Boden vor. Es bleibt ungewifs, ob das $\mathrm{P}_{2} \mathrm{O}_{5}$ als $\mathrm{Ca}$ - oder als $\mathrm{Fe}$-salz berechnet werden murs. Das Eisen ist überall als Oxydul berechnet, da es doch in diesem Zustande gewesen ist, und da also das bei den Analysen gefundene Eisenoxyd durch Luftzutritt enstanden ist. Eine Ausnahme habe ich für Nr. 13, 14, 17 gemacht, weil GaErTwer meint, dals er in diesen Substanzen Eisenoxyd als solches ursprünglich annebmen mufs. Mir scheint dies noch unsicher. 
die Mecklenburger Moore war es nicht möglich, weil der krystallinische Zustand des Eisenspats $G_{\text {AERTNER noch unbekannt war. Unzweifelhaft }}$ befinden sich unter Nr. 2-17 solche, die viel krystallinischen Eisenspat enthalten, wie z. B. Nr. 7 aus Laupin, denn dieses war stahlgrau und hart, und bestand zur Hälfte aus Eisenspat, zur Hälfte aus Vivianit, mit noch keinen $2 \% \mathrm{CaCO}_{3}$. Es war mit wenig Pflanzenfasern gemischt.

Aus der Tabelle lälst sich folgern, dafs man diese Konkretionen nicht zu zwei getrennten Abteilungen bringen darf: Vivianit und Eisenspat, wie es GaERTNER gethan hat. ${ }^{1}$ Man darf nur sprechen von Konkretionen von Vivianit und Eisenspat, mit Angabe des Molekül-Prozentverhältnisses.

Alle diese Konkretionen haben sich zwischen Pflanzenresten, einige auch zwischen Thon und Sand oder Sand allein (E. V.) gebildet. $^{2}$

1 Gakrtwer nennt Nr. 2-6 und 8-11 Vivianit.

"Nr. 7-13, 14, 17 Eisenspat.

"Nr. 12, 15, 16 Rote Knollen von oxydiertem Eisenspat.

2 Die von GaERTNER gefolgte Untersuchungmethode erlaubt nicht, die Menge der Planzenfasern in Prozenten zu berechnen, denn er erwähnt, dafs er die Versuchssubstanz vorher durch Dekantieren mit kohlensaurem Wasser vom grörsten Teil der Pflanzenfasern befreit hat. Es blieben jedoch noch viele übrig, denn er erhielt:

Tabelle IX.

Auf 100 Teilen wasserfreie Substanz berechnet:

\begin{tabular}{|c|c|c|c|c|c|c|c|c|}
\hline Folgenummer & 2 & 3 & 4 & 5 & 6 & 7 & 8 & 9 \\
\hline Pflanzenfaser & & $36^{2}$ & $46^{5}$ & $8^{6}$ & $3^{2}$ & $4^{9}$ & $16^{7}$ & $7^{7}$ \\
\hline Sand und Thon. & $21^{*}$ & $13^{4}$ & $6^{8}$ & $6^{0}$ & $0^{8}$ & $0^{5}$ & $28^{2}$ & $42^{5}$ \\
\hline Eisenverbindungen . & $78^{6}$ & $50^{4}$ & $46^{7}$ & $85^{4}$ & $96^{\circ}$ & $94^{8}$ & $55^{1}$ & $49^{8}$ \\
\hline & 100 & 100 & 100 & 100 & 100 & 100 & 100 & 100 \\
\hline
\end{tabular}

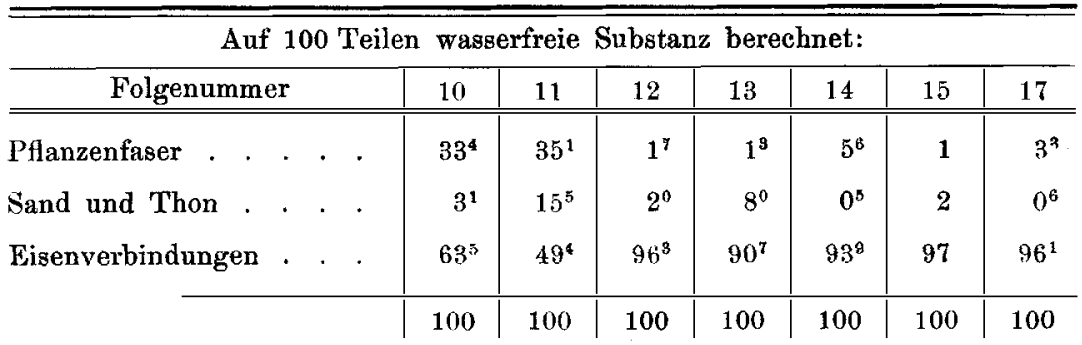


Tabelle $\mathbf{X}$.

Übersicht der Zusammensetzung der Eisenkonkretionen, im Anbetreff ihres Gehalts an Eisf phosphat und Eisenkarbonat, im Moore des Emmer Compascuums, in den Mooren von Meckle burg, und im Raseneisenstein von Ederveen.

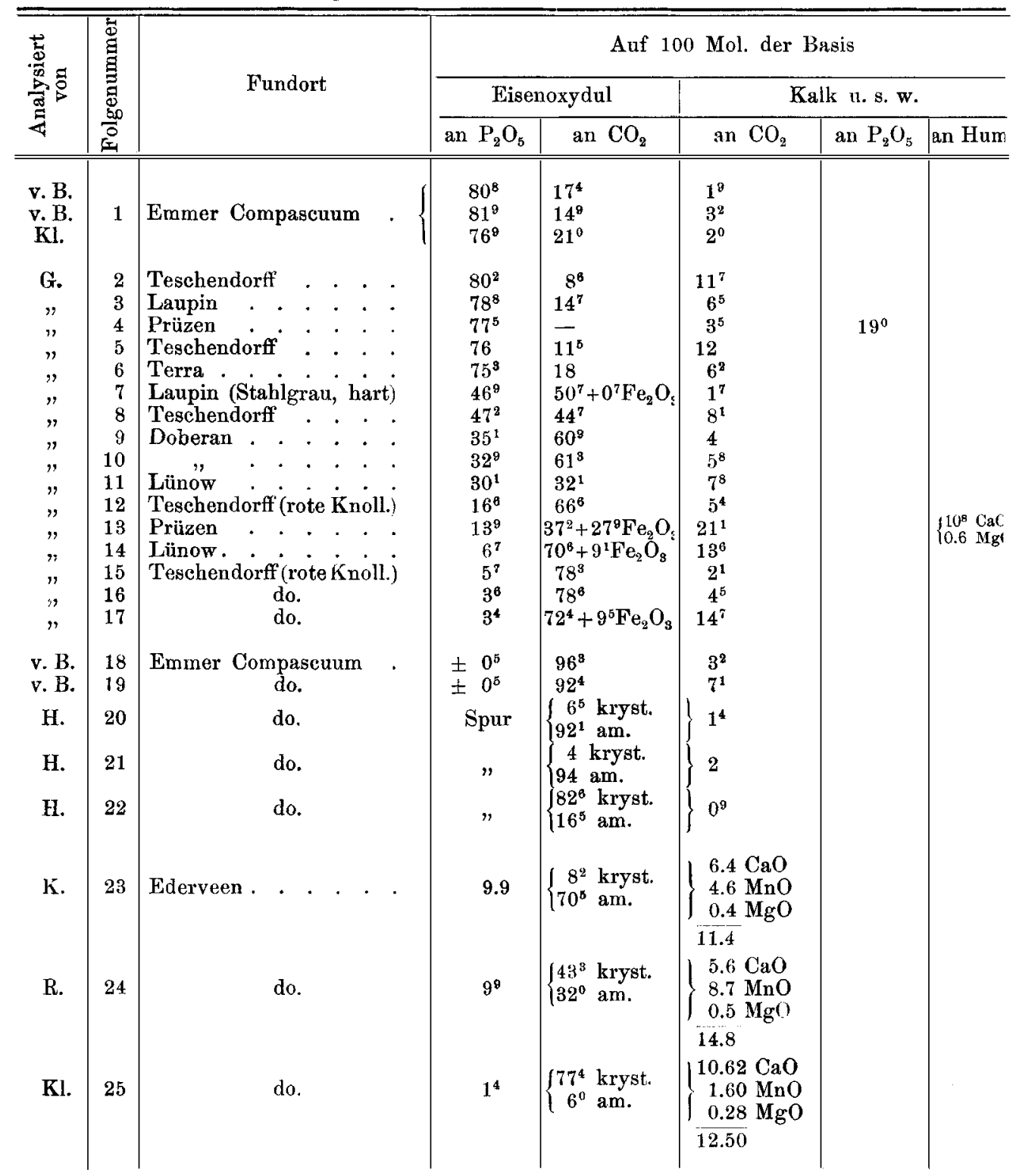

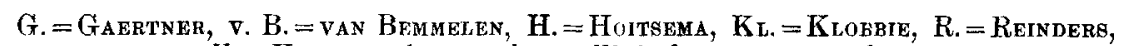
K.= KeTtNeR, kryst. = krystallinisch, am. $=$ amorph. 
E. Das Quellwasser zu Ederveen.

Es war von Interesse, die Zusammensetzung dieses Quellwassers unter einer Raseneisensteinbildung, von welcher man annehmen darf, dals sie noch fortdauert, kennen zu lernen. Herr ReIndERs hatte die Güte, dieses Wasser zu sammeln. Dazu war ein kurzes Standrohr unter der „Oer"-Schicht zu Ederveen im Quellsand eingeschlagen. In diesem quellte das Wasser klar, farblos und sandfrei auf, wurde mit einem Eimerchen geschöpft, und gleich in eine Flasche übergebracht. ${ }^{2}$

Tabelle XI.

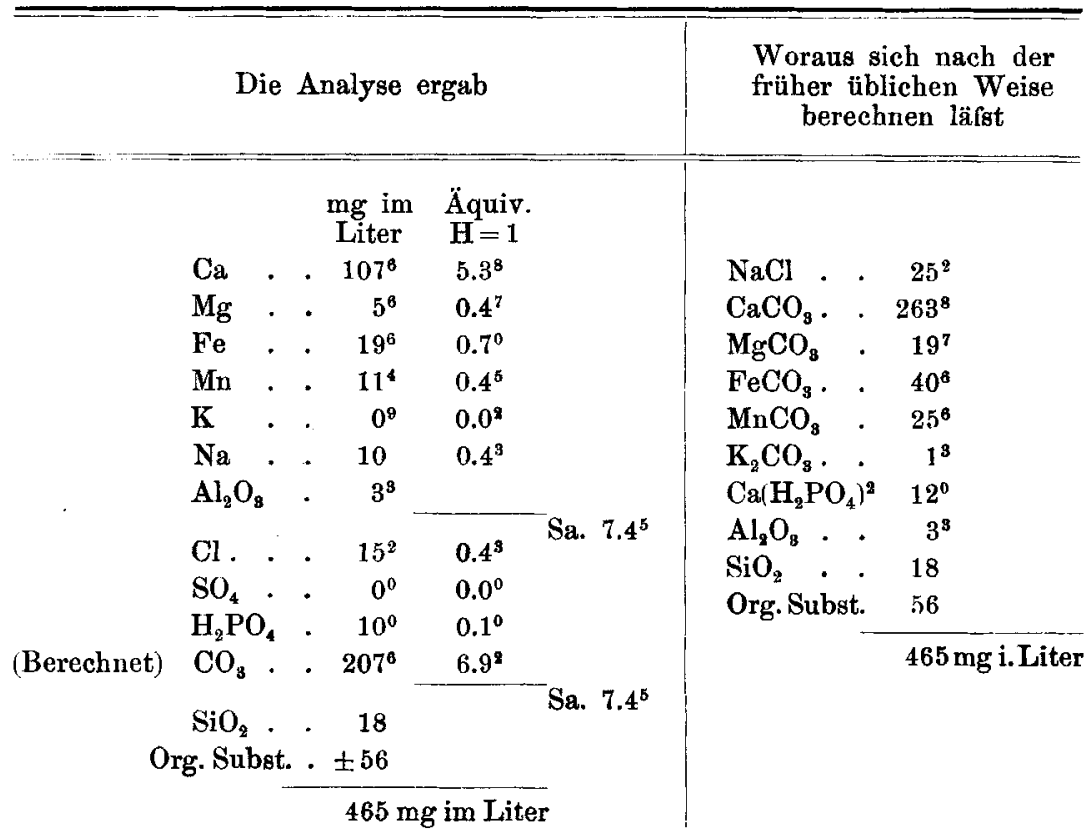

Neben den Gewichtszahlen (auf 1 Liter) stehen die Äquivalentzahlen, weil man nicht weils, wie die Säuren die Basen unter sich teilen, oder - nach den heutigen Begriffen - weil in verdünnten Lösungen von krystallordalen Salzen nur positive und negative Radikale (Ionen) anzunehmen sind. Demnach ist daneben die Berechnung der Salze nach der alten Weise angegeben, zur Vergleichung mit älteren Wasseranalysen.

1 Leider konnte es nicht gleich analysiert werden, wodurch die Bestimmung des ganzen Kohlensäuregehalts ausfiel. Es ergab sich jedoch genügend, dafs alle Karbonate als saure Karbonate gelöst waren. Die genaue Analyse wurde unter meiner Aufsicht von Herrn G. Moli van Charavte chem. cand. gemacht. 
Weil die Gewichtszahlen den Molekülzahlen nicht entsprechen, und doch nur von Molekülen die Rede sein kann, wenn man über den Gehalt an Kalk, an Eisen, an Phosphorsäure u. s. w. Betrachtungen anstellt, so gebe ich in der folgenden Tabelle die Zusammensetzung des Wassers nach $\mathrm{mg}$-Moleküle berechnet: ${ }^{1}$

In einem Liter

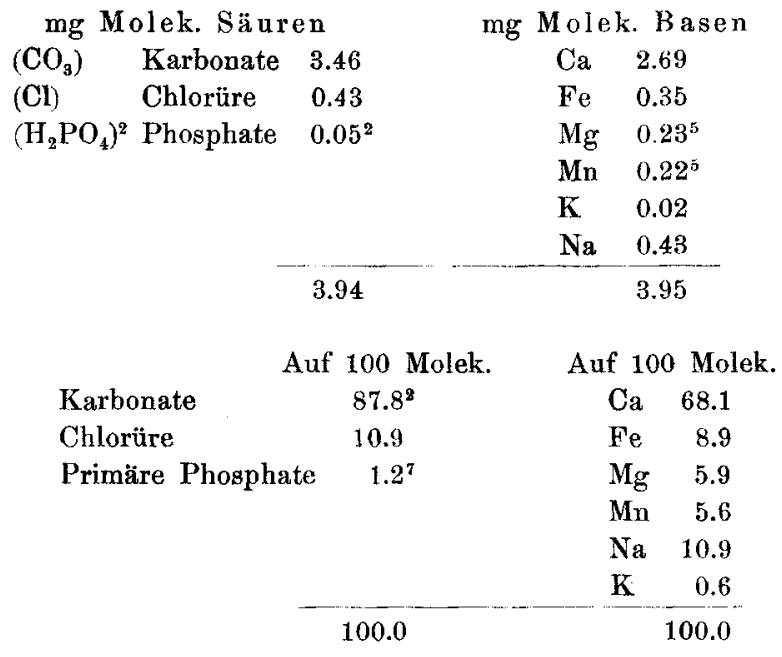

Hieraus ergiebt sich, dals die Molekül-Chlorüre (innerhalb der Genauigkeit der Analyse) den Alkalien entsprechen und $1 / 8$ der Molekül-Karbonate betragen; dafs die Menge $\mathrm{FeCO}_{3}$ Molekül $1 / 8$ der $\mathrm{CaCO}_{3}$ Molekül beträgt; dafs die Mengen $\mathrm{MgCO}$ und $\mathrm{MnCO}_{3}$ Molekül gleiche Gröfse haben und $1 / 12$ der $\mathrm{CaCO}_{3}$ Molekül betragen; dals die Menge Phosphat Molekül 1.2\% der ganzen Molekülzahl beträgt.

Die Schwefelsäure fehlt, was beweist, dafs sie in den tieferen Bodenschichten, zufolge der Reduktion, als Pyrit oder als Schwefel (in Humussubstanzen) festgelegt wird.

Die Kieselsäure ist aufser Berechnung gehalten, weil ihre Salze hydrolytisch dissoziiert sind; und die Alaunerde, weil man wahrscheinlich annehmen darf, dafs sie durch kollordale Humussubstanzen in Lösung gehalten wird.

${ }^{1}$ Es wäre nach meiner Ansicht wünschenswert, dafs alle Wasseranalysen und dergleichen auf diese Weise berechnet und zusammengestellt wiirden. Ich habe mir deshalb an dieser Stelle diese ausführliche Betrachtung erlaubt. 
Die Zusammensetzung des Quellwassers lehrt, dafs es das Eisen, Mangan und auch die Phosphorsäure des Raseneisensteines zuführen kann. ${ }^{1}$

\section{Die chemischen Reaktionen.}

Bevor ich die Eisenkonkretionen in und unter Mooren beschreibe, und über ibre Bildung Hypothesen aufstelle, kommt es mir zur Vermeidung von Wiederholungen zweckmäfsig vor, um von unserer Kenntnis über den Gang der chemischen Reaktionen, die dabei anzunehmen sind, eine kritische Übersicht zu geben.

Die vornehmsten Reaktionen sind: die Reduktion von $\mathrm{Fe}_{2} \mathrm{O}_{3}$ zu $\mathrm{FeO}$, die Oxydation von $\mathrm{FeO}$ zu $\mathrm{Fe}_{2} \mathrm{O}_{3}$, die Absetzung von $\mathrm{FeCO}_{3}$, die Bildung von Vivianit aus Ferrosalz und Phosphat.

a) Humusbildung und Reduktion von $\mathrm{Fe}_{2} \mathrm{O}_{3}$ zu $\mathrm{FeO}$. Die Reduktion findet statt bei der Humifikation von organischen Resten in Berührung mit Eisenoxyd, unter Bildung von sogenanntem löslichen Ferrohumat oder von löslichem Ferrobikarbonat. Von dem chemischen Gang der Humifikation von stickstofffreien und stickstoffhaltigen Pflanzenstoffen wissen wir so gut als nichts. Die Humusstoffe sind verwickelte, kollordale Komplexe, deren Zusammensetzung gänzlich unbekannt ist.

Auch das sogenannte Ferrohumat ist keine chemische Verbindung, sondern ein kollordalles Komplex. ${ }^{2}$ Die kollor̈dalen Lösungen (Sols) von Humussubstanzen, besonders ammoniakhaltige, können $\mathrm{FeO}$ und $\mathrm{Fe}_{2} \mathrm{O}_{3}$ in kolloìdaler Lösung halten. Wenn sich eine Verbindung von Humussubstanzen mit $\mathrm{FeO}$ oder $\mathrm{Fe}_{2} \mathrm{O}_{3}$ daraus abscheidet, so ist diese ebenso wenig eine chemische, sondern eine Absorptionsverbindung im Gel-Zustande. Die Humussubstanz kann

1 Reinders hat 1896 zwei annähernde Bestimmungen des Kalkes und desEisenoxyds im Quellwasser von Ederveen und von Herinckhave gemacht:

$\begin{array}{lccc} & & & \mathrm{mg} \\ & \mathbf{C a} & \mathrm{Fe} \\ \text { Ederveen . . . . . . } & 58 & 37^{5} \\ \text { Herinckhave . . . . } & 50 & 36\end{array}$

Die Menge Ca ist kleiner, die Menge Fe grölser als von mir gefunden ist.

${ }^{2}$ Die Namen Humate, Ulmate 1. s. w. sollten darum nicht länger angewendet, sondern die Namen Sols (kolloïdale Lösungen) und Gels eingeführt werden; z. B.: Humusferrohydrosol, Humusferrohydrogel u.s w. Die Humussubstanz selbst kann im jetzigen Zustande unserer Kenntnisse nicht näher definiert werden. Die Namen Humussäure, Ulminsäure, Apokrensäure u. s. w, deuten unbestimmte Komplexe kolloïdaler Substanzen an. 
auch $\mathrm{Al}_{2} \mathrm{O}_{3}, \mathrm{CaO}, \mathrm{MgO}$, in kollơdale Lösung bringen, oder im GelZustande dieselbe absorbieren. Solche Komplexe kommen im Ortstein vor (siehe S. 366).

Nach Beyerinck wirken bei der Reduktion keine Mikroorganismen mit.

Unbekannt ist es, ob die Reduktion in einem alkalischen Medium, oder auch in einem sauren stattfinden kann; ebenso unter welchen Umständen ein Karbonat oder ein Humuskomplex von Eisenoxydul entsteht.

b) Oxydation von FeO-Verbindungen und Absetzung von $\mathrm{Fe}_{2} \mathrm{O}_{3}$. Die Oxydation durch Luftzutritt ist die gewöhnliche. Es hat sich jetzt ergeben, dals nur das amorphe, nicht das krystallinische Ferrokarbonat oxydiert wird. Jedoch darf man wahrscheinlich auch eine Oxydation ohne Luftzutritt - und also eine Abscheidung im festen Zustande - annehmen, die von drahtförmigen Eisenbakterien bewirkt wird, nämlich: Leptothrix ochracea KÜTZING und Crenothrix Kühniana RABENHonst. ${ }^{1}$ Denn diese nehmen aus $\mathrm{FeCO}_{3}$ Lösungen alles Eisen fort, und scheiden es als $\mathrm{Fe}_{2} \mathrm{O}_{3}$ in ihrer gelatinösen Hülle wieder aus. ${ }^{2}$ Es mufs also eine Wasserzersetzung hierbei stattfinden. Die Eisenbakterien häufen das Eisen aus Grundwasser in sich an, in Mengen, die sehr grofs sind im Vergleich mit ihrem eigenen Gewichte. Sie können bis auf eine Tiefe von $20 \mathrm{~m}$ im Boden leben. In Grundwasserleitungen sind sie gefunden, so z. B. zu Prag durch Sitensixy, za Arnhem durch BakhUis Roozeboom, zu Zandvoort bei Haarlem durch van DER SLEEN. ${ }^{3}$

1 Auch Wolriny erwähnt diese: Die Zersetzung der organischen Stoffe und die Humusbildungen (Heidelberg 1897, C. WinTre) S. 37 und 237.

${ }^{2}$ Das Eisenoxydul ist für das Wachstum der Cladothrix unerlälslich. Tolomer (Z. anorg. Ch. 5, 102); Winogradsky (Bot. Zieit. 1888, 210); Molisch: Die Planzen in ihren Beziehungen zum Eisen. (Jena 1892.)

${ }^{3}$ Sehr merkwürdig ist die folgende Beobachtung, mir von Herrn N. vas Der Steen mitgeteilt. Auf dem Terrain der Amsterdammer Wasserleitung zu Zandvoort, in den Dünen, war ein Brunnen gebohrt von $12 \mathrm{~m}$ Tiefe. Das aufquellende Grundwasser entbielt $12.5 \mathrm{mg} \mathrm{FeCO}$ im Liter $\left(196^{4} \mathrm{CaCO}_{3}, 184^{2} \mathrm{CaSO}_{4}\right.$, $87^{8} \mathrm{NaCl}, 0.48 \mathrm{NH}_{8}, \pm 30$ organ. Substanz). Im Brunnen war ein eisernes (0.1 m Durchmesser) Pumprohr niedergelassen, unten mit Öfnungen versehen. In diesem Rohr war ein Pegelrohr von Zink (4 cm Diameter) angebracht, worin ein zinkenes Eimerchen hing. Vierzehn Tage und Nächte wurde ohne Unterbrechung Wasser ausgepumpt. Während dieser Zeit sammelte sich auf der Aufsenwand des Pegelrohrs und in dem Eimerchen eine Menge Eisenbakterien 
SITENSKY $^{1}$ hat den Leptothrix und Crenothrix im Eisenocker von Drainröhren und überhaupt in sehr vielen Drainwässern, namentlich in den Quellen- und Grundwässern der Wiesen, bei jeder Brauneisenockerbildung konstatiert. Er ist $\mathrm{zu}$ der Überzengung gekommen, dafs diese Bildung der physiologischen Wirkung dieser Organismen seine Entstehung verdankt. ${ }^{2}$

Schon früher hat man eine ähnliche Rolle anderen Organismen zugeschrieben. So z. B. meint STAPFF, dals Diatomeen durch Sauerstoffabscheidung das gelöste Eisenkarbonat als Eisenoxyd auf die Pänzer niedersehlagen können, woraus dann später Eisensilikat entsteht. Diese Erscheinung ist noch unbewiesen. Eine andere physiologische Wirkung wird den Wasserpflanzen, wie Chara, zugeschrieben, die Kohlensäure absorbieren, wodurch das Ferrokarbonat unlöslich sich darauf niederschlägt. Selbst eine Aufnahme von gelöstem Karbonat oder Humusverbindung von Eisen durch Moorpflanzen in ihrem Gewebe, wie Equisetum limosum, einige Junci und Carices (welche alle in einem sauren Boden, der lösliche Eisensalze enthält, am liebsten wachsen), kann von Bedeutung sein.

Jedoch, alle diese Wirkungen sind viel zu unvollständig untersucht und bekannt. Sie müssen noch in der Natur selbst in ihren

(Leptothrix ochracea) an, mit einer viel gröfseren Menge amorphen kolloüdalen Eisenoxyds. Die Menge im Eimerchen betrug $80 \mathrm{~g}$.

Die Analyse der schleimigen rotbraunen Substanz ergab:

$\begin{array}{lr}\text { Organ. Substanz } & 18.7 \\ \text { Eisenoxyd } & 71.6 \\ \mathrm{CaCO}_{8} & 2.7 \\ \mathrm{FeS} & 0.8 \\ \mathrm{ZnO}_{\mathrm{S} O} & 3.5 \\ \text { Sand } & 2.4 \\ & 99.7\end{array}$

Das Pumprohr war oben vollstïndig von der Luft abgesehlossen. Zwischen den Brunnenwänden und dem Pumprohr waren drei Schichten angebracht: Kies, grober Sand, feiner Sand, zusammen $0.6 \mathrm{~m}$ Durchmesser. Alle Vorsorge wurde genommen, dafs keine Luft im Pumprohr zutrat. Das aufgepumpte Wasser war dann auch sauerstofffrei; und beim Eisenoxyd befand sich etwas Schwefeleisen, ein Reduktionsprodukt einer anaërobien Bakterie (nach BeYernNcr).

Der Versuch wurde noch zweimal mit gleichem Ergebnis wiederholt, und ist von Gewicht, um die Eisenoxydbildung aus Ferrokarbonat durch Organismen, ohne Zutritt von Luft, zu beweisen.

1 Sitensky: Über die Torfmoore Böhmens. Prag 1891. S. 217.

${ }^{2}$ Nach einer brieflichen Mitteilung von Herrn SixEnskx, der bis jetzt durch Amtsgeschäfte verhindert wurde, seine Arbeit zu publizieren. 
Einzelheiten nachgespürt werden, bevor man beurteilen kann, inwiefern sie zu der Anhäufung von $\mathrm{Fe}_{2} \mathrm{O}_{3}$ aus Bodenwässern unter bestimmten Umständen beitragen können.

c. Absetzung von Eisenkarbonat aus Lösungen. Von den Ursachen, wodurch das Eisen sich als Ferrokarbonat aus Grundwässern in Bodenschichten absetzen kann, wissen wir sehr wenig. Kann es da stattfinden, wo das Wasser, nach der Oberfläche auf steigend und also unter niederem Druck kommend, die Kohlensäure (wodurch das Salz in Lösung gehalten wird) verliert, und wo das Karbonat nicht oxydiert wird, weil der Luftsauerstoff nicht zutreten kann wegen der noch darüberliegenden Moorschicht? ${ }^{1}$ Mufs die Humifikation im Moor bis zu einem gewissen Stadium fortgeschritten sein, derart, dals die sogenannten Humussäuren nicht mehr entstehen, welche die Absetzung von Karbonat verhinderen können? Auf beide Fragen lälst sich noch keine Antwort geben. Auch wissen wir gar nicht, wodurch das $\mathrm{FeCO}_{3}$ an der einen Stelle kolloidal, an der anderen krystallinisch abgeschieden wird.

d) Bildung von Vivianit. Wie oben erwähnt, hat Dr. KLonsie den Vivianit, auch den scheinbar erdigen Vivianit im E.C. und E.V., von krystallinischer Struktur befunden.

Eine Bildung von Vivianit, unter Umständen, die bei den oben beschriebenen Moorschichten und in den Sandschichten unter Moor habe vorkommen müssen, ist experimentell verwirklicht. WIEGMaN und nach ihm auch GaEkTnER haben im humussäure- und phosphorsäurehaltigen Moorwasser, mit Limonit gemischt, die langsame Bildung von weilsem (schliefslich blauwerdenden) Vivianit erhalten, selbst als die Flüssigkeit an der luft stand. ${ }^{2}$

Ferrokarbonat und Eisenoxyd sind oft in der Natur von Ferrophosphat begleitet. Wie er zwischen den Eisenspatkonkretionen zerstreut liegt, entweder an den Enden derselben, oder auf deren Oberfläche angehäuft liegt, wird unten ausführlich beschrieben. (S. 354 und 371.) Wo Pflanzenteile in Eisenrost metamorphosiert sind, kommt darauf

${ }^{1}$ Gaertner (S. 51 seiner Schrift) weifst auf das Ammoniak, das sich bei der Humifikation von stickstoffhaltigen Pflanzenteilen bildet und Koblensäure aus dem Bodenwasser fortnehmen kann. Dies würde jedoch nicht genügen für die Masse des abgesetzten Karbonats; aufserdem bindet der Humus selbst das Ammoniak.

${ }^{2}$ GaErTner S. 50. Selbst beim längeren Verweilen von Eisen mit Phosphatlösungen in Gegenwart von organischen Substanzen hat Becquerex Vivianit bekommen. Ann. Chim. Phys. 54, 149. 
vielfach Vivianit vor (S. 370). ${ }^{1} \quad$ GAERTNER $_{\text {fand im Mecklenburger }}$ Moor eine Druse von Eisenspat von der Grölse eines Hühnereis, die im Innern mit Vivianit bekleidet war. ${ }^{2}$ Alle diese Beobachtungen machen es höchstwahrscheinlich, wenn nicht sicher, dafs amorphes sowohl wie krystallinisches Ferrokarbonat in Vivianit verwandelt wird, durch eine Einwirkung: entweder des im Bodenwasser zugeführten Phosphats, entweder des bei der Verwesung von Pflanzenund Tierresten in Lösung kommenden Alkaliphosphats (von K, $\mathrm{Na}$ oder $\mathrm{NH}_{4}$ ). Kollordales Ferrokarbonat und kolloidales Eisenoxyd können dabei Phosphorsäure aus ihren Salzen (in Lösung) absorbieren, und daraus kann, unter gewissen Verhältnissen, krystallinischer Vivianit entstehen. Im Falle des Eisenoxyds mufs daran noch eine Reduktion zu $\mathrm{FeO}$ durch Humussubstanzen vorhergehen. Der Übergang von kollordalem Ferrophosphat in krystallinisches Vivianit ist eine schon bekannte Erscheinung. Sie ist erhalten von DribraY durch Erhitzung des Ferrophosphats ${ }^{3}$ mit einem grofsen Überschufs von Natriumphosphat, während 8 Tagen bei $50-60^{\circ}$. Dr. KLoBbIE hat gefunden, dals diese Umsetzung schon bei der gewöhnlichen Temperatur in einem Tage stattfindet, wenn man zusammenbringt und von der Luft abschliefst:

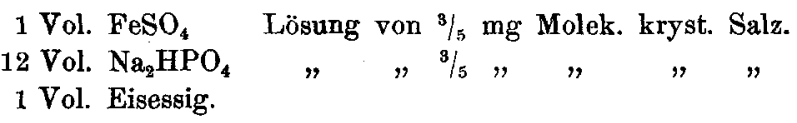

Der kollordale Niederschlag löst sich grölstenteils zu einem Sol durch die Essigsäure. Allmählich bilden sich daraus Krystallaggregate von Vivianit, die alle optischen Eigenschaften der natürlichen Krystalle besitzen, und sich schnell oberflächlich an der Luft oxydieren. Auch mit $\mathrm{H}_{2} \mathrm{O}_{2}$ oxydieren sie sich, jedoch wieder nicht vollständig.

Man kann nicht behaupten, dals dieser Bildungsgang der einzig mögliche ist. Aus einer Lösung, die $\mathrm{FeO}, \mathrm{CaO}, \mathrm{MnO}, \mathrm{P}_{2} \mathrm{O}_{5}, \mathrm{CO}_{2}$ in gewissen Verhältnissen enthält, können vielleicht bei Änderungen von Temperatur, Konzentration, Druck (Konzentration der Gasphase),

${ }^{1}$ Rohrstengelteile, Wurzeln, tierische Reste u. s. w. in Sand und Thonböden, worin sich Eisenoxyd abgesetzt hat, zeigen oft blaue Fleckchen oder selbst blaue Wände.

${ }^{2}$ Die Öffnung war noch sichtbar, worin nach GaERTreR's Meinung die phosphorsäurehaltige Flüssigkeit eingedrungen war, welche die unterste Schicht des Eisenspats in Vivianit verwandelt hat.

s Aus Ferrosulfat- und Natriumphosphatlösung bereitet. Compt. rent. 59, 40. 


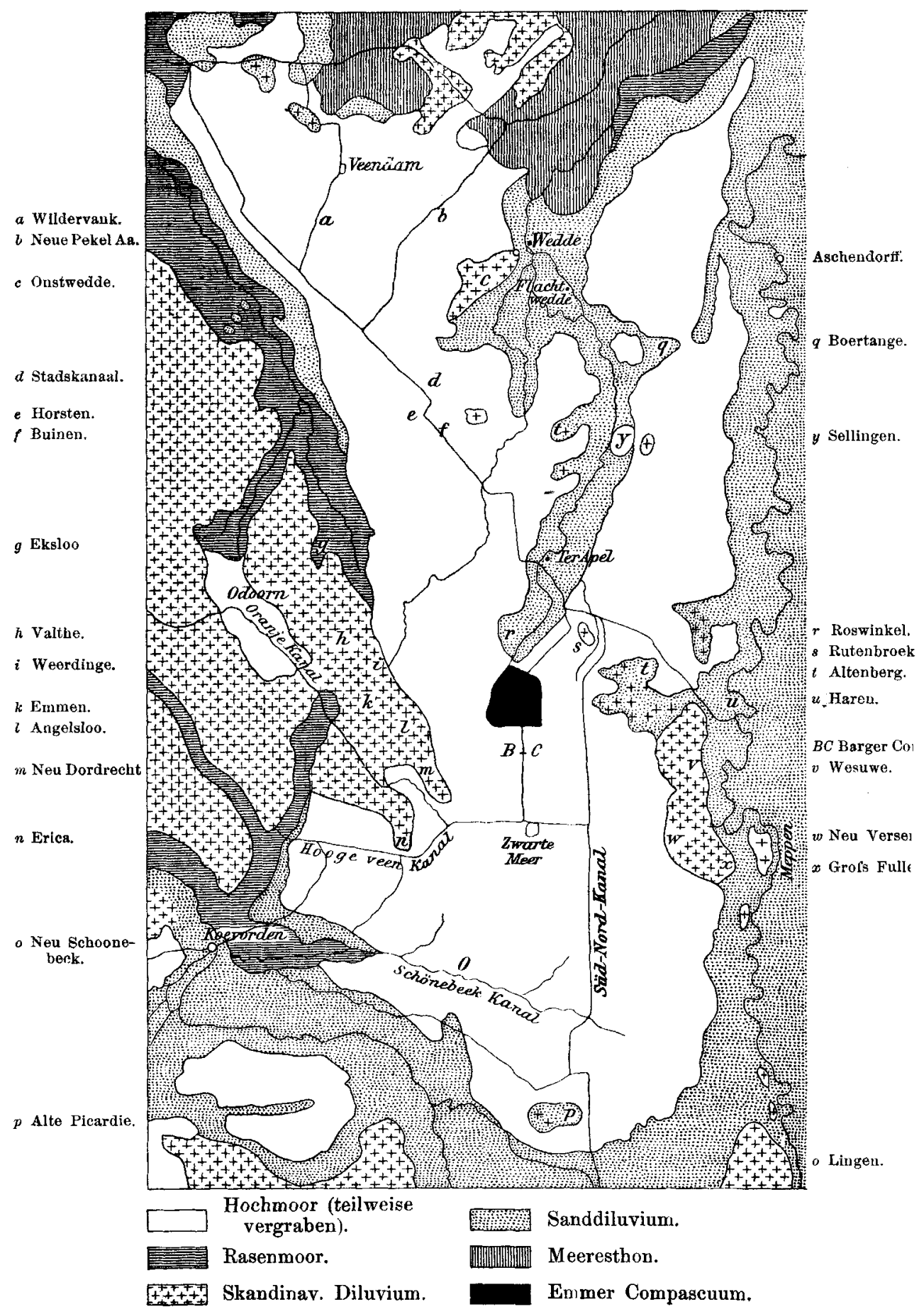


Anziehungscentra - verschiedene Verbiniungen $\mathrm{FeCO}_{3}, \mathrm{Fe}_{3}\left(\mathrm{PO}_{4}\right)^{2}$, $\mathrm{CaCO}_{3}, \mathrm{Ca}_{3}\left(\mathrm{PO}_{4}\right)_{2}$ auskrystallisieren, ohne dals Metamorphose dabei stattfindet.

Aus dieser Übersicht ergiebt sich, wie höchst dürftig unsere Kenntnisse noch sind über die Bildung dieser Eisenverbindungen in der Natur. -

\section{Die Eisenanhäufungen in den Niedermooren unter Hochmoor von Drenthe (Emmer Compascuum).}

Bevor, ich diese Bildung beschreibe und eine Erklärung derselben versuche, ist es nötig, die Lage des Moores in Beziehung des umgebenden Terrains und dessen Bau zu betrachten.

\section{A. Die Lage.}

Das E.C.-Moor liegt in der Mitte der ausgedehnten Hochmoorformation im östlichen Teil der Provinzen Drenthe und Groningen und im angrenzenden Teil von Hannover. Die kleine geologische Karte ${ }^{1}$ (auf S. 344) umfafst dieses Moorgebiet, mit den dasselbe umschliefsenden Diluvialböden. Die letzteren bestehen hauptsächlich aus diluvialem Sand. Nur an einzelnen Stellen, ungefähr in der Mitte, wird die Moorbildung durch Skandinavisches Geschiebediluvium begrenzt, nämlich: im Westen durch die Ausläufer des Diluvialgebietes in Drenthe den Hundsrücken -, an der östlichen Seite durch ein Geschiebe Diluvium (Grofs-Fullen, Wesuwe, bis Altenberg), welches das Hochmoor von den mehr östlich gelegenen Sandböden der Ems trennt. Der nördliche Teil der Hochmoorformation wird durch die ausspringenden Sandböden von der Landschaft Westerwolde in der Provinz Groningen (südlich bis Roswinkel sich ausdehnend).in zwei Teile getrennt.

Der Untergrund des Moores ist Sanddiluvium. Das Liegende des ganzen Moores fällt ab, ohne Unterbrechung von Süd nach Nord, erst etwas stärker, weiterhin schwächer. ${ }^{2}$

In der Mitte dieses ausgedehnten Gebietes, ungefähr da, wo die Trennung in einem westlichen und einem östlichen Teil anfängt, liegt

1 Diese Karte ist einer Abhandlung von Dr. J. Lorit entnommen: Les hautes tourbières au nord du Rhin. Archives du Musée, Teyler 1895, (2. Serie) Tom VI. 4. Partie.

${ }^{2}$ Zum Beweise führen wir die folgenden Zahlen an. In Salfeco's Geographische Beschreibung der Moore vom nordwestlichen Deutschland sind die Höhenzahlen des Sandbodens entlang des Süd-Nordkanals angegeben. Von z. anorg. Chem. XXII. 
das E.C.-Moor. Von da aus nach dem Westen gehend, erreicht man den hohen Hundsrücken; nach dem Osten gehend gleichfalls Skandinavisches Diluvium (von Altenberg und Wesuwe). Das E. C. hat also eine eigentümliche Lage, denn die genannten Grenzen, besonders der Hundsrücken, liegen bedeutend höher als der Sandboden, der zwischen diesen beiden Grenzen unter dem Moorgebiet liegt. Dieses Terrain hat einigermalsen die Form einer breiten Rinne mit aufstehenden Rändern, welche langsam in nördlicher Richtung herabfällt. ${ }^{1}$

Nordhorn bis zum Kanal Haren-Rutenbroek sind diese: 221/4, 25, 20, 18 $3 / 4$, $171 / 2,16^{3} / 4,15^{3} / 4,13^{3} / 4,12^{1 / 3}$ M. + A. P. (Amsterdamer Pegel.)

Mit Hilfe der niederländischen ,Waterstaats"-Karte, und von einigen anderen Terrainkarten kann man die folgenden Höhezahlen finden, in der Richtung vom Süd mach Nord. Für den südlichen Teil des Moores ist das Mittel der Höhenzablen genommen, über eine Ost-Weststrecke des Gebietes,

$\mathrm{M}+\mathrm{A} . \mathrm{P}$.

Schönebeck-Kanal . . . . . . . . 18.15

Auf der Breite von Grofs-Fullen . . . 16.75

Neu-Dordrecht . . . . . . . . . . 15.80

f Grenzscheidung zwischen

\{ Barger Compase. und Emmer Compasc. 14.40

Mitte des E. C. . . . . . . . . . 13.60

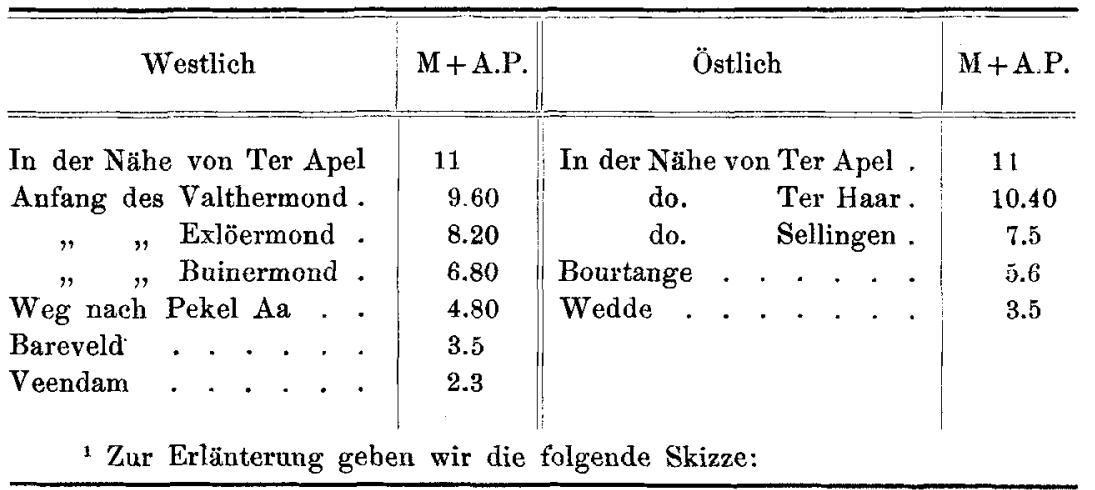

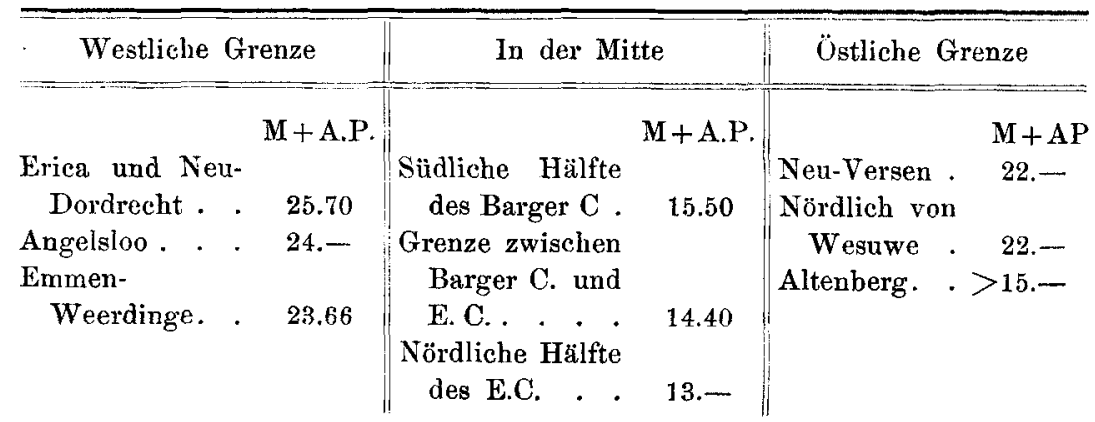


Das Grundwasser, das aus den höheren Diluvialschichten in die tieferliegende Sandschicht, welche die Grundlage des grofsen Moores bildet, abströmt und darin aufquellt, enthält Eisen gelöst, wie man an vielen Orten beobachten kann. ${ }^{1}$ Die Absetzungen von Eisenoxyd sind jetzt noch am leichtesten in den Bruchländern zu beobachten, unter einer dünnen Moorschicht oder unter moorigen Wiesen, z. B. im Gebiete von Roswinkel ( $r$ auf der Karte), bei den Horsten ( $e$ auf der Karte) u.s.w. Unter dieser Schicht kommt oft viel Wiesenerz vor, und stellenweise auch Vivianit. ${ }^{2}$

Aus allem diesem folgt:

Die Lage des E.C. erlaubt die Annahme, dafs die unterliegende Sandschicht und die darauf liegende Moorschicht (der Darg mit den Nestern) aus dem höheren diluvialen Boden durch abströmendes und

${ }^{3}$ Dr. Borgman, der seine Inauguraldissertation über die Bildung der Hochmoore in Drenthe und Nord-Brabant geschrieben hat, teilte mir mit, dals er den Eisengehalt des Grundwassers am deutlichsten gesehen hat beim Bau der grofsen Schleuse an der Stelle, wo der Oranjekanal jetzt im Hoogeveenkanal ausmündet (siehe die Karte). Die Kanäle waren damals noch nicht verbunden. Der Boden war tief ausgegraben zum Bau der Grundlagen der Sehleuse. Der Boden des Kanals war auf einer Tiefe von $14.9 \mathrm{~m}+\mathrm{A}$.P. gelegen; das Wasser stieg darin bis $16.9+$ A.P. Der Sandboden unter der Moorschicht gehört hier zum Hundsrücken, und besteht aus Sand und Blocklehm (eine Moräne). An dieser Stelle wurde tagelang beobachtet, dafs aus dem östlichen Ufer des Oranjekanals ein violettrotes Wasser strömte, das von den Arbeitern „Ochsenblut" genannt wurde. Der Strom kam aus einer Sandschicht oberhalb einer lehmhaltigen Diluvialfalte am Tage, war $\pm 10 \mathrm{~m}$ breit, und folgte dem Abhang der Falte. Die rote Farbe wurde durch das sich an der Luft oxydierende Ferrokarbonat hervorgebracht.

Auch das Wasser der Kanäle bei Roswinkel $(r)$, Valthe $(h)$ ist durch das Eisen des aufquellenden Grundwassers braunrot gefärbt.

${ }^{2}$ In der Mitte des Bargermeeres liegt ein kleiner See, das „Zwartemeer" (siehe die Karte), woraus eir Moorbach entspringt, der längs des E. C. läuft, und östlich von Roswinkel $(r)$ sich in einigen Ästen zerteilt. Hier, am Ende des Sanddiluviums (bei Ter Apel) liegt nur wenig Moor; die Bruchländer in der Umgegend sind moorige Grasländer. Bei den Horsten (e a. d. Karte) wird Eisenerz ausgegraben.

In der Landschaft Westerwolde (Sanddiluvium) findet man eisenreiche Bruchländer zwisehen Onstwedde (c) und Stadskanal (d), im Marsinger Broek. Entlang der verschiedenen Bäche in Westerwolde, die den Namen $A$ tragen, findet man gleiches. 
aufquellendes Wasser ihren Eisengehalt bekommen haben. Gleiches ist von REInders für den Raseneisenstein im Diluvialboden zu Ederveen, Gorssel, Herinckhave, Haaksbergen konstatiert.

\section{B. Bau des Moores.}

Das E.C.-Moor besteht aus vier Schichten (Fig. 6). Die unterste, Darg genannt, ruht auf dem Sandboden. Eine dünne Schicht von

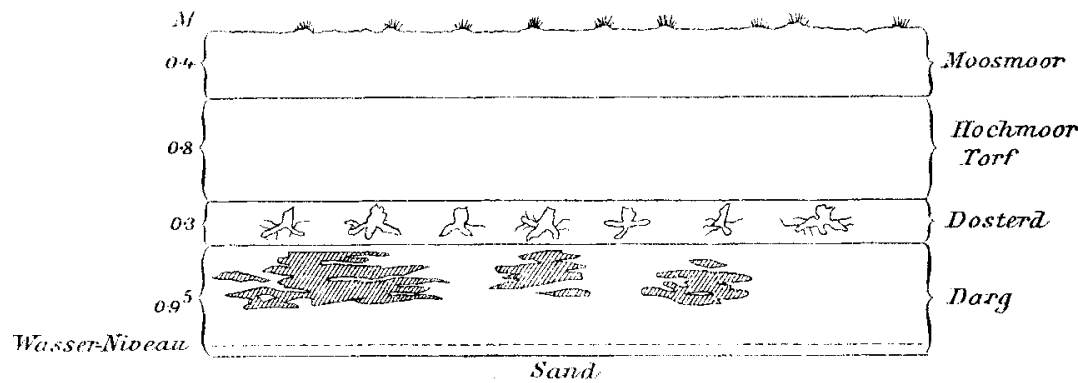

Fig. 6.

\pm 1 d. M. bildet den Übergang von Sand und Darg, und wird „Klip“ genannt. Nur in dieser untersten Schicht des Moores kommen, wie schon gesagt, die Eisennester vor. Sie ist kein Hochmoor, sondern ein Bruchmoor und hat eine Dicke von $0.5-1 \mathrm{~m}$, zuweilen von $1.5 \mathrm{~m}$. Sie ist später überdeckt worden durch einen Wald, dessen Wurzeln und unterste Stammteile (Stumpfe) noch übrig sind in einer Schicht von \pm 3 d. M. Diese Schicht trägt den Namen von ,Stobbe“oder "Dosterd"-Schicht. Auf dieser Schicht hat sich nachher gewöhnliches Hoochmoor gebildet (Blaue Klien genannt), ${ }^{1}$ und zuletzt eine Schicht graues Moor („Mosveen“ = Spagnummoor). Das ganze erreicht eine Dicke von 2.5 bis $4 \mathrm{~m}^{2}$

Die folgenden zwei Profile aus dem E.C., nebst zwei Profilen nördlich und südlich davon, und die Fig. 6 erläutern den Bau des Moores:

"Dieser "blaue Klien" liefert den gewöhnlichen guten Hochmoortorf, welcher in diesen Gegenden gestochen wird.

${ }^{2}$ Das Moor bot bei unseren Besuchen eine gute Gelegenheit zur Beobachtung ihres Baues, weil es über eine grofse Oberfläche „angeschnitten" ist. Jedes Jahr werden schmale Streifen von einigen hunderten Meter Länge, durch Twischenräumen getrennt, vergraben. Die senkrechten Wände geben ein ausgedehntes Feld für die Beobachtung der Schichten und der Eisennester; jeden- 


\section{Tabelle XII.}

Mächtigkeit der Schichten in Meter.

\begin{tabular}{l|c|c|c|c}
\hline & $\begin{array}{c}\text { Nördlich } \\
\text { vom E. C. }\end{array}$ & E. C. & E. C. & $\begin{array}{c}\text { Südlich vom E. C. } \\
\text { b. d. schwarz. See }\end{array}$ \\
\hline Sphagnum-Moor. & 1.1 & 0.4 & $0.7^{5}$ & 0.8 \\
Blaue, „Klien“ . & 1.4 & 0.8 & 0.3 & 2.0 \\
Stobbe-Schicht . & 0.4 & 0.3 & $0.2^{5}$ & 0.3 \\
Darg . . . . & 0.5 & $0.9^{5}$ & 1.0 & 0.8 \\
Klip ..... & - & \pm 0.1 &.- & -
\end{tabular}

Auch die Moorböden, ${ }^{1}$ die nördlich vom E.C. zwischen der westlichen Grenze des Moores und dem Stadskanal liegen, haben gröfstenteils eine ähnliche Zusammensetzung. Auch in diesen kommen in der Dargschicht Nester vor, doch in welcher Menge und Ausbreitung ist mir nicht bekannt.

\section{Die Dargschicht.}

Diese Schicht, worin die Eisenkarbonatnester so zahlreich vorkommen, ist, wie gesagt, kein Hochmoor, sondern ein Bruchmoor. Dr. J. FRÜH (Zürich) hatte die Güte, sie mikroskopisch zu untersuchen, und teilte mir das folgende mit, wofür ich ihm zu grofsem Dank verpflichtet bin.

Probe A. Torf unmittelhar an einem Neste grenzend:

Makroskopisch: Sehr dünnschieferig, schwarz, enthält Samen von Menyanthes.

Mikroskopisch (nach Aufweichung mit verdünnter KalilaugeVergrölserung 450): Blattreste von: Almus oder Betula von Hypneen, von unbestimmbaren krautartigen Pflanzen - Radizellen von Grami-

falls solange sie nicht bedeckt („,bestopt" sagen die Arbeiter) werden mit dem "Graaw veen" (Sphagnummoor) aus der obersten Schicht, welches im Spätsommer dagegen aufgeschichtet wird.

1 Siehe die Karte.

Die Moorfläche trägt verschiedene Namen, die den naheliegenden Dörfern entlehnt sind. So folgen von Süd nach Nord aufeinander die Moore von Valthe, Exloo, Buinen, Drouwen, Gasselter-Nyveen, Gasselter-Boerveen, Bonnerveen. (Diese Orte sind alle auf der Karte angezeichnet.) In allen liegen die vier Schichten: Grauwveen (Moosmoor), Blaner Klien, Dostert, Darg. Nur fehlt hier und da die Dosterdschicht, z. B. in Gasselter-Nyveen und Exlöerveen, und hinten im Drouwenerveen und Buinerveen. Die drei letztgenannten Moorteile und die vorderen Teile vom Buiner- und Drouwenermoor sind schon vergraben. 
neen - Pollenkörner von Alnus, Betula, Ulmus campestris, Salix, Pinus, vereinzelt von Vaccineen (Heidelbeergewächse, wahrscheinlich von Calluna vulgaris), Gramineen - Sporen von Filices, vereinzelt von Sphagnum, aber keine anderen Reste von Sphagneen.

Probe B. Torf auf 2 Meter Abstand von einem Neste gelegen.

Makroskopisch: Wie A und ziemlich viel Betulaborke.

Nikroskopisch: Vorherrschend Wurzeln, Zweige, Blätter von Vaccineen, namentlich von Calluna vulgaris (nach der vorhandenen Epidermis der Blätter zu schliefsen) - Radizellen wie A - Pollenkörner wie A, jedoch viel von Vaccineen und Betula, sparsamer von Alnus und Pinus. Ein einziges Mal wurde ein Teil des Blattes von Sphagnum acutifolium beobachtet, der eine Art 'Torfmoor bildet, welche in Wäldern gemein ist.

Die für Hochmoor charakteristischen Sphagneen kommen also in dieser Moorschicht nicht vor. Die mikroskopische Untersuchung zeigt ein Flachmoor an, und zwar ein Bruchmoor (Rasenmoor) mit zahlreichen Gesträuchern und Farnkräntern, das gewifs unter reichlicher Bewässerung gestanden hat. Das Anzeichen einer lakustren Bildung, Diatomëen, Spongillennadeln fehlt. Auch fehlen die Mineralsplitter fast ganz. - (So weit Dr. FRÜH).

Der Torf ist schwärzer, dichter und härter als der Hochmoortorf, und nähert sich dadurch dem Torfe aus den lacustren Torfbildungen in den Niedermooren der Provinzen Holland, Utrecht und Friesland. Deswegen wird dieser Torfschicht der Namen „Darg“" gegeben.

Die chemische Untersuchung stimmt mit dieser Diagnose überein. Der Gehalt an mineralen Bestandteilen ist nach Abzug des Eisenoxyds sehr gering (0.5-1.2); das Eisenoxyd dagegen ist verhältnismäfsig hoch. Zur Vergleichung füge ich die Analyse der Moorsubstanz aus der untersten Schicht im Teschendorfer Moore (Mecklenburg) dazu.

(Siehe Tabelle XIII auf Seite 351.)

Die Asche hat durch das Eisenoxyd eine rote Farbe. Die ganze Moorschicht ist also mit einer kleinen Menge Eisenoxyd durchdrungen, enthält dagegen sehr wenig mineralische Bestandteile, namentlich wenig Kalk. Dieses bestätigt, was oben gesagt, dals das Moor unter reichlicher Bewässerung, und zwar mit kalkarmem Wasser, auf einem Sandboden gebildet ist. Es unterscheidet sich in dieser 
Tabelle XIII.

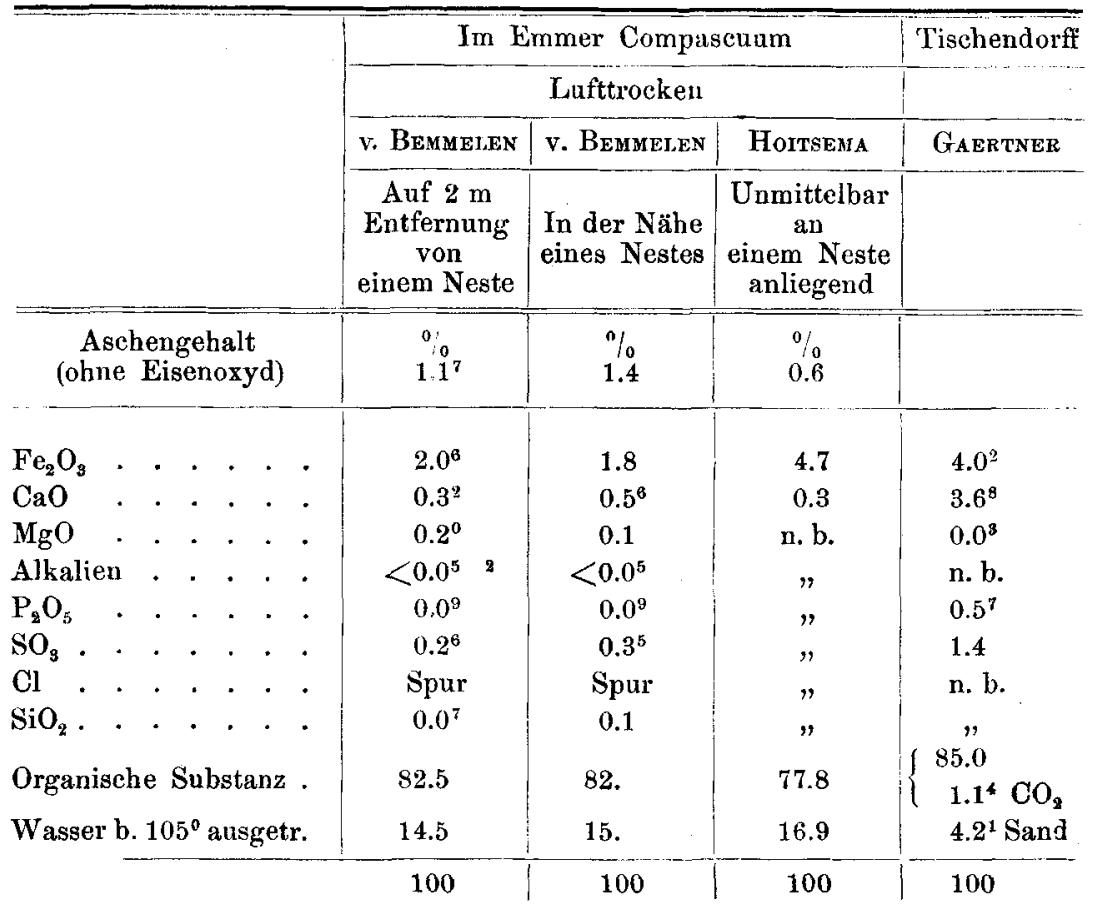

Hinsicht von den lacustren Moorbildungen, die in einem kalkreichen Wasser entstanden sind, ${ }^{3}$ and von Grünlandsmooren im allgemeinen.

1 n. b. = nicht bestimmt.

${ }^{2}<0.05=$ kleiner als 0.05 .

3 Z. B. in den Niedermooren der Provinzen Nord- und Südholland, Utrecht, Friesland, welche lacustrisch gebildet sind. Ich fand in verschiedenen Proben Torf aus Reeuwyk (Prov. Südholland) nur 0.4-0.5 Eisenoxyd:

$$
\begin{aligned}
& \% \\
& \text { Miner. Bestandt. } \begin{cases}4-6 & \text { Thon u. Sand. } \\
5-7 & \text { Übrige. }\end{cases} \\
& \text { Kalk . . . } 3^{5}-4^{3} \\
& \text { Magnesia . . } 0.3-0.4 \\
& \text { Kali . . . . 0.06- } 0.07 \\
& \text { Natron . . . 0.08-0.09 } \\
& \text { Phosphorsäure . } 0.05 \\
& \mathrm{NaCl} \text {. . . . } 0.1-0.2 \\
& \text { Schwefelsäure * } 0.5-1.3 \\
& \text { Schwefel . . . 1-1.3 } \\
& \text { Eisenoxyd . . 0.4-0.5 }
\end{aligned}
$$

Die Asche dieser Torfart (Baggertorf) ist weifs. Bei der Bildung dieser Mooren ist kein Eisen zugefürt. 
Es enthält selbst noch eine geringere Menge, als gewöhnlich für Hochmoor angegeben wird. ${ }^{1}$

D. Lage, Verbreitung und Zusammensetzung der Nester.

Die Nester liegen auf verschiedener Höhe in der Dargschicht, von der Sandschicht ${ }^{2}$ abgerechnet.

Der oberste Teil der Schicht enthält jedoch keine oder nur sparsam kleine Nester; ein einzelnes Mal wurde beobachtet, dals ein Nest sich bis in die Dosterdschicht ausdehnte.

Die Grölse der Nester ist aul'serordentlich verschieden. Sie variieren von sehr grofsen bis zu Flecken und Flecklein. Bisweilen ist eine Menge Nester zusammen; anderswo liegen sie weiter auseinander. An gewissen Stellen ist die Menge so grols, dals es der Mühe nicht lohnt, das dazwischen liegende Moor zu vergraben. Die Arbeiter nennen sie „Witte Klien" (weilse Torfsubstanz).

Die Nester sind von sehr unregelmälsiger Form, immer in der Länge und der Breite ausgedehnt, nie in der Höhe. Sie besitzen Ausläufer und Verzweigungen, zwischen der schwarzen Moorsubstanz, in horizontaler Richtung. Einzelne Nester zeigen eine schwach gebogene Form mit der konvexen Seite nach oben. Wo mehrere Nester auf gleicher Höhe neben einander vorkommen, beobachtet

1 Ich entlehne Woruny die folgende Übersicht und gebe die Zahlen des E. C.-Moors dabei :

\begin{tabular}{|c|c|c|c|c|c|c|}
\hline \multicolumn{2}{|c|}{ In Mittelzahlen enthält } & $\begin{array}{l}\text { Mineral- } \\
\text { stoffe }\end{array}$ & $\mathrm{P}_{2} \mathrm{O}_{5}$ & $\mathrm{~K}_{2} \mathrm{O}$ & $\mathrm{CaO}$ & $\mathbf{N}$ \\
\hline & Niederungsmoor & 10.0 & 0.25 & 0.10 & 4.0 & 2.5 \\
\hline Grünlandsmoor & Gebirgsmoor & 5.0 & 0.20 & 0.10 & 1.0 & 2.0 \\
\hline & Heidehumus & 3.0 & 0.10 & 0.05 & 0.35 & 1.2 \\
\hline Hochmoor & Moostorf & 2.0 & 0.05 & 0.03 & 0.25 & 0.8 \\
\hline Bruchmoor & $\begin{array}{l}\text { Torf des Emmer } \\
\text { Compaseuum } \\
\text { (lufttrocken) }\end{array}$ & $\begin{array}{l}0.6^{*} \\
\text { bis } \\
1.2\end{array}$ & 0.09 & $<0.05$ & $\begin{array}{l}0.3 \\
\text { bis } \\
0.5\end{array}$ & \\
\hline
\end{tabular}

* Nach Abzug des Eisenoxyds.

${ }^{2}$ Ich habe einzelne, aus der Sandschicht stammende, harte Sandkonkretionen mit Eisenspat und Vivianit gefunden, doch kommen diese selten in der Sandschicht unter dem Moore im E. C. vor. Sonst würde sich dieses beim Graben der zahlreichen gröfseren und kleineren Kanäle ergeben haben. Kundige Leute verneinen dies. 
man in dem Profil zwischen denselben und an beiden Seiten kleinere Flecken und Streifen, welche nach unten im Moor eine gröl'sere Ausdehnung erhalten. Die Nester thun sich also vor, als eine mehr oder weniger scheibenartig begrenzte Höhle (mit dem weifsen Klien ausgefüllt), welche zahlreiche seitliche Ausläufer besitzt.

Die Fig. 6 (S. 348) giebt die Ansicht eines Profils, das in einem gegrabenen Loch mit senkrechter Wand beobachtet wurde. In Fig. 7

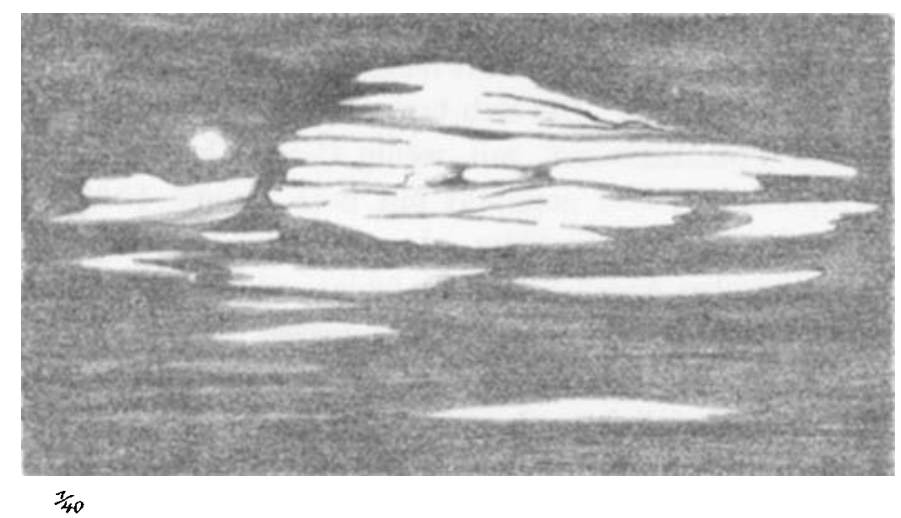

Fig. 7.

ist das eine Nest auf gröfserem Malsstabe gezeichnet. Fig. 8a giebt einen (nach CD) horizontalen, ${ }^{1}$ Fig. $8 \mathrm{~b}$ einen (nach $\mathrm{AB}$ ) vertikalen Durchschnitt eines Nestes, wie wir uns dasselbe vorstellen. Es er-

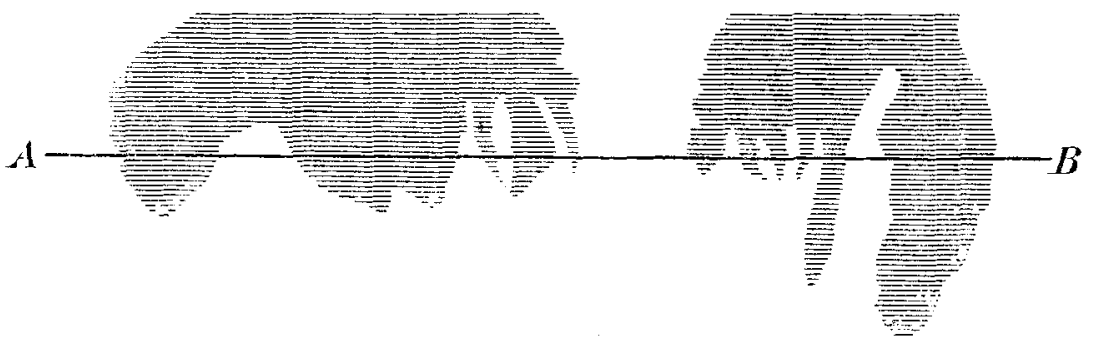

Fig. 8a.

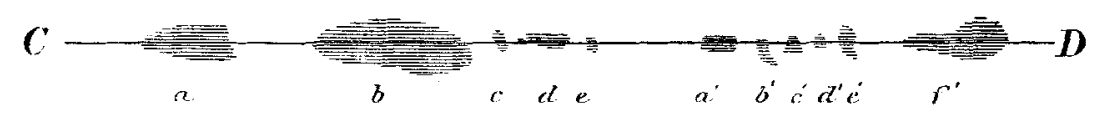

Fig. 8 b.

1 Die Ausbreitung des Nestes nach hinten, in horizontaler Richtung, ist in der Zeichnung abgebrochen. 
läutert, dafs die Teile $a, b, c, d, e$, welche sich im vertikalen Durchschnitt (wie in Fig. 6) getrennt vorthun, zu demselben Neste gehören. Ebenso $a^{\prime}$ bis $f^{\prime}$.

Das gröfste Nest, das von Dr. Hortsema beobachtet wurde, hatte eine Länge von $14 \mathrm{~m}$, eine Breite von mehr als $6 \mathrm{~m}$ und eine Höhe von $\pm 1 / 2 \mathrm{~m}$, nach den Seiten scheibenförmig abnehmend.

Diese Höhe ist beträchtlich, da die ganze Dargschicht nur $\pm 1 \mathrm{~m}$ Mächtigkeit hat.

Diese gröfseren, kleineren und kleinsten Nester sind ausgefüllt mit „Witte Klien", der an der Luft feuerrot wird, und dessen Analyse mitgeteilt ist auf S. 316. Die Substanz ist ein gröfstenteils amorphes wasserreiches Ferrokarbonat, mit wenig Calciumkarbonat und eine Spur Ferrophosphat, und gemischt mit noch keinen $10 \%$ Parzellen von Pflanzenfasern. Merkwürdig ist es, dafs darin einige Prozente mikrokrystallinisches Eisenspat nicht fehlen, und dafs auch einzelne Aderchen vorkommen, die nebst Pflanzenfasern hauptsächlich daraus bestehen. Eine Ader daron wurde von $0.5 \mathrm{~m}$ Länge und $0.1 \mathrm{~m}$ Höhe und wahrscheinlich auch einige Dezimeter Breite beobachtet. Sie enthielt (siehe die Analyse auf S. 318) $1 / 4$ Pflanzenfaser, $1 / 8$ amorphes $\mathrm{FeCO}_{3}$ und $62 \%$ krystallinisches $\mathrm{FeCO}_{3}$ (Eisenspat). Der Gedanke drängt sich auf, dal's der Krystalleisenspat schon ursprünglich sich im Moor abgesetzt hat, und dafs das amorphe (kolloidale) Ferrokarbonat aus abgesetztem Eisenoxyd durch Reduktion entstanden ist, nachdem die Schicht vom Wasser ganz getränkt und von der Luft abgeschlossen worden ist. Wir kommen darauf im VI. Abschnitt (Konkretionen im Ederveen) zurück.

Sehr merkwürdig ist es, dafs oft an dem östlichen und westlichen Ende der Nester eine Anhäufung von Vivianit vorkommt. Dies ist wiederholt beobachtet ${ }^{1}$ und war sehr deutlich beim Riesennest von $14 \mathrm{~m}$ IJänge, das wir oben erwähnt haben (S. 354). Man bedenke dabei, dafs die Fläche, nach welcher das Moor eingeschnitten wird, von Ost nach West gerichtet ist, und der Untergrund im ganzen von Süd nach Nord fällt.

Die Analyse I (S. 331) bezieht sich auf dem auf diese Weise vorkommenden Vivianit. An der Luft getrocknet wird er hellblau. Er ist sanft beim Anfühlen und im trockenen Zustande blätterig,

${ }^{1}$ Die Beobachtung liefs sich an vielen Orten deutlich anstellen, weil beim Abgraben des Moores die unbrauchbaren Eisenverbindungen nach hiuten geworfen werden, und in der Ordnung, worin sie aufeinander in den Nestern folgten, zurückzufinden waren. 
wie eine lose zusammenhängende Masse von unregelmälsig aufgehäuften dünnen Schichtchen. Die Substanz besteht aus mehr oder weniger Torfteilen, viel krystallinischem Ferrophosphat (Vivianit) und etwas amorphem Ferrokarbonat (das beim Trocknen zu Eisenoxyd oxydiert). Sie ist also wohl als ein Übergang von den "Weifsen Klien" in Vivianit zu betrachten.

Indessen kommt der Vivianit auch stellenweise in dem „Weissen Klien" der Nester eingesprenkelt vor, also in kleinen Flocken. Es sind dies kleine, mehr oder weniger runde Bröcklein; sie sind härter, denn sie geben beim Schneiden mit einem Messer einen kreischenden Klang. Oft bestehen sie aus Schichtchen Ferrokarbonat und Ferrophosphat, gröistenteils krystallinisch. So wurden Stücken beobachtet, dessen änfsere Schicht weifsartig blieb, indem dagegen der Kern, bei der Berührung mit Luft, bald blau wurde. Im allgemeinen hängen die blauwerdenden Fleckehen in der "Weifsen Klien"-Masse zusammen mit kleinen Mengen, die weils bleiben. An einzelnen Stellen wurden weilsbleibende Stellen von Phosphat angetroffen, allein, oder in der Mitte von blauwerdendem Vivianit, kristallinischem oder amorphem Eisenspat. Auch kommen Adern vor, die hauptsächlich aus amorphem weifsen, grau bis graubraunwerdendem Ferriphosphat bestehen, wie die Aualyse II auf Tab. IV (S. 331) ausweist. Es scheint also, dafs neben dem krystallinischen Vivianit, welcher sich an der Luft unter Oxydation bläut, ein amorphes Phosphat vorkommt, das eine Ferriverbindung ist und sich also nicht bläut (siehe darüber S. 333, 334).

Vivianit in sichtbar ausgebildeten Krystallen, wie sie von REINDERS und von uns in dem Raseneisenstein von E.V. beobachtet sind, haben wir in dem Moore von E.C. nie gefunden.

\section{E. Versuch zur Erklärung von der Bildung der Nester im E. C.}

Aus allem, was oben angeführt ist, lälst sich ableiten, dafs die Bildungsweise der Nester von „Witte klien“ eine andere gewesen ist, als die der "Oerbänke".

Sie müssen während der Bildung der Dargschicht, worin sie vorkommen, entstanden sein; nicht später, denn sie enthalten nur wenig organische Rester $(<10 \%$ Pflanzenfasern) und sind vom Darg ganz umschlossen. Sonst mülste Moorsubstanz auf bedeutenden Strecken verschwunden sein. Auch kann das Eisen nicht später von oben zugeführt sein, denn die Dargschicht ist mit einem Wald 
überdeckt worden und dieser wieder mit einer dicken Hochmoorschicht. Diese Schichten enthalten kein Eisen.

Die Kisenanhäufungen müssen in Wassergruben und Wasserläufen in dem sich bildenden Moor abgesetzt sein. Ihre Form entspricht daran vollständig. Die Nester sind alle in horizontaler Richtung gestreckt und besitzen Verzweigungen und Ausläufer, gleichfalls in horizontalen Richtungen.

Der mikroskopische Befund hat gelehrt, dals die nesterführende Dargschicht ein Bruchmoor ist, welches aus zahlreichen Gesträuchen und Farnkräutern gebildet und unter reichlicher Bewässerung gestanden hat. Wie oben erwähnt (S. 347), hat die Lage des E. C. es mit sich gebracht, dafs reichlich Wasser aus den höheren Diluvialböden dahin geflossen ist, und dals es in einem morastigen Zustande verkehrt hat.

Dieses Wasser enthielt damals wie jetzt noch Eisenkarbonat, durch Kohlensäure gelöst (S. 347). ${ }^{1}$ Es flol's gewils für einen Teil als Grundwasser durch die Sandschicht (in der Richtung Sïd-Nord), jedoch auch in den Bettungen von Bächen und Wasserläufen. Mit den Jahreszeiten muls die Zufuhr von Bodenwasser periodisch gestiegen und gefallen sein. Beim Fallen des Wassers entstand Gelegenheit zur Absetzung von Eisenverbindungen, namentlich wo eine Vegetation und ein daraus entstehendes Moor das Abfliefsen und das Fallen des Wassers erschwerte und also das Stagnieren desselben beförderte.

Die Tränkung der Moorschicht (soweit sie allmählich gewachsen war) mit dem eisenhaltigen Wasser kann jedoch die Nesterbildung nicht verursacht haben; was sich an der Oberfläche der Verdampfung absetzte, kann nicht bedeutend gewesen und muls wieder fortgeschwemmt sein; höchstens kann dadurch das ganze Moor schliefslich die schwache Einmischung von $\pm 2 \%$ Eisenoxydul bekommen haben, die bei der Analyse des Torfes sich ergeben hat (S. 351).

Auch kann man die Nester nicht betrachten als eine Eisenkonkretion, die sich aus der unteren Sandschicht im Moore ausgebreitet hat. In der Sandsehicht könnten sie zwar entstanden sein an Stellen, wo ein geringer Widerstand das Aufquellen des Bodenwassers verursachte. Jedoch in dieser Sandschicht ist wohl stellen-

- Vielteicht ist das Wasser damals noch eisenreicher gewesen, weil es aus früher in der Nachbarschaft abgesetztem Eisenocker wieder Eisen gelöst hatte. 
weise etwas „Oer" gefunden, aber nur spärlich. ${ }^{1}$ Auch würden dann die Nester nicht abgesondert in den höheren Teilen der Dargschicht vorkommen.

Man mufs darum Gruben und Wasserläufe im Moor während der ganzen Zeit ihrer Bildung annehmen. Dieselben müssen wohl in der so ungleichmälsig anwachsenden Moorschicht, wodurch fortwährend viel Wasser flofs, entstanden sein. In Gruben und Wasserläufen konnte das damals wahrscheinlich eisenreiche Wasser länger stagnieren, der Luftsauerstoff besser zutreten und die Absetzung von Eisenoxyd aus Eisenbikarbonat reichlicher stattfinden. Hatte sich also eine dünne Schicht abgesetzt, so beförderte diese im nächsten Jahre das Stagnieren des Wassers, weil das Eisenoxyd den Boden weniger durchlässig gemacht hatte, und zugleich die Vegetation (und also auch die Moorbildung) zurückbleiben that bei derjenigen in der Umgebung.

Dieser Prozefs mufs Jahre fortgedauert haben, bis die von den Seiten und nach der Mitte zu überwachsenden Pflanzen die Gruben und Wasserläufe wieder überwuchert und abgeschlossen hatten. Eine Zeitlang kann das Wasser noch in diesen Räumen einen Weg gefunden haben, bis sie ganz mit Eisenoxyd und Pflanzenfasern angefüllt waren, und also ein Nest mit dessen vielen Verzweigungen entstanden war.

Die Absetzung in Gruben und Adern kann nur eine endliche Zeit gedauert haben. Denn das stets höher wachsende Moor muls ein Hindernis für das zufliefsende Wasser geworden sein, so dafs es andere Wege wählte. Die Morastpflanzen wurden durch Landpflanzen ersetzt. Ein Wald entstand, und darauf wieder eine Vegetation, woraus sich das Hochmoor gebildet hat (siebe die Profile S. 349 und Fig. 6).

Das aus den höheren diluvialen Böden herstammende Grundwasser und die daraus entstandenen Bäche und Wasserläufe haben keine Sand-oder Thonteilchen in die Nester gebracht; auch nur wenig koblensauren Kalk. Das stimmt damit überein, dals die Sandformation in Drenthes und Groningens östlichem Teil kalkarm ist. ${ }^{2}$

1 Siehe die Bemerkung 2 auf S. 352.

2 Überdies setzt sich kohlensaures Eisenoxydul viel rascher ab, als kohlensaurer Kalk, aus der Lösung in Kohlensäurewasser, wenn diese an die Luft tritt. Ich habe oft beobachtet, dals eisenbaltiges Wasser, klar aus dem Brunnen aufgepumpt, rasch an der Luft einen weilsen Niederschlag bekam, der sich bald rötete. 
Jedoch wir finden in den Nestern kein Eisenoxyd, sondern Ferrokarbonat (gröfstenteils amorph, nur in geringer Menge krystallinisch). Ich halte es darum für höchst wahrscheinlich, dafs das Eisenoxyd erst später, während der Vertorfung des Moores und dessen Abschliefsung von der Luft, durch Reduktion mittels Humusstoffen in amorphes kolloidales $\mathrm{FeCO}_{3}$ verwandelt ist. Doch bleibt die Frage offen, ob wir diese Reduktion den $\pm 8 \%$ Pflanzenüberresten, die sich zwischen dem Eisenkarbonat befinden, zuschreiben dürfen, oder auch die Einwirkung von löslichen Humusstoffen aus der umgebenden Moorschicht annehmen müssell. An unserer Kenntnis des Reduktionsprozesses fehlt noch zu viel, um die Frage zu erledigen.

Kann die Form und die Lage der Nester auf obige Weise nicht unbefriedigend erklärt werden, so ist es fraglich, ob dies auch von der Ausfüllung der Nester mit $9 / 10$ Ferrokarbonat auf $1 / 10$ Pflanzenresten gilt. Es ist nicht ausgeschlossen, dafs noch andere Ursachen mitgewirkt haben, welche die Anhäufung von Eisenoxyd zu Nestern beförderten.

Die Mitwirkung von Diatomeen, Wasserpflanzen u. s. w. können wir zwar hier nicht annehmen (S. 350). Doch können wir fragen, ob nicht Eisenbakterien dafür in Betracht kommen, welche in dem stagnierenden Wasser der Gruben und Adern Iebten, das Eisenoxydul dieses Wassers ansammelten und als Eisenoxyd ausschieden (S. 340), welches später zu amorphem $\mathrm{FeCO}_{3}$ reduziert ist.

REINDERS erwähnt, dafs er dieselben zweimal in einem braunen Absatz von Eisenoxyd auf dem Boden eines Wassergrabens gefunden hat, und zwar den ganzen Sommer durch. In diesem Graben quoll eisenbaltiges Wasser auf. Das Wasser war stagnierend.

Auf dem Boden eines stagnierenden Wassers können also die Eisenbakterien leben, wenn es Ferrokarbonat gelöst hält. Dafs wir die Bakterienreste in den Nestern nicht zurückfinden, ist kein Beweis, dals sie früher nicht dagewesen sind. Von Ferrokarbonat nehmen wir doch an, dafs es erst später durch Reduktion aus dem $\mathrm{Fe}_{2} \mathrm{O}_{3}$ entstanden ist, wobei die organische Substanz in den Nestern mitgewirkt hat und die zarten Hüllen der Bakterien verschwinden konnten.

Sitensky nimmt, wie oben gesagt (S. 341), eine derartige Bildung für die Brauneisensteinabsetzungen an, welche er in den 
böhmischen Mooren beobachtet hat. ${ }^{1}$ Dafs diese Bildung mit derjenigen im E. C. Ähnlichkeit hat, ist wahrscheinlich, weil Srtenskr sie beschreibt als Nester und Adern. Nur ist das Eisenoxyd nicht wieder zu Eisenspat reduziert, vielleicht weil das Moor nicht durch spätere Formationen von der Luft abgeschlossen ist oder weil auf das Vorkommen des Ferrokarbonats keine Acht gegeben ist. In Anbetracht dieser Beobachtungen ist die Hypothese der Mitwirkung von Eisenbakterien im E. C. noch nicht zu verwerfen. Wir sehen den näheren Mitteilungen SiTENskY's und seiner Beweisführung entgegen.

Krystallinischer Eisenspat. Dafs ein kleiner Teil des $\mathrm{FeCO}_{3}$ in den Nestern mikrokrystallinisch ist (und nicht an der Luft oxydiert) und dafs dieser Eisenspat in Äderchen angehäuft vorkommt (S. 354), davon kann keine Erklärung gegeben werden. War er schon ursprünglich krystallinisch abgesetzt und also nicht aus $\mathrm{Fe}_{2} \mathrm{O}_{3}$ durch spätere Reduktion entstanden? Oder ist er aus amorphem Karbonat unter gewissen Umständen entstanden? Das erste ist viel wahrscheinlicher, jedoch, wie oben gesagt, wir wissen noch nichts Nüheres darüber: weder von einer krystallinischen Absetzung desselben aus einer Kohlensäurelösung, noch von einer Umsetzung von amorphem in krystallinischen Eisenspat.

Vivianitbildung. Viele Fragen ergeben sich über die Entstehungsweise des Vivianits, der (S. 354) in den Nestern nur sehr wenig und sporadisch vorkommt, jedoch an den Enden der Nester angehäuft liegt - und weiter, mit Eisenspat gemischt, in kleinen Adern und Knollen vorkommt. Ursprünglich mufs alle Phosphorsäure, die wir jetzt in der Dargschicht des Moores und in den Nestern finden, aus dem Grundwasser herstammen, womit das Moor während der ganzen Zeit seiner Bildung bewässert gewesen ist. Dieses Grundwasser enthält eine kleine Menge Phosphorsäure, womit Pflanzen und Tiere sich ernährt haben. Doch ist es nicht wahrscheinlich, dals Vivianit sich unmittelbar aus diesem Grund-

${ }^{1}$ Simensky, Über die Torfmoore Böhmens (Prag 1891, S. 217): „Der in den böhmischen Moorlagern ungemein verbreitete Brauneisenstein hat häufig seine Entstehung der physiologischen. Wirkung der Crenothrix- und Cladothrixkolonien zu verdanken, die hier oft das Quellwasser und Grundwasser bewohnen. Er kommt meistens mit organischen und auch mineralischen, namentlich Thonbestandteilen verunreinigt vor. Am verbreitetsten ist der erdige, ockerige Brauneisenstein, hell, ockergelb, bis rotbraun gefärbt; der namentlich an den Quellen, aber auch im stngnierenden Grundwasser, Nester, Adern, als auch ganze (viele, bis einige C.d. M. mächtige) Schichten bildet, in den meisten Torflagem Böhmens." 
wasser abgesetzt hat. Denn dann liefse sich erwarten, dafs das amorphe Karbonat schwächlich mit Vivianit durchdrungen wäre, was nicht der Fall ist. Nur einzelne Fleckchen und Äderchen von Vivianit kommen darin vor (S. 355). Mehr wahrscheinlich ist der Vivianit aus dem Ferrokarbonat oder dem Eisenoxyd durch Einwirkung von Phosphaten entstanden, welche Umsetzung in der Natur stattfindet (S. 343).

Dann mufs das Phosphat aus den Moorpflanzen und besonders aus den Wassergruben und Wasserläufen, wo das Tierleben seine Leichen hinterlassen hat, durch das Bodenwasser gelöst und sich mit dem Eisenoxyd unter Mitwirkung von Humusstoffen oder mit dem Ferrokarbonat umgesetzt haben. Nun ist der Darg im E. C. wohl ärmer an Phosphorsäure als viele Niederungsmoore, jedoch er ist auch ärmer an den übrigen mineralischen Bestandteilen. Es ist deshalb die Frage, ob die Phosphorsäure des Vivianits nicht gröfstenteils von Tierleichen stammt, die im Moor gelebt und Phosphorsäure angesammelt haben.

Ist die Bildung von Vivianit aus schon abgesetztem Eisenoxyd (oder $\mathrm{FeCO}_{3}$ ) annehmbar, ganz unerklärt dagegen bleibt, warum sich dieser Vivianit an den Enden der Nester angehäuft hat.

\section{v. Eisenspat und Vivianit in den Wiesenmooren von Mecklenburg.}

In den Niedermooren (Wiesenmooren) von Mecklenburg hat GaERTNER eine Bildung von Eisenspat und Vivianit beobachtet und untersucht (1897). Diese hat mit derjenigen des E. C. grolse Ähnlichkeit, jedoch auch einige Differenzen. Die Vergleichung beider Formationen scheint mir darum erwünscht.

Gaertner untersuchte Material von sechs Fundstellen, namentlich von dem nördlichen Ausläufer vom Teschendorffer Moor (zwischen Teschendorff, Petschow, Lüsewitz gelegen). Dieser Ausläufer, der an Vivianit reichste Teil des Moores, ist begrenzt von einem Laubwald und von Ackerböden. Eine Limonitbildung liegt unter diesem Walde. Eine andere Untersuchung betraf ein kleines Moor bei Prützen (zwischen Tarnow und Bützow), teilweise schon abgegraben. ${ }^{1}$

Alle diese Moore sind, nach der Bestimmung von J. FrüH, Rasenmoore und gehören zum Typus eines Erlenbruchs; in fast

1 Die übrigen Fundstellen waren: ein kleines Moor bei Laupin, bei Gr.-Lunow, bei Doberan und ein anderer, südlich gelegener Teil des Teschendorffer Moores, die wilde Wiese, von der Kösterbeck durchströmt. 
allen sind Farne eine markante Erscheinung. Die Pfianzenreste sind homogen vertorft, was auf eine reichliche Bewässerung des Moores weist. ${ }^{1}$ Die Moore sind nicht, wie im E. C., mit Hochmoor bedeckt. Das Liegende ist diluvialer Sand; jedoch in einem Teile der Moore liegt eine Schicht Seekreide (Wiesenkalk), entweder mitten in der Moorschicht (Teschendorff) oder auf dem Sande (Prützen). Die Mächtigkeit des Moores an beiden Orten, die Kalkschicht eingerechnet, ist höchstens $5 \mathrm{~m}$, nach beiden Seiten abnehmend.

Gaertner untersuchte zwei Profile, ${ }^{2}$ die ungefähr das folgende zeigten:

\begin{tabular}{|c|c|c|}
\hline Schicht & Tiefe & \\
\hline 1 & von 0 bis $0.2 \mathrm{~m}$ & Humuserde; mit roten Knollen. \\
\hline 2 & von 0.2 bis $0.4(0.5) \mathrm{m}$ & $\begin{array}{l}\text { Sand und thonbaltiges Moor, mit vie } \\
\text { roten Knollen. }\end{array}$ \\
\hline 3 & von 0.4 bis $\pm 0.6 \mathrm{~m}$ & $\begin{array}{l}\text { Moor mit Vivianit und weifsem (an der } \\
\text { Luft rotwerdendem) Eisenspat, überall } \\
\text { eingesprengt. }\end{array}$ \\
\hline 4 & von \pm 0.6 bis $1.1 \mathrm{~m}$ & $\begin{array}{l}\text { Moor, mit kleinen }( \pm 1 \mathrm{ccm}) \text { zerstreuten } \\
\text { Knollen von Eisenspat (wenig Phos- } \\
\text { phorsämre). }\end{array}$ \\
\hline
\end{tabular}

Unter der vierten Schicht liegt Sand oder Seekreide. Die gröfsten Konkretionen von Eisenspat kommen unmittelbar auf diesem Sande vor; sie waren grölser als ein Kubikfufs. ${ }^{3}$ Sonst waren dieselben nur bis ungefähr $1 \mathrm{ccm}$ grols. Nester, so grols wie im E. C., sind nur ausnahmsweise gefunden. GaERTNER erwähnt ein grofses Nest von Raseneisenstein in der vivianithaltigen Schicht des Prützener Moors, über $3 / 4 \mathrm{~m}$ breit, $\pm 2 \mathrm{~m}$ lang, $2 \mathrm{dcm}$ hoch. ${ }^{4}$ Man darf annehmen, dafs, wo GaERTNer rote Knollen oder rote gröfsere Konkretionen gefunden hat, diese im noch geschlossenen $\mathrm{Moor}_{\mathrm{FeCO}}$ gewesen und durch den Zutritt der Luft oxydiert worden sind.

1 Nie wurde eine Andeutung auf Hochmoortorf oder Lebertorf gefunden; es sind keine faserigfilzigen Radizellentorfe, wie solche von dem subterranen Wurzelsystem von Arundinetum- und Carexwiesen geliefert werden.

2 Das eine im Teschendorffer Moor war durch Bohrung erhalten; das andere war eine senkrechte Wand, durch Abgraben sichtbar geworden.

${ }^{3}$ Gaertner, S. 41 seiner Abh.

4 Nach Gaterner's Zeichnung des Profils Fig. 3.

Z. anorg. Chem. XXII. 
Der Vivianit kam in der dritten Schicht angehäuft vor in weifsen Flocken und Adern; so wurde eine Vivianitader von 5-10 mm Mächtigkeit gefunden.

Die Kisenspat- und Vivianitbildung in den Mecklenburger Mooren kommt mit derjenigen im E. C. darin überein, dafs sie im Wiesenmoor stattgefunden hat. Sie unterscheidet sich davon:

1. dafs auf dieses Wiesenmoor kein Hochmoor gefolgt ist, sondern dals während der letzten Periode der Moorbildung eine Überschlickung mit viel eisenhaltigem Thon und Sand stattgefunden liat;

2. dafs die Konkretionen des Ferrokarbonats kleinere Dimensionen haben und noch mehr im Moore zerstreut sind;

3. dafs der Vivianit auf einer gewissen Tiefe in der Moorschicht in kleinen Flocken und Adern angebäuft ist;

4. dals Gemische in allerhand Verhältnissen von $\mathrm{FeCO}_{3}, \mathrm{Fe}_{3}\left(\mathrm{PO}_{4}\right)^{2}$, $\mathrm{CaCO}_{3}$ und $\mathrm{Ca}_{3}\left(\mathrm{PO}_{4}\right)^{2}$ vorkommen, und dafs der Kalkgehalt in vielen Fällen gröfser ist als beim E. C., wie oben schon mitgeteilt (S. 336).

Das Ferrokarbonat ist unzweifelhaft teilweise krystallinisch S. 335). ${ }^{1}$ Der Vivianit, welchen GaERTner als erdige Varietät beschreibt, ist nach der mikroskopischen Untersuchung (S. 324) von Dr. KLOBBie ebenso als krystallinisch $\mathrm{zu}$ betrachten. Die oben gegebene Betrachtung (S. $355 \mathrm{E}$ ) über die Bildungsweise der Nester im

1 So ergiebt sich, wach meiner Berechnung, aus Gaertner's Analyse von Vivianit von Teschendorff (S. 26 seiner Abh.), dafs dieses nach $1 / 2 \mathrm{Jahr}$, indem es dabei einen Monat an der Luft ausgesetzt gewesen war, noch Ferrokarbonat enthielt:

Tabelle XIV.

\begin{tabular}{|c|c|c|}
\hline & $\%$ & Äquivalente \\
\hline $\mathrm{FeO}$ & 19.55 & 27.15 \\
\hline $\mathrm{Fe}_{2} \mathrm{O}_{3}$ & 18.11 & 22.64 als $\mathrm{FeO}$ oder 11.32 als $\mathrm{Fe}_{2} \mathrm{O}_{3}$ \\
\hline $\mathrm{CaO}$ & 2.40 & 4.3 \\
\hline $\mathrm{MgO} \cdot \cdot$ & 0.09 & Summa 54.3 Äquiv. \\
\hline $\mathrm{P}_{4} \mathrm{O}_{5}$ & 12.02 & $25.5(=3 \times 8.5)$ \\
\hline $\mathrm{CO}_{2}$ & 7.30 & Summa 42.1 Äquiv. \\
\hline Org. Subst. & 12.39 & \\
\hline Thon . . & 2.09 & \\
\hline \multirow{3}{*}{$\begin{array}{l}\text { Wasser und } \\
\text { Verlust. }\end{array}$} & & \\
\hline & 26.05 & $144^{7}$ \\
\hline & 100.0 & \\
\hline
\end{tabular}

(Die Fortsetzung dieser Note befindet auf S. 363.) 
E. C. gilt nach meiner Ansicht auch grölstenteils für die Eisenkonkretionen in den Mecklenburger Mooren und wird dadurch bestätigt; nur sind die Verhältnisse in den letzteren komplizierter gewesen als im E. C.

In der ganzen Formation lassen sich mit GaERTNer drei $\mathrm{Pe}$ rioden unterscheiden. Die unterste Schicht (IV) gehört zur ersten Periode. Ein Moor entstand damals auf einem eisenreichen Sandboden, wie im E. C. Die Knollen an zahllosen Stellen und einzelne gröfsere Konkretionen erkiärt auch GAERTNER durch die Absetzungen aus Wasserläufen und eine spätere Reduktion zu $\mathrm{FeCO}_{3}$. Da das Wasser kalkreicher war als im E. C., ist die Menge $\mathrm{CaCO}_{3}$ in den Knollen grölser.

Die zweite Periode umfaist nach GafrTwer die Bildung einer zweiten Moorschicht (Schicht III) auf der ersten - oder einer Fortsetzung derselben -, als die Betten der alten Wasserläufe mit Moor angefüllt waren. Das Moor entstand aus einer reichen Erlen- und Tannenvegetation. In dieser waren neue Wasserläufe entstanden, die aus anderen Mooren viel Eisen und auch Phosphorsäure zufübrten und absetzten. In einer dritten und letzten Periode der Moorbildung fand nach GaERTNER eine Überschlickung statt mit eisenreichem Thon und Sand, von eisenreichem und phosphorsäure-

Daraus erfolgt die Zusammensetzung:

\begin{tabular}{|c|c|c|c|c|c|}
\hline & Mol. & & \multicolumn{3}{|c|}{$\%$} \\
\hline \multirow{5}{*}{$\frac{27.15-12^{2}}{3}$} & 4.3 & $\times 100$ & $\mathrm{CaOCO}_{2}$ & $=4.3$ & \\
\hline & 0.2 & $\times 88$ & $\mathrm{MgOCO}_{2}$ & $=0.1^{7}$ & \\
\hline & 12.1 & $\times 116$ & $\mathrm{FeOCO} 2$ & $=14.0^{4}$ & \\
\hline & $15.0^{5}$ & \multirow{2}{*}{$\times 358$} & \multirow{2}{*}{$(\mathrm{FeO})^{3} \mathrm{P}_{2} \mathrm{O}_{5}$} & \multirow{2}{*}{$=17.9^{\circ}$} & \multirow{2}{*}{ Vivianit } \\
\hline & 3 & & & & \\
\hline \multirow{7}{*}{$\begin{array}{c}\frac{25.5-15.0^{5}}{3}= \\
11.32-\frac{3}{2}\left(\frac{10.45}{3}\right)=\end{array}$} & 10.45 & $\times 382$ & $\left(\mathrm{Fe}_{3} \mathrm{O}_{3}\right)^{3}\left(\mathrm{P}_{3} \mathrm{O}_{5}\right)^{2}$ & $=13.3$ & Beraunit \\
\hline & 3 & & & & \\
\hline & 6.09 & $\times 160$ & $\mathrm{Fe}_{2} \mathrm{O}_{3}$ & $=9.75$ & \\
\hline & & \multicolumn{2}{|c|}{ Organische Substanz } & $=12.39$ & \\
\hline & & \multirow{2}{*}{\multicolumn{2}{|c|}{$\begin{array}{l}\text { Thon . . . } \\
\text { Wasser und Verlust. }\end{array}$}} & $=2.09$ & \\
\hline & & & & $\cdot=26.05$ & \\
\hline & & & & 100.00 & \\
\hline
\end{tabular}

Weil also nach dieser Berechnung noch $14 \%$ FeO als Karbonat anwesend war, so hat diese Menge sich nicht an der Luft oxydiert und mufs krystallinisch gewesen sein. 
haltigem Wasser zugeführt. Dadurch enthält, aufser den vielen Knollen :

$\begin{array}{ccc} & \text { Sand und Thon: Eisenoxy } \\ \text { die Schicht III } & 13^{5} \% & 11 \% \\ " \text { II } & 32, & 25,\end{array}$

indem dagegen die Schicht IV nur $4 \%$ enthält (siehe die Analyse Tabelle XIII auf S. 351) und mit der Dargschicht im E. C. übereinstimmt.

In der zweiten Periode der Moorbildung hat sich eine viel gröfsere Zahl Knollen von amorphem Eisenspat, jedoch von viel kleineren Abmessungen als im E. C., abgesetzt. ${ }^{1}$ Kann man vielleicht annehmen, dals die Wasserläufe noch viel mehr verzweigt und dazu enger waren als im E. C.?

In dieser Periode mufs auch das Pflanzen- und Tierleben viel Phosphorsäure angehäuft haben (GAERTNER).

In der dritten Periode haben wahrscheinlich viele chemische Umsetzungen und Versetzungen stattgefunden, die im F. C. fehlen, weil da keine Überschlickung von Thon, Sand und Eisenoxyd, sondern eine Waldbildung stattgefunden hat und die eisenführenden Wasserläufe einen anderen Weg genommen haben.

Diese Umsetzungen und Versetzungen betreffen namentlich die eigentümliche Anhäufung von Vivianit und Eisenspat in Schicht III. GaERTNER stellt sich vor, dafs das viele Eisenoxyd der Schicht I und II, bei der Humifikation reduziert und in Lösung gekommen, sich in der Schicht III abgesetzt und dabei auf die in dieser Schicht angehäuften Phosphate von Pflanzen- und Tierleichen eingewirkt hat, so dals die Schicht mit Vivianit und Eisenspat imprägniert worden ist. ${ }^{2}$ An anderen Orten, wie im Moor von Terra, sind Eisenspatknollen teilweise in Vivianit umgesetzt.

Die bedeutende Menge Kalk im Bodenwasser ist Ursache, dals die Absetzungen in den Mooren nicht so einfach sind als im E. C.

1 In den höheren Schichten I und II fand G. dieselben schon oxydiert durch Luftzutritt; in den Schichten III und IV noch gröfstenteils als Ferrosalz.

${ }^{2}$ Die Fundstelle zu Doberan scheint ein Beispiel einer derartigen Wirkung zu sein. Die $\pm 1 / 2 \mathrm{~m}$ dicke Moorschicht liegt zwischen zwei Sandschichten; teilweise zwischen einer Lehmschicht und einer Sandschicht. Die zwei obersten Decimeter der Moorschicht sind vivianithaltig, und haben diesen Gehalt wahrscheinlich aus der später aufgeschwemmten Lehmschicht bekommen, welche reich ist an Eisen und an Phosphorsäure. Eine solche Bildung kommt oft in Bruchwiesen vor, im Gebiete von Bächen, die Lehm und Sand nebst Eisen mitführen. 
Dafs abwechselnd Gemische vorkommen von: 1. Ferrokarbonat und Calciumkarbonat mit Vivianit, 2. Calciumkarbonat mit Vivianit, 3. Calciumphosphat mit Vivianit (siehe Tabelle X, S. 336), beweist, dafs diese Bestandteile in sehr verschiedenen Mengeverhältnissen zusammengekommen und abgesetzt sind. Nach GaERTNER hat viel Kalk die Bildung von $\mathrm{FeCO}_{3}$ verhindert und wird darum in den Konkretionen von Eisenphosphat, Calciumphosphat und Calciumkarbonat das Eisen als Eisenoxyd (nicht als $\mathrm{FeCO}_{3}$ ) angetroffen. ${ }^{1}$ Mit der Abnahme der Kalksalze in den Konkretionen nimmt der Gehalt an Ferrosalz zu.

Wie ich für das E. C. die Wahrscheinlichkeit hervorhob, dafs das Eisenoxyd erst später zu Ferrokarbonat geworden ist, so nimmt auch GAERTNER an, dafs das $\mathrm{FeCO}_{3}$ in Schicht III erst gebildet ist, nachdem die Vertorfung der Pflanzensubstanz (und deshalb aucb die Bildung von Humussäuren) darin aufgehört hatte und die Schicht II und I die Schicht III überdeckten."

Wie ich oben angeführt habe (S. 339-343), ist es noch nicht möglich, von der Aufeinanderfolge der chemischen Reaktionen bei allen diesen Bildungen Rechenschaft zu gehen. ${ }^{3}$

Dafür ist es noch mehr als beim E. C. notwendig, dals die Beobachtungen während der Bildung derartiger Moore selbst gemacht werden. Dazu ist noch niemand gekommen.

Das allgemeine Ergebnis ist, dafs die Konkretionen von Eisenspat, Vivianit, Calciumkarbonat, Calciumphosphat in den Mecklenburger Rasenmooren (Teschendorff u. s. w.) zu dem Fall gehören, wobei 1. die Wasserläufe in einem sich bildenden Moore Eisen, Kalk und Phosphorsäure zugeführt haben, wodurch Karbonat und Phosphat von $\mathrm{Fe}$ und $\mathrm{Ca}$ sich abgesetzt haben; 2. nachher eine Überschlickung und neue Moorbildung stattgefunden hat, wodurch neue Absetzungen und später Umsetzungen und Versetzungen der Eisen- und Kalksalze von oben nach unten entstanden sind.

${ }^{1}$ Gaertner, Seite 51.

2 G. schreibt dieser Decke die Rolle zu, um die Humussäuren, die nach seiner Ansicht die Bildung von $\mathrm{FeCO}_{3}$ verhindern, bei dem Weiterwachsen des Moores zurückzuhalten.

${ }^{3}$ G. stellt einige Hypothesen darüber auf, wie das Eisenoxyd, der Kalk, die Phosphorsäure bei der Humifikation, durch Humusstoffe, Ammoniak, Kohlensäure in Lösung gebracht werden, und aufeinander eingewirkt haben; wodurch verschiedene Bildungen in den auffolgenden Perioden abgesetzt sind. Diese Betrachtungen kommen mir zu unsicher vor, um darauf näher einzugehen. 
VI. Die Eisenanhäufungen unter Mooren oder moorigen Wiesen im Niederländischen Diluvium.

In den zwischen höheren Sandrücken oder Sandplateaux des Diluviums liegenden Niederungen, die eine feuchte Lage besitzen den sogenannten „Broeklanden" (Bruchländer) - kommen vielfach Bildungen vor von Raseneisenstein (Wiesenerz), in den Niederlanden „Yzeroer" (Eisenocker) genannt. Die Schicht liegt $1 / 5-1 / 4 \mathrm{~m}$, bisweilen noch tiefer (bis $1 \mathrm{~m}$ ), unter dem moorigen Rasen wie eine Bank.

Noch allgemeiner kommt im nicht urbar gemachten Sanddiluvium (dem Heideboden) unter der mit Heidepflanzen, Gesträuchen oder Wälder bedeckten Oberfläche eine Schicht vor, die das Wasser nicht durchlälst, und ebenso den Namen von „Oerbank" trägt. Jedoch, sie enthält nur eine geringe Menge Eisen und ist von dem Yzer-Oerbank streng zu unterscheiden. Sie mufs mit dem Namen Sand-Oerbank bezeichnet werden. Dieses „Oer" kommt überein mit dem sogenannten Ortstein.

Sandoer (Ortstein). Ihre Zusammensetzung ist von Rernders ${ }^{1}$ zuerst richtig erkannt. Es liegt auf einer Tiefe von 0.3-0.8 unter der Oberfläche und hat eine Dicke von $1-2 \mathrm{dcm}$. Es besteht aus Sandkörnern, die durch eine geringe Menge eines kollołdalen Humus Kieselsäure - Aluminiumoxyd - Eisenoxyd - Komplex ${ }^{2}$ und einige

1 „De Samenstelling en het ontstaan der zoogenaamde Oerbanken in de Nederlandsche heidegronden". (Verh. der Koningl. Akad. van Wetensch. Amsterdam 1889. S. 1-46.) Siehe auch Tuxen und MüLLER: Über die natürlichen Humusformen und deren Einwirkung auf Vegetation und Boden. Berlin 1889.

${ }^{2}$ In der ,Sandoerbank" von acht versehiedenen Orten im Niederländischen Diluvium fand REINDERS:

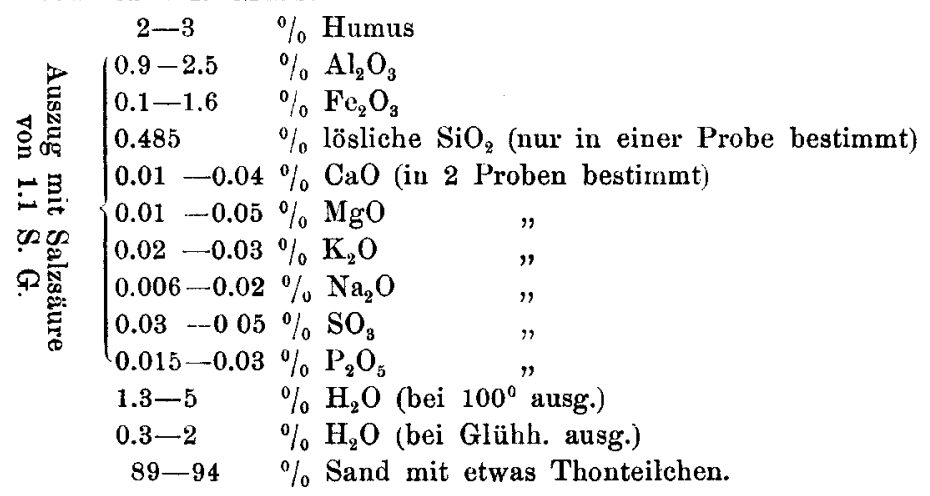

Siehe auch die ausführliche Analyse des Auszugs mit Wasser und mit Ammoniak verschiedener Koncentration, und die Analyse der oberen Schichten. 
Thonteilchen zusammengekittet, und dadurch undurchlässig geworden sind. Das Komplex hat durch freie Schwefelsäure einen sauren Charakter. Diese freie Schwefelsäure ist der Anwesenheit von sauren Humusstoffen zuzuschreiben. In diesem kollordalen Komplex (eine Absorptionsverbindung) sind kleine Mengen $\mathrm{CaO}, \mathrm{MgO}, \mathrm{K}_{2} \mathrm{O}, \mathrm{Na}_{2} \mathrm{O}$ und $\mathrm{P}_{2} \mathrm{O}_{5}$ absorbiert. Die Alaunerde überwiegt das Eisenoxyd. Durch verdünnte Ammoniake wird schon ein Teil dieses kollordalen Komplexes gelöst, wobei die ammoniakale Humuslösung auch $\mathrm{Fe}_{2} \mathrm{O}_{3}$ und $\mathrm{Al}_{2} \mathrm{O}_{3}$ in Lösung bringt.

Dieser Ortstein entsteht durch eine Wirkung von oben nach unten. Die Bestandteile, welche der Kitt desselben bilden, werden in den höheren Schichten durch die Humifikation (und dabei stattfindenden Reduktion insofern das Eisenoxyd anbetrifft) in Lösung gebracht und mit den feinsten Teilchen aus der Krume nach unten versetzt. Dadurch werden die höheren Schichten ärmer, die Bankschicht reicher an in Salzsäure löslichen Bestandteilen.

Die nähere Erklärung dieses Prozesses, warum auf einer gewissen Tiefe das Silikathumuskomplex sich unlöslich auf den Sandkörnern absetzt und diese zusammenkittet, kann noch nicht gegeben werden.

In dieser Wirkung von oben nach unten liegt der kennzeichnende Unterschied zwischen dem Ortstein (Sandoer) und dem Raseneisenstein (Yzeroer) unter Mooren oder moorigen Wiesen.

Raseneisenstein besteht aus Sand, wozwischen sich sehr viel Eisenoxyd abgesetzt hat, welches von unten zugeführt ist. An einzelnen Orten ist dabei krystallinisches Ferrokarbonat gefunden.

A. Raseneisenstein mit krystallinischem Eisenspat.

Wie S. 319 mitgeteilt, hat ReIndERs diese Bildung entdeckt im Ederveen (bei Ede, Provinz Gelderland) und zu Haaksbergen (zwischen Enschedé und Groenloo, Provinz Overyssel). Die erste hat er näher untersucht und analysiert und mich durch Zusendung frisch ausgegrabenen Materials in den Stand gesetzt, die Untersuchung fortzuführen.

Das Ederveen liegt in einer Niederung des Diluviums. An der Ostseite liegt ein höherer Boden, der in westlicher Richtung bis zum Ederveen ungefähr $10 \mathrm{~m}$ herabfällt. ${ }^{1}$

1 Von der Chaussee bei Lunteren bis zum Bahnhof von Veenendaal fält der Boden $10^{5} \mathrm{~m}$. Zwischen dem erstgenannten Punkte und dem Ederveen ist der Fall $18^{5}-9.07=9^{4} \mathrm{~m}$. 
Wie der Name andeutet, ist das Ederveen ${ }^{1}$ ein Wiesenmoor oder ein mooriges Wiesenland. Die Wiesen werden im Winter nicht überschwemmt, sondern werden ,drassig“ (feucht) durch das aus der Tiefe aufquellende Grundwasser.

a) Bau des Raseneisensteins. Unter dem moorigen Rasen, von 2-3 dcm Dicke, liegen hier und da, nur an einzelnen Stellen, die Konkretionen: entweder Blöcke (A) von grölserer Ausdehnung, oder „Kuchen" (B), die an einander schliefsen. Von den Blöcken mulsten mit der Hacke Stücke abgeschlagen werden; die „Kuchen“ liefsen sich beim Kappen an den Berührungsflächen leichter trennen (Fig. 9).

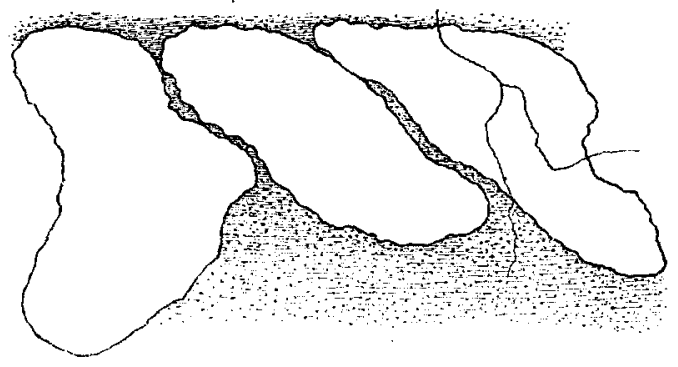

Fig. 9.

Oberfläche.

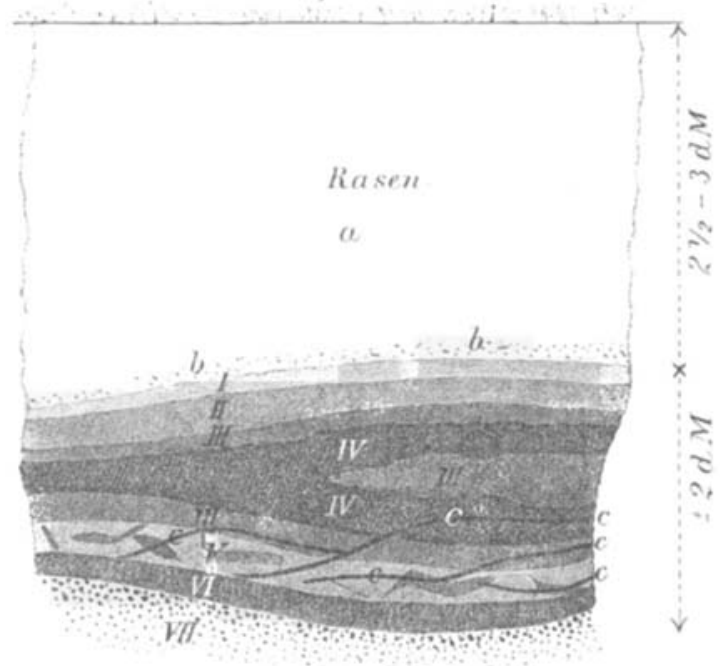

Fig. 10.

1 Veen $=$ Moor. 
Das Profil von $\mathrm{A}$ ist in der Fig. 10 abgebildet. Es ist nur schematisch, denn in der Wirklichkeit sind die Grenzlinien der angegebenen Schichten (III, IV und $\nabla$ ) noch unregelmäfsiger und variierter, als in der Figur.

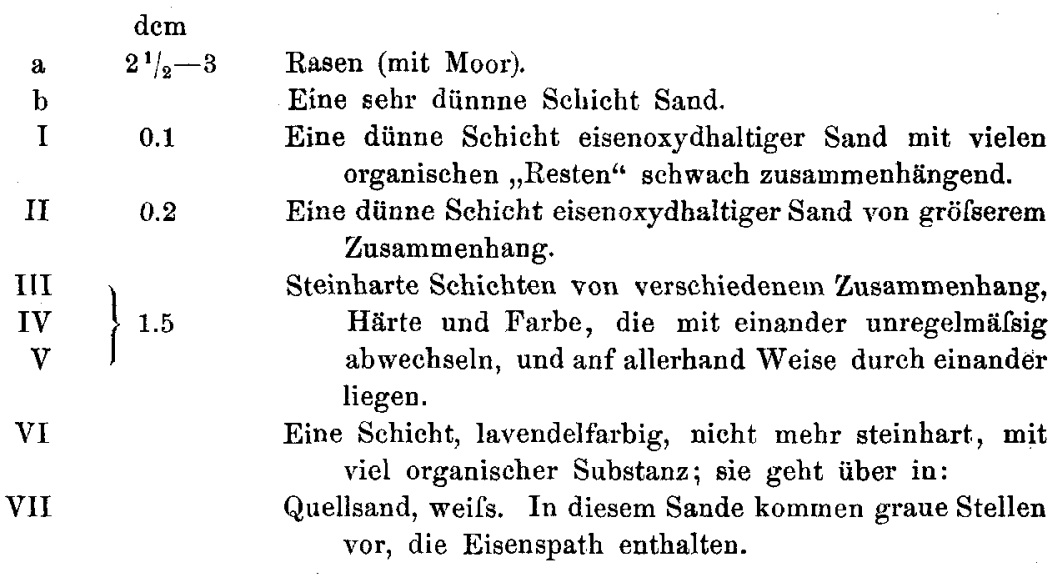

Durch die Schichten laufen rotfarbige Adern ( $c$ in der Fig.), d. h. Hache, sich horizontal ausbreitende Rinnen, gefüllt mit Eisenoxyd, welches eine Pseudomorphose von Pflanzenresten (Wurzeln) ist. Diese sind nur wenig zusammengeprefst.

Die Lage der "Kuchen" ist schematisch in Fig. 9 abgebildet. Sie enthalten dieselben Schichten; nur liegen die mürberen Partien nicht allein oben und unten, sondern auch seitwärts im Umkreis von jedem Kuchen. Auch hier sind Pflanzenwurzeln, in Eisenoxyd metamorphosiert, beobachtet.

In dem steinharten Teile des Blockes oder Kuchens (III, IV, V) sind zu unterscheiden: Die härtesten Partien (IV auf dem Profil) von grauer Farbe (mit grünem Schein); beim Ritzen ist der Strich weifs.

Sie enthalten nach der Analyse I, Tab. II (S. 319) in Prozenten:

\pm 50 Feinen Sand; abgerundete Körner.

$<1 \quad$ Organ. Substanz.

\pm 45 Krystallinische Karbonate von $\mathrm{Fe}, \mathrm{Ca}, \mathrm{Mn}, \mathrm{Mg}$, grölstenteils Ferrokarbonat $(38 \%)$.

$\pm 2^{5} \quad$ Eisenoxyd.

2-3 Eisenphosphat.

Die sanfteren und dunkelsten Partien kommen in den Schichten III und $\mathrm{V}$ vor. Sie zeigen beim Ritzen einen braunroten Strich und enthalten nach Analyse IV Tab. II (S. 319) in Prozenten: 
\pm 20 Feinen Sand (noch etwas feiner wie der vorige, glashell, abgerundet).

$\pm 1 \quad$ Organische Substanz.

\pm 50 Eisenoxyd (das damit verbundene Wasser mitgerechnet).

$\pm 13^{\mathrm{b}}$ Krystallinische Karbonate, wobei $\pm 6 \mathrm{FeCO}_{3}$.

$\pm 7^{5}$ Eisenphosphat.

\pm 6 Lösliche Kieselsäure, die vom Eisenoxyd absorptiv gebunden sein mufs.

Die übrigen Partien des Blockes, die, was Härte und Farbe anbetrifft, zwischen der Substanz von Analyse I und von Analyse IV die Mitte halten, bilden auch in ihrer Zusammensetzung Übergänge dazwischen; der Gehalt an Sand und Ferrokarbonat ist kleiner, der Gehalt an Eisenoxyd ist grölser, je nachdem sie härter und von lichterer Farbe sind. Umgekehrt enthalten sie mehr Eisenoxyd und weniger Ferrokarbonat und Sand, je nachdem sie sanfter und dunkler sind. Das ergiebt sich auch aus den Analysen II und III (Reinders). Die letzte bezieht sich auf einen Kuchen, wie in Fig. 9 abgebildet ist, und zwar auf ein Gemisch von den härtesten und weniger harten Teilen aus den Schichten IV und III in diesem Kuchen. In Schicht V sind die dunkler gefärbten Partien vorherrschend, doch schliefsen sie scharf begrenzte, graue, härtere Teile (wie die von Schicht IV) ein, wodurch das Ganze ein marmorartiges Ansehen bekommt.

Die roten Adern sind augenscheinlich die Überbleibsel der Stellen, wo sich Pflanzenwurzeln befunden haben. Sie sind in Eisenrost metamorphosiert und zeigen noch die Faserform. Darum haben sie eine etwas horizontale und verzweigte Richtung und sind die Räume, worin die Wurzeln gelegen haben, nicht ganz mit Eisenoxyd ausgefüllt. Beim Kappen zerbricht ein Block oft eben an diesen Stellen. Wie die schematische Figur zeigt, liegen die meisten roten Adern unten in $\mathrm{V}$.

Obgleich Vivianit überall stellenweise vorkommt, so liegt er doch meistens über und unter den roten Adern. Gröfsere Aggregate von sichtbaren Krystallnadeln sind dabei an einzelnen Stellen gefunden (S. 324c).

In III, IV und $\nabla$ kommen kleine Höhlen vor, jedoch nicht in allen Teilen in derselben Menge; viele in den bärtesten Partien von Schicht V. Oft sind sie leer, bisweilen mit losem, gelbem Sand gefüllt. Die leeren Höhlen haben entweder eine mehr runde, oder eine mehr flach ausgedehnte Form. Unter denselben sind diejenigen 
merkwürdig, bei denen das folgende beobachtet ist (wie in Fig. 11 abgebildet): Die Höhle oder der Schacht ist bekleidet mit einer halb-

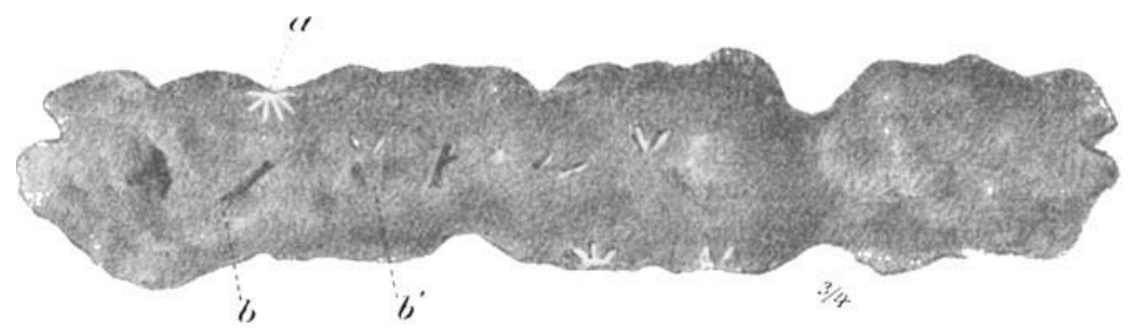

Fig. 11.

durchsichtigen, grüngelben, fast sandfreien Substanz, die aus krystallinischem $\mathrm{FeCO}_{3}$ und etwas $\mathrm{Fe}_{3}\left(\mathrm{PO}_{4}\right)_{2}$ besteht, und an einzelnen Stellen zu kleinen cylindrischen Ästchen ( $b$ in Fig. 11) oder Wärzchen $\left(b^{\prime}\right)$ ausgewachsen ist (Fig. 2 und 3). Sie sind aus einer Mischung von krystallinischem Ferrokarbonat und Phosphat auf eine eigentümliche Weise aufgebaut, wie oben (S. 326) beschrieben. Auf der Wand der Höhle, wie auch auf den Ästchen (Fig. 2) oder Wärzchen ist an einzelnen Stellen ein nadelförmiges Krystall von Vivianit, oder eine federförmige Ansammlung desselben eingepflanzt (Fig. 1 und $a$ in Fig. 11). In dem Schacht kommen auch Spalten vor, mit einer krystallinischen schmutziggelben Masse und einzelnen Krystallnadeln gefüllt.

Nicht alle Höhlen besitzen diese Krystalle; am meisten die flach ausgedehnten. Schliefslich ist noch die lehrreiche Beobachtung gemacht, sowohl in Ederveen wie in Haaksbergen, dafs im Quellsand unter dem Raseneisensteim Stellen zu finden sind, wo die Bildung von krystallinischen Ferrokarbonat angefangen hat. Diese graue Stellen im wenig gefärbten Sande (Schicht VII im Profil) haben schon einigen Zusammenhang erbalten durch das darin abgesetzte krystallinische $\mathrm{FeCO}_{3}$. Eine solche Knolle enthält einzelne Prozente davon, und dabei eine nicht unbedeutende Menge Phośphat; dagegen wenig $\mathrm{Fe}_{2} \mathrm{O}_{3}$ und sehr wenig Kalk.

REINDERs hatte gleiches schon zu Haaksbergen beobachtet, auf $1 \mathrm{~m}$ Tiefe, als eine intensiv weifse Masse im bläulichen Sande. Er fand darin:

$$
\begin{array}{lll}
5.1 \% & \mathrm{FeCO}_{3} \\
0.35 & \text {, } & \mathrm{CaCO}_{3}, \\
0.05 & \ldots & \mathrm{MnCO}_{3}
\end{array}
$$


Die Knolle ist umgeben von einer an der Luft gelbwerdenden Zone. Also enthält der die Knolle umschlielsende Sand etwas Eisenoxydul.

Es lälst sich also denken, dals, wenn an verschiedenen Stellen in der Sandschicht solche Bildungen entstehen und sich nach allen oder verschiedenen Seiten ausbreiten, nach längerer Zeit eine „Bank"“ von der oben beschriebenen Struktur daraus entstehen kann.

b) Bildung des Raseneisensteins. Dafs die Bildung nicht von oben herab, wie es der Fall ist bei der Ortsteinbildung in höheren Haideböden (S. 367 Al. 1), oder bei der Versetzung von Eisen aus höheren nach tieferen Schichten (S. 315 Zeile 9 v. u.), sondern von aufquellendem Grundwasser herrührt, ist, wie REINDERS schon dargelegt hat, unzweifelhaft. ${ }^{1}$ An den Stellen, wo die Blöcke oder Kuchen zu Ederveen liegen, befindet sich darunter Quellsand, worin das Grundwasser aufquillt, ${ }^{2}$ das von den umliegenden höheren Sandböden abfliefst. Nur wo dieser Quellsand vorhanden ist, liegt der. Raseneisenstein.

Im Laufe des Jahres steigt und fällt das Quellwasser periodisch und können beim Stagnieren und Verdampfen desselben Bestandteile daraus sich absetzen. Die genaue Analyse (Tab. XI, S. 337) des Wassers ergab, dafs, neben Calciumkarbonat, Ferrokarbonat und Mangankarbonat die vornehmsten Bestandteile des Wassers waren und dals die Phosphorsäure nicht fehlte. Aus diesem Wasser stammen gewifs das Eisen, Kalk, Mangan und die Phosphorsäure des Raseneisensteins. Es bestätigt sich hier wieder, was schon oben (S. 357, Bem. 2) bemerkt ist, dafs die Absetzung von $\mathrm{FeCO}_{3}$ viel stïrker stattfindet, als die von $\mathrm{CaCO}_{3}$; denn der Absatz enthält wenig, das Bodenwasser viel $\mathrm{CaCO}_{3}$ im Vergleich zum $\mathrm{FeCO}_{3}$. Das gilt auch einigermalsen für das Mangankarbonat. ${ }^{3}$

Im Quellsande, unter dem Wasserspiegel, fängt die Absetzung des krystallinischen Eisenspats u. s. w. mit etwas Vivianit zwischen den Sandkörnern an, wie die Beobachtung der Schicht VII gelehrt hat. In VI hat die Menge Eisenspat zugenommen, und diese Absetzung ist am gröfsten in der Schicht IV. Dabei hat sich mehr oder weniger amorphes $\mathrm{FeCO}_{3}$ abgesetzt in denjenigen Partien, wo

1 Seite 15-35 seiner Abhandlung.

2 Mehrmals von Reinders in den Bohrlöchern beobachtet.

${ }^{3}$ In dem Phosphat eines fossilen Knochens fand ich mehr $\mathrm{Mn}$ als Fe aus dem Bodenwasser absorbiert. Doch war das Eisen als Pyrit im Gewebe und namentlich in den Höhlen des Knochens festgelegt. Z. anorg. Chem. (18ף7) 15, 105. 
mehr Pflanzenüberreste - also weniger Sand - sich befanden wie in VI und auch in III. In den Räumen, die durch die verwesten Wurzeln entstanden sind, hat sich nur amorphes $\mathrm{FeCO}_{3}$ gebildet, so dafs die Wurzeln nach der Oxydation an der Luft in Eisenrost verwandelt sind. In den obersten Schichten II und I hört die Bildung auf, so dafs II nicht mehr steinhart ist und in I der Sand nur lose mit dem Eisenoxyd zusammenhängt. Wo die Luft in den oberen Schichten des Raseneisensteins durch das periodische Stagnieren und Fallen des Wassers zutritt, wird das amorphe $\mathrm{FeCO}_{3}$ zu amorphem $\mathrm{Fe}_{2} \mathrm{O}_{3}$ oxydiert. Die von uns untersuchten Kuchen oder Blöcke waren bei einem niedrigen Wasserstande ausgegraben und an der Luft trocken geworden; sie enthielten neben krystallinischem $\mathrm{FeCO}_{3}$ nur Eisenoxyd. Wahrscheinlich ist dieses letztere ursprünglich gröfstenteils oder ganz amorphes $\mathrm{FeCO}_{3}$ gewesen.

Die Absetzung von krystallinischem Eisenspat scheint also hauptsächlich, wenn nicht ganz, zwischen den Sandkörnern stattgefunden zu haben.

Vergleichen wir das oben Angeführte mit den Absetzungen in einem Moor (wie in dem E. C. und in Mecklenburg), so drängt sich der Gedanke auf, dals die Sandkörner die Absetzung von krystallinischen Eisenspat, die Pflanzenreste die Absetzung von amorphem wenn nicht bedingen, so doch befördern. Doch bleibt dann unerklärt, warum 1. in der Mehrzahl der Fälle, wo Raseneisenstein im Sand unter einer Moorschicht gebildet wird, kein Eisenspat, sondern Eisenoxyd (der gewöhnliche Eisenocker, siehe den folgenden Abschnitt) sich absetzt - warum 2. im amorphen Ferrokarbonat des E. C. u. s. w. ein kleiner oder gröfserer Teil krystallinisch ist.

Aufserdem sind unsere Kenntnisse noch ganz ungenügend, um die Wirkung zu begreifen, welche die Pflanzenwurzeln und Stengel, die sich zwischen dem Raseneisenstein befinden oder befunden haben, auf die Absetzung von amorphem Eisenoxyd oder Eisenkarbonat geübt haben.

Das Entstehen der leeren Räume und kleinen Höhlen können wir noch nicht genügend erklären, denn wir wissen nicht, inwiefern sie dem Verwesen der Pflanzentheile, und inwiefern sie den $\mathrm{Zu}-$ sammenziehungen im Stein zuzuschreiben sind.

Der Vivianit begleitet die Eisenabsetzungen, jedoch ist es klar, dafs er in den leeren. Räumen und Höhlen angehäuft ist.

Ganz annehmlich ist es, dals alle Phosphorsäure aus dem Quellwasser herstammt. Jedoch, wie der Vivianit entstanden, ist 
wieder nicht gewifs. Auch hier, wie im E. C. ist eine Metamorphose des schon abgesetzten Ferrokarbonats (namentlich des krystallinischen). durch ein gelöstes Phosphat in Vivianit am wahrscheinlichsten. Doch ist es fraglich, ob das Phosphat vorher immer ein Bestandteil einer organischen Substanz gewesen ist. Denn obgleich die Vivianitanhäufungen meistens über und unter den mit Pflanzenresten gefüllten Rinnen (den roten Adern im Gestein, S. 369) liegen, so scheint es doch, -dafs diese Reste bei weitem nicht genügend sind, um die Phosphorsäure für die Vivianitanhäufungen, die sichtbaren Krystalle, die Bekleidung der Höhlen, die Wärzchen und Ästchen, zu liefern. Darum mufs vielleicht eine Einwirkung der Phosphate des Quellwassers auf den Eisenspat angenommen worden. Die nähere Erklärung dieser Bildungen kann noch nicht gegeben werden.

\section{B. Die Raseneisensteinbildungen unter Mooren ohne krystallinischen Eisenspat.}

Dafs die Bildung von Raseneisenstein mit krystallinischem Eisenspat nicht die meist vorkommende ist, folgt schon daraus, dafs sie früher nicht bemerkt und zuerst von REINDERs im niederländischen Diluvium, zu Ederveen und bei Haaksbergen, später von uns (in geringer Menge) im E. C. beobachtet ist. Was früher beschrieben oder analysiert ist, betrifft das gewöhnliche sogenannte "Yzeroer" (Eisenocker), welches aus Sand oder thonhaltigem Sand mit viel Eisenoxyd besteht und an sehr vielen Orten vorkommt. Dals es eine Bildung unter Bruchländern ist, hat REINDERS an verschiedenen Orten konstatiert; ${ }^{1}$ eine Bildung also von Raseneisenstein unter niedrig und feucht gelegenen Wiesen (die an höhere Böden grenzen), an Stellen, wo das Wasser bei hohen Wasserständen aufquellt. Die von mir untersuchte Probe (S. 322) stammte aus einem derartigen Wiesenland. ${ }^{2}$ Das Profil des Bodens war: ${ }^{3}$

${ }^{1}$ Bei Apeldoorn in der "Stroe weide", bei Herinckhave (Gemeinde Tubbergen), bei „Roode Haan“ (Gemeinde Gorssel zwischen Deventer und Zutphen).

2 Das Wiesenland ist gelegen nördlich und in der Nähe vom Dorfe Tubbergen (Provinz Overyssel), beim Hofe Eschede, zwischen den Chausseen, welche westlich nach Langeveen, östlich nach Mander führen. Sowohl nördlich als südlich und westlich liegen höhere Haideböden oder Waldböden. Das Wiesenland liegt also in einer Niederung. Früher wurden diese Wiesen im Winter vom hochaufquellenden Bodenwasser überdeckt, jetzt nicht mehr.

${ }^{3}$ Herr Reinders hat auf meine Bitte die Ausgrabung beaufsichtigt und die Proben gesammelt. 


\subsection{Rasen \\ 0 25-0.45 "Yzer Oerbank" (Raseneisenstein). \\ $0.45-0.80$ Sand, weifs mit Stellen von brauner Farbe. \\ $0.80-1.00$ Sand von bläulicher Farbe. \\ 1.00-? Quellsand.}

Der Wasserstand war in der Zeit der Ausgrabung ausnahmsweise sehr niedrig, ungefähr $1 \mathrm{~m}$ unter der Oberfläche.

Die "Oerbank" besteht aus an einander schliefsenden Knollen, mit mehr oder weniger Sand dazwischen. Pflanzenwurzeln kommen hier und da zwischen denselben vor. An anderen Stellen liegt die "Oerbank" etwas tiefer $(0.50-0.60 \mathrm{~m})$.

Nach der Analyse (Tab. III, S. 322) enthält dieser „Oer" in abgerundeten Zahlen:

Tabelle XV.

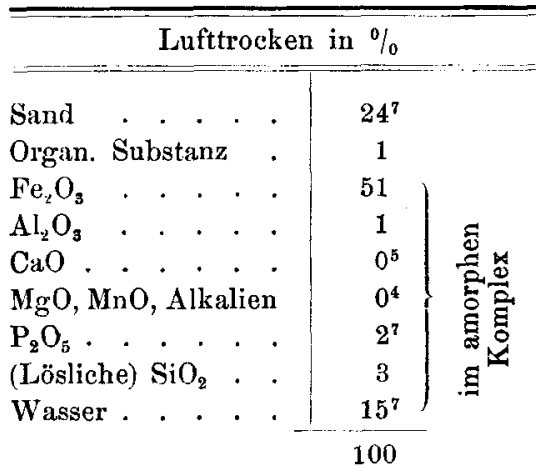

Es bildet also ein Konglomerat von $1 / 3$ Sand und $2 / 3$ Eisenoxyd (wasserfrei berechnet). Krystallinischer Eisenspat und Vivianit kommen darin nicht vor. Die Menge Phosphorsäure ist jedoch nicht unbedeutend. Es fällt auf, dafs der Gehalt an Kalk so gering ist $(0.45 \%)$, wie auch an Mangan $(0.2 \%)$. Auch der Gehalt an Kieselsäure, im Eisenoxyd absorbiert, ist nicht grofs $(3 \%$ ).

Eine älnnliche Zusammensetzung hat Reinders früher für einen Raseneisenstein aus der Stroewiese (ein Bruchland in der Gemeinde Apeldoorn) erhalten (Analyse II, Tab. III), nur ist der Gehalt an Phosphorsäure viel geringer und der Sand thonhaltig. Aus diesen und den älteren Analysen (S. 321) ergiebt sich, dafs der Gehalt an Eisenoxyd bei diesem Raseneisenstein zwischen 30 und $80 \%$ schwankt, und dals die Menge Phosphat oft gering ist, wie auch bei den alkalischen Erden. Dals das Grundwasser, welches unter der "Oerbank" aufquillt, eisenhaltig ist, hat sich auch hier bewährt. Es enthielt bei Herinckhave (Gemeinde Tubbergen) im Liter $74 \mathrm{mg} \mathrm{FeCO}_{3}$ und 
$90 \mathrm{mg} \mathrm{CaCO}_{3}$ und etwas Phosphorsäure. In allen Stellen, die untersucht sind, ist eine Sandschicht gefunden, worin das Wasser aufquillt. Aus dem Ferrokarbonat dieses Wassers mufs also beim periodischen Steigen, Stagnieren und Fallen desselben die „Oerbank" gebildet sein. Der schlagendste Beweis für diese Bildungsweise ist die Thatsache, dafs, wenn dieses "Yzeroer" ausgegraben wird, ${ }^{1}$ es sich von neuem bildet. Die Ursache der Bildung ist geblieben. Reinders erwähnt eine Wiese bei Gorsel und eine bei Herinckhave, wo vor etwa 30 Jahren die Ausgrabung stattgefunden hat und jetzt eine Neubildung zu beobachten ist. Jedoch genaue Beobachtungen über den Gang des Prozesses und dessen Geschwindigkeit fehlen leider noch gänzlich.

Es steht also fest, dafs dieser Raseneisenstein entstanden ist durch Absetzung (unter Oxydation) von Ferrobikarbonat aus dem Quellwasser, welches von höheren Böden herstammt. Diese Absetzung findet statt unter dem Rasen von niedrig und morastig gelegenen Ländern an den Stellen, wo Quellsand und also Wasserquellen anwesend sind.

Merkwürdig ist es, dal's dabei kein Eisenspat und Calciumkarbonat abgesetzt und kein Vivianit gebildet wird. Die Ursachen, warum diese hier - was der häufiger vorkommende Fall zu sein scheint fehlen, jedoch an anderen Orten, wie zu Ederveen und Haaksbergen, im Raseneisenstein vorkommen, kennen wir noch nicht. ${ }^{2}$ Neue Untersuchungen an vielen Orten sind dazu notwendig.

\section{Zusammenfassung.}

Obgleich das Vorkommen, die Zusammensetzung und das Entstehen der Eisenanhäufungen in alluvialen Bodenschichten schon im allgemeinen bekannt sind, so waren doch die verschiedenen Fälle, an bestimmten Orten und unter bestimmten Umständen, noch nicht genügend von einander unterschieden und in den Einzelheiten untersucht, so dâfs die Erklärung noch sebr viel zu wünschen überliefs.

Im Obigen sind Untersuchungen der Eisenanhäufungen in und unter Mooren oder moorigen Rasen, an drei Orten im niederländischen Diluvium, mitgeteilt und mit einer ähnlichen Bildung in den Niedermooren von Mecklenburg (nach GAERTNER) verglichen.

1 Zum Verkauf an die Eisenhütten.

${ }^{2}$ Eine der Ursachen kann sein, dals die obenliegende Rasenmoorschicht im zweiten Fall dichter ist, und den Luftzutritt mehr abschliefst. 
Dabei ist auf die Umgebung, die Lage, den Bau und auf die Zusammensetzung des Moores, der Eisenanhäufung und des Bodenwassers Rïcksicht genommen. In den Niedermooren sind Nester gefunden, mit amorphem Ferrokarbonat gefullt, wobei etwas krystallinischer Eisenspat und Vivianit vorkommt. Nach den gesamten Beobachtungen ist ihre Bildung am wahrscheinlichsten zu erklären durch die Annahme, dafs ein eisenhaltiges Bodenwasser in Gruben und Wasserläufen während der Bildung des Moores stagniert und Eisenoxyd abgesetzt hat, welches nachher zu Ferrokarbonat reduziert ist.

Die Anhäufung unter einem Moore oder moorigen Rasen ein Raseneisenstein, wohl zu unterscheiden rom Ortstein - besteht ans einer Absetzung von Eisenoxyd im diluvialen Sand unter dem Moore in niedrig gelegenen Bruchländern, an Stellen, wo Quellen von eisenhaltigem Grundwasser liegen und wo das Ferrokarbonat beim periodischen Steigen und Fallen des Wassers zugeführt und als Eisenoxyd abgesetzt wird.

Es sind Orten gefunden, wo dieser Raseneisenstein neben Eisenoxyd mikrokrystallinischen Eisenspat und Vivianit enthält. Ihr Bau und ihre Zusammensetzung sind genau beschrieben, doch bleibt die Ursache dieses Unterschiedes mit dem erstgenannten Raseneisenstein unerklärt. Es hat sich als wahrscheinlich ergeben, dafs der mikrokrystallinische Eisenspat unmittelbar zur Absetzung kommt und dals der Vivianit in den meisten Fällen aus dem Eisenspat entstanden ist. Der Vivianit ist krystallinisch befunden; auch die sogenannte erdige Varietät. Über die Oxydation des Vivianits, unter Beibehaltung der krystallinischen Struktur, sind einige Beobachtungen gesammelt.

Aus der Betrachtung der chemischen, physikalischen und biologischen ${ }^{1}$ Reaktionen, die bei diesen Bildungen stattfinden müssen oder können, im Zusammenhang mit den gemachten Beobachtungen, hat sich ergeben, dal's dieselben noch sehr unvollständig bekannt sind. Für eine bessere Erklärung der Prozesse wird es notwendig sein die Bildungen $\mathrm{zu}$ beobachten und denselben nachzuspüren, während sie in der Natur unter bestimmten Umständen stattfinden.

Schliefslich bezeuge ich den Herren Hortsema und KlobBie meinen besten Dank für ihre vielseitige Mitwirkung bei diesen Untersuchungen.

${ }^{1}$ Die Mitwirkung von Organismen.

Leiden, Anorg.-chem. Laboratorium der Universität, August 1899.

Z. anorg. Chew. XXII. 


\section{Anhang.}

Die Bestimmung der löslichen Kieselsäure, des Wassers und des Humus im Raseneisenstein.

a) Die lösliche Kieselsäure. Die Bestimmung geschah nach der von mir früher angegebenen und erprobten Methode: Ausziehen mit Salzsäure (entweder verdünnter, oder stärker oder heifser konzentrierter) und nachher mit Kalilösung von 1.05 spec. Gew. bei $50^{\circ}$ während 5 Minuten; aus beiden Lösungen $\mathrm{SiO}_{2}$ abscheiden und wägen. ${ }^{1}$

Dafs diese Kalilösung den Sand nicht angreift, wurde noch bei der Analyse des Raseneisensteins (An. IV, S. 319) bewiesen, indem die Behandlung mit Kali wiederholt wurde und nichts in Lösung kam. Vor der Ausziehung mit heifser Salzsäure löste das Kali nur $0.4 \% \mathrm{SiO}_{2}$ auf; nachher löste die Salzsäure $0.6 \%$, und darauf das Kali $5.3 \% \mathrm{SiO}_{2}$, zusammen $6.3 \%$ lösliche Kieselsäure. Es ergab sich also, dafs diese im amorphen Eisenoxyd absorbiert war, und zwar stark genug, um der lösenden Kraft des Kalis Widerstand zu leisten (während den 5 Minuten bei $50^{\circ}$. Erst nachdem das Eisenoxyd sich in der Salzsäure gelöst hatte, kam die $6 \%$ Kieselsäure frei. Dals sie sich in der heifsen konzentrierten Salzsäure in so geringer Menge löste, war zu erwarten. Ich habe diese Eigenschaft der Kieselsäure, wenn sie aus einem Silikat freikommt, immer bei der Analyse von Ackerböden bemerkt. Sie löst sich dagegen viel leichter, wenn das Silikat (oder sonstige kollordale Komplexe) durch verdünnte Salzsäure zersetzt wird.

Indem der Teil des Raseneisensteins, der nach Analyse IV $36.5 \%$ kollordales Eisenoxyd enthielt, $6.3 \%$ lösliches $\mathrm{SiO}_{2}$ ergab, wurden nur $0.8 \%$ angetroffen in dem Teil des Raseneisensteins, welcher $2.5 \% \quad \mathrm{Fe}_{2} \mathrm{O}_{3}$ und dagegen $38 \%$ krystallinisches $\mathrm{FeCO}_{3}$ enthielt (Analyse I). Daraus folgt, dafs die Kieselsäure mit dem Eisenoxyd eine Absorptionsverbindung bildete.

Wassergehalt. Dieser wurde annähernd bestimmt durch Addieren des Sauerstoffes (vom Eisenoxydul aufgenommen) und Abziehen des Kohlensäuregehaltes der Karbonate und des Humusgehaltes, zum - resp. vom - Glühverlust.

1 Bestimmung von Wasser, Humus, Schwefel, Kieselsäure, Mangan im Ackerboden. Landw. Vers.-Stat. 1890, 37, 279-290. 
Humusgehalt. Dieser wurde annähernd bestimmt auf die folgende Weise: Erwärmen mit Chromsäure und Schwefelsäure nach der Methode von KöNIG ${ }^{1}$ und Auffangen der Kohlensäure in Natronkalk, mit allen von mir beschriebenen Vorsorgen. ${ }^{2}$ Aus der Kohlensäure wurde, nach Abzug der besonders bestimmten Karbonatkohlensäure, durch Multiplikation mit dem Faktor 0.47 der Humusgehalt annähernd erhalten.

Phosphorsäure. Bestimmt mittels Ammonmolybdat.

1 Die Untersuchung landwirtsehaftlicher und gewerblicher Stoffe. (1. Aufl.) Seite 15.

2 Bestimmung von u. s. w. Seite 281.

Bei der Redaktion eingegangen am 15. August 1899. 